\title{
A ALIMENTAÇÃO E A ANEMIA CARENCIAL EM ADOLESCENTES
}

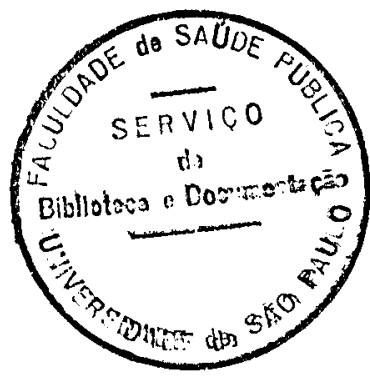

Tese apresentada ao Departamento de Nutrição da Faculdade de Saúde Pública da Universidade de São Paulo para obtenção do título de doutor.

Orientador: Dra. Sophia Cornbluth Szarfarc

SÃO PAULO 
"At work, you think of the children you left at home. At home you think of the work you've left unfinished. Such a struggle is unleashed within yourself. Your heart is rent."

Golda Meir 
Aos meus três amores: Jacques, pelo incentivo, paciência e compreensão.

Cadu e Pati, pela inspiração, aprendizado e renovação que, continuamente, me proporcionam. 
Aos meus pais Clara e Henrique, e aos meus "pais" Guita e Boris, pelo apoio e carinho sempre presentes. 
A Aldonia Cekaunaskas Kalil "in memorium", exemplo de pessoa e de pesquisador no qual procuro me espelhar. 
A Sophia Corbluth Szarfarc, "orientadora perfeita", pelo carinho e dedicação que sempre acrescentou à sua orientação firme, clara e objetiva. 


\section{AGRADECIMENTOS}

Este trabalho é resultado do esforço e incentivo de um conjunto de pessoas, sem as quais não teria se concretizado.

Malu, Sandra e Doris, amigas sempre presentes nas discussões, sugestões e principalmente nas horas de desespêro.

Dilene e sua "escola" pela possibilidade da realização do pré teste dos formulários e dos instrumentos.

Maria Silvéria Emigdia pelos muitos "uis e ais" da coleta de sangue em campo.

Rita, Silvana e Juliana pela ajuda na coleta das medidas antropométricas em campo.

Lenise pela amizade, incentivo e ajuda no trabalho de campo.

Marcello Sampaio di Pietro, colega do GAP-Grupo de Informática e Apoio à Pesquisa

do Instituto de Saúde, pela paciência e atenção no desenvolvimento de "programas fantásticos" que atenderam às necessidades deste trabalho.

Biba e Bernardete, colegas do GAP, que me atenderam na análise estatística dos dados.

Nelson Francisco Brandão pelo trabalho de editoração.

Bi pela revisão do português e da coerência de idéias. 
Carmem e Maria Aparecida pela revisão bibliográfica.

Lilia pela versão do resumo para inglês.

Natália e Rosita pela datilografia e paciência com que sempre pude contar.

Agradecimentos especiais à $2^{\mathrm{a}}$ Delegacia de Ensino de Osasco, na pessoa da Mary, delegada na época da execução do trabalho, aos diretores, professores auxiliares, funcionários e pricipalmente aos alunos das escolas ALÍPIO DA SILVA LAVOURA, FRANCISCO MANOEL LUMBRALES DE SÁ CARNEIRO, GASPAR MADRE DE DEUS, HORÁCIO QUÁGLIO, JOSÉ LIBERATTI, MARIA AUGUSTA SIQUEIRA, MARINA SADDI HAIDAR E TEREZINHA MARTINS PEREIRA. 


\section{ÍNDICE}

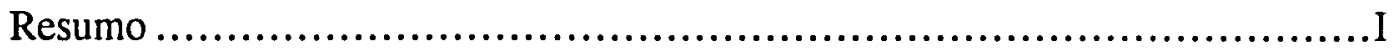

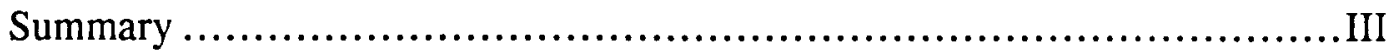

I. Introdução......................................................... 1

II. Objetivos .............................................................. 11

III. Metodologia ....................................................... 12

- Local do estudo ...................................................

- População de estudo .................................................. 14

- Seleção das escolas ................................................... 14

- Diagnóstico da Anemia ............................................... 17

- Consumo e prática alimentar ........................................ 18

- Adequação de consumo .............................................20

- Atividades físicas do adolescente .......................................22

- Nível sócio-econômico .............................................24

- Estado nutrional e perfil de crescimento...............................24

IV. Resultados e discussão ...........................................26

V. Conclusões........................................................ 78

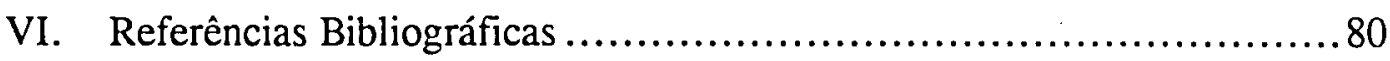

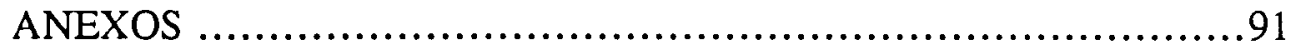




\section{RESUMO}

\section{A ALIMENTAÇÃO E A ANEMIA CARENCIAL EM ADOLESCENTES}

A anemia ferropriva é o problema nutricional de maior prevalência atualmente no mundo. Sua ocorrência é considerada maior nos países em desenvolvimento, onde $36 \%$ da população apresenta essa patologia.

No Brasil uma parcela considerável da população está afetada. Em São Paulo o quadro não é diferente: $35 \%$ das crianças de seis a sessenta meses do município de São Paulo apresentavam anemia por carência de ferro na década de oitenta. Em Osasco, município da área metropolitana de São Paulo, $51 \%$ dos escolares de sete a oito anos são anêmicos.

Com o objetivo de verificar o papel da alimentação como um dos determinantes da anemia prevalente entre adolescentes do município de Osasco - São Paulo (Brasil), foram estudados 509 escolares das quintas e oitavas séries de escolas da Rede Pública de Ensino de Osasco. 
A prevalência de anemia, identificada através da determinação da concentração de hemoglobina do sangue em amostras colhidas por punção digital, pelo método da cianometahemoglobina, foi baixa $(5,3 \%)$, não havendo diferença entre os sexos.

O perfil nutricional, identificado através de medidas antropométricas, revelou que $17,3 \%$ dos adolescentes se localizaram abaixo do percentil 10 para peso/idade e $4,7 \%$ abaixo do percentil 3. A proporção de desnutridos foi maior entre os alunos das quintas séries. Os homens apresentaram-se em piores condiçōes nutricionais do que as mulheres.

A prática alimentar, conhecida através do registro dos alimentos consumidos pelos alunos em três dia alternados, mostrou-se semelhante àquela encontrada em São Paulo em 1974/75. Foi observado pequeno consumo de alimentos fonte de vitamina C (elemento importante na absorção de ferro) e a tendência da substituição do jantar tradicional por um lanche.

A maior parte dos adolescentes tem consumo energético adequado e de ferro, inadequado.

A dieta consumida pelos adolescentes pode ser considerada de boa qualidade, justificando a baixa prevalência de anemia encontrada, embora a pequena densidade do ferro e do ferro biodisponível da dieta seja um indicador da provável existência de indivíduos deficientes em ferro em proporção apreciável na população. 


\section{SUMMARY}

\section{NUTRITION AND IRON DEFICIENCY ANEMIA IN TEENAGERS}

Iron deficiency anemia is currently the most prevalent nutritional problem in the world. Its incidence is more significant in developing countries, where $36 \%$ of the population develops this pathology.

A substancial part of Brazilian population is affected by it. Even in the State of São Paulo the situation is the same: $35 \%$ of the children aged six to sixty months had iron deficiency anemia in the 80's in the city of São Paulo; and in Osasco, a town in the metropolitan area of São Paulo, $51 \%$ of the school children aged 7-8 are anemic.

Aiming at assessing the role of the diet as one of the determining causes for the anemia which is prevalent among teenagers in the town of Osasco, State of São Paulo, Brazil, a study was carried out with 509 students from 5 th and 8th grade in the public school network in Osasco.

The prevelence of anemia was checked through blood hemoglobin sampling, using digital puncture and the cyanomethahemoglobin method. The results have shown a discrete $5,3 \%$, regardless the sex of the students. 
The nutritional profile, identified through anthropometric measurement, indicated that $17,3 \%$ of the teenagers were under percentil 10 for weight/age and $4,7 \%$ under percentile 3. The proportion of undernourished youngsters was higher among students in 5th grade. Boys showed worse nourishment conditions than girls.

The nutritional practice, known through the records of the teenagers' food intake during three alternating days, proved similar to that of 1974/75, in São Paulo. It was noted that the intake of foods containing Vitamin $\mathrm{C}$ is low - Viatmin $\mathrm{C}$ being an important element for the absortion of iron - and there is a trend of replacing the traditional dinner by a light meal.

Most teenagers' energy intake is adequate whereas iron's is inadequate.

The teenagers' diet may be considered good, thus explaining the discrete prevalence of anemia among this group. Nevertheless, the low density of iron and bioavaiable iron in the diet are indications of the probable substantial proportion of iron deficient teenagers among the population. 


\section{I - INTRODUÇÃO}

Atualmente o problema nutricional de maior prevalência no mundo é a anemia ferropriva, atingindo mais de 700 milhões de pessoas ${ }^{18.19 .33 .69}$. Sua ocorrência é consideravelmente maior nos países em desenvolvimento; $36 \%$ da população desses países apresentam esta patologia enquanto, nos industrializados essa porcentagem é de cerca de $8 \%$.

A África e a Ásia são os continentes mais afetados por esta carência, sendo que mais de $40 \%$ de sua população é anêmica. Na América Latina a prevalência é menor, variando entre $13 \%$ nos homens adultos e $30 \%$ nas gestantes ${ }^{19.83 .84}$.

No Brasil a anemia ferropriva afeta um número elevado de pessoas. Documento do Instituto Nacional de Alimentação e Nutrição (INAN) destaca a prevalência da anemia carencial em diferentes regiōes do país ${ }^{39}$. No estado de Pernambuco, em Recife, ela varia de $20 \%$ a $30 \%$ entre as crianças menores de seis anos, chegando a $39 \%$ na Zona do Sertão. No estado da Paraíba, 20\% dos pré-escolares apresentam anemia, e em Minas Gerais $60 \%$ das crianças, de cinco a oito anos da área rural, são anêmicas. A situação é semelhante no Pará, onde $70 \%$ dos menores de seis anos, e $50 \%$ da população de seis a quatorze anos apresentam anemia por deficiência de ferro ${ }^{39}$. No 
estado de Mato Grosso do Sul a anemia é prevalente em $36 \%$ das crianças de 6 a 14 $\operatorname{anos}^{74}$.

No Município de São Paulo o quadro não é diferente. Estudo epidemiológico realizado na década de setenta apresentou $22 \%$ das crianças de seis a sessenta meses com anemia $^{79}$. Na década seguinte este número elevou-se para $35 \%$, representando um aumento de $60 \%$ de casos em cerca de dez anos. Ainda na cidade de São Paulo, no início dos anos oitenta, pesquisa realizada entre três mil e trezentos escolares de sete anos de idade revelou $20 \%$ de anêmicos ${ }^{54}$. Em Osasco, município da região metropolitana de São Paulo, em um estudo com mil escolares ingressantes no ciclo básico da rede pública de ensino encontrou-se uma prevalência de anemia de $51 \% 82$.

A anemia constitui um sério problema de saúde pública, quer pela sua elevada prevalência, quer pelos efeitos deletérios que impõem ao organismo, trazendo impactos negativos ao desenvolvimento físico e psicológico, no comportamento e na capacidade de trabalho ${ }^{19.56}$.

A anemia é definida pela incapacidade do organismo em manter niveis de hemoglobina adequados. Embora vários nutrientes e co-fatores estejam envolvidos na manutenção de concentrações normais de hemoglobina, do ponto de vista da saúde pública, a carência de ferro é a deficiência mais comum ${ }^{41}$. Por isso, e a exemplo do que faz o "International Nutritional Anemia Consultative Group" - INACG ${ }^{+1}$, o termo anemia será usado, aqui, como sinônimo de anemia nutricional.

A anemia é o estágio mais severo da deficiência de ferro, quando as reservas do mineral estão totalmente esgotadas, as células vermelhas se encontram microcíticas e hipocrômicas, e os níveis de hemoglobina reduzidos ${ }^{34.41}$. 
A deficiência se instala lentamente, espoliando as reservas de maneira progressiva. O primeiro sinal de redução de ferro em um indivíduo normal é o decréscimo da ferritina sérica. Com a continuidade de um balanço negativo de ferro, tanto o nível de transferrina saturada, quanto a concentração de protoporfirina eritrocitária livre saem de seus níveis habituais, a primeira sofrendo diminuiçāo enquanto a segunda aumento $^{34.41}$. Estudos indicam a existência, já nesta fase, de redução na "performance" de exercícios físicos ${ }^{76}$. A concentração de hemoglobina é o último parâmetro a se modificar, quando as reservas do mineral já estão totalmente esgotadas.

Muitas são as causas do balanço negativo de ferro:

- baixa ingestão de alimentos;

- baixa ingestão do mineral;

- baixa biodisponibilidade do ferro alimentar;

- aumento de necessidade;

- perdas aumentadas do mineral, por patologias

(úlceras, hemorróidas, etc) ou espoliação

causada por verminoses.

Os grupos populacionais mais vulneráveis às deficiências de ferro são as crianças de seis a vinte e quatro meses, jovens no princípio da adolescência, mulheres na idade fértil e gestantes ${ }^{18,19.39}$.

As crianças maiores de seis meses normalmente já esgotaram as reservas de ferro providas durante a gestação. Suas necessidades nutricionais são altas, por estarem em fase de intenso crescimento. A dieta, eminentemente láctea, com teores reduzidos de ferro, passa a ser, então, fator determinante da deficiência ${ }^{52.73 .85}$. 
Os jovens, no princípio da adolescência apresentam rápida expansão da massa celular vermelha e intensa deposição de ferro na mioglobina. Suas necessidades nutricionais são grandes, sendo presas fáceis da anemia ${ }^{23.34}$.

Nas mulheres em idade fértil as necessidades de ferro são ainda aumentadas pela perda de sangue menstrual, tornando-as mais suscetiveis a balanços negativos do nutriente ${ }^{23}$.

Gestantes necessitam de quantidades maiores de todos os nutrientes, e em especial de ferro, para atender ao aumento do volume de sangue, à demanda de ferro do feto e placenta e à reposição do sangue perdido no transcorrer do parto $\mathrm{e}$ do puerpério 23.49 .83 .84 .

Os agravos à saúde conseqüentes à anemia são muitos. Na infância foram observados efeitos negativos de longa duração no desenvolvimento motor, psicológico e cognitivo, muitas vezes irreversíveis, mesmo depois de tratamentos prolongados, resultando em atraso na aprendizagem, mudanças de comportamento e diminuição de atividade física $2.6,17,64.65,66.67 .80 .90 .93 .96$.

Com relação a gestação, a presença da carência de ferro está associada ao aumento da morbi-mortalidade materna e fetal e a um risco maior de geração de crianças com baixo peso de nascimento ${ }^{19,48.49,70,90,99}$.

Adultos de ambos os sexos também sofrem efeitos da baixa quantidade de ferro orgânico, que se traduz, principalmente, por uma diminuição na capacidade de trabalho físico, menor resistência à fadiga e anomalias da termogênese, levando os afetados a uma situação desprivilegiada no mercado de trabalho 5 7.31.38.90.95. 
Embora os estudos não sejam ainda conclusivos, vem sendo associada à anemia uma maior suscetibilidade às infecções, uma vez que a deficiência de ferro tem efeitos adversos no sistema imunológico ${ }^{6.16 .69 .90}$.

A demanda de ferro para a manutenção das funçōes vitais do organismo é satisfeita através de três mecanismos ${ }^{30}$ :
a)reutilização contínua do ferro de células vermelhas senis,
b)alimentação diária e
c) regulagem da absorção do mineral.

O ferro proveniente da alimentação atende a pequena parte das necessidades do nutriente, sendo o mecanismo da reutilização responsável pela satisfação de sua maior parte. Embora a dependência do ferro externo seja pequena, o processo de regulagem da absorção do mineral dificulta essa obtenção. A absorção do ferro alimentar, por sua vez, é dependente de inúmeros fatores, entre eles: quantidade e tipo de ferro ingerido, reservas orgânicas do mineral e combinação de alimentos em cada refeição ${ }^{6.11 .28 .43 .92}$.

O ferro se apresenta nos alimentos sob duas formas: heme e não-heme. O ferro heme é constituinte da hemoglobina e da mioglobina, e está presente exclusivamente na carne dos diferentes animais e seus derivados, assim como nos alimentos feitos a partir de sangue. O ferro nāo-heme está presente, principalmente em alimentos de origem vegetal, cereais, leguminosas, raizes, verduras e frutas 28.30 .

A absorção destes dois tipos de ferro é muito diferente. O heme tem absorção de $20 \%$ a $30 \%$, sendo responsável por um quarto do ferro absorvido de uma alimentação rica no mineral. Sua biodisponibilidade não é influenciada pelo tipo, composição ou combinaçāo de alimentos presentes em uma mesma refeição ${ }^{43.92}$. 
O ferro não-heme, que contribui com a maior parte do ferro alimentar, tem absorção que varia entre $1 \%$ e $8 \%$ e depende dos alimentos que compõem a refeição. Carnes de mamíferos, de peixes e de aves são favorecedores da absorção do ferro não-heme, e têm papel duplo, contribuindo também como fontes ricas do mineral de boa absorção $0^{43.78,92}$.

O ácido ascórbico (vitamina C) é outro favorecedor importante do potencial de aproveitamento do mineral, principalmente na alimentação de populações cuja dieta básica não contém quantidades apreciáveis de alimentos de origem animal. Cinquenta miligramas de ácido ascórbico, puro ou proveniente de frutas ou vegetais, são suficientes para duplicar o teor do ferro não-heme absorvivel em uma mesma refeição 11.28 .32 .37 .43 .64 .92 .

Outros compostos agem como inibidores de absorção do ferro não-heme, destacando-se entre outros os fitatos, os taninos e os fosfatos, todos abundantes em alimentos de origem vegetal 10.20,32.57.92.

O quadro abaixo mostra a origem do ferro consumido pela população brasileira, em 1974/75, por região geográfica, segundo os dados da Fundação Instituto Brasileiro de Geografia e Estatística - IBGE - no Estudo Nacional de Despesas Familiares ENDEF ${ }^{30}$.

\begin{tabular}{|lcc|}
\hline \multicolumn{2}{|c|}{$\begin{array}{c}\text { Quadro1- Consumo de ferro da população brasileira, por } \\
\text { região geográfica, } 1974-1975 .\end{array}$} \\
\hline REGIAO & $\begin{array}{c}\text { Fe ( animal) } \\
\text { (mg/dia) }\end{array}$ & $\begin{array}{c}\text { Fe (outras fontes } \\
\text { (mg/dia) }\end{array}$ \\
\cline { 1 - 1 } I - Rio de Janeiro & 3,03 & 11,17 \\
II - São Paulo & 2,45 & 11,20 \\
III - PR, SC, RS & 2,53 & 12,63 \\
IV - MG ES & 1,55 & 13,11 \\
V - Nordeste & 2,55 & 15,53 \\
VI - DF & 2,62 & 10,51 \\
VII - Territórios+outros & 3,39 & 10,21 \\
\hline
\end{tabular}

Fonte: Perfil estatistico das crianças e mäes do Brasil, 1979 
Analisando esses dados, pode-se concluir que o ferro dietético oferecido não apresenta, a "priori", boa biodisponibilidade. Considerando ainda, que a mesma fonte informa que $40 \%$ da população urbana de baixa renda, em São Paulo, não ingere alimentos suficientes para atingir às recomendaçōes de energia, é possivel concluir que a baixa biodisponibilidade, acrescentada à pequena oferta de ferro predispōe a população ao risco da deficiência orgânica do mineral.

A literatura apresenta grande número de trabalhos que documentam a prevalência da anemia em crianças, mulheres em idade fértil e gestantes. Poucos são os estudos dedicados a quantificar a deficiência de ferro entre adolescentes ${ }^{19.90}$.

DeMAEYER e ADIELS-TEGMAN (1985)18, em sua revisão "The Prevalence of Anaemia in the World", registram que entre 1960 e 1983 somente trinta e nove países apresentaram algum estudo relevante sobre a prevalência de anemia entre adolescentes. O Brasil não figura entre eles. Na América Latina, na região "Tropical South America" que engloba o Brasil, somente dois países, a Bolívia e o Colômbia, registram dados sobre adolescentes, sendo a prevalência de anemia de $15 \%$ e $8 \%$, respectivamente, entre homens e mulheres com idade entre 10 e 20 anos.

HERBERT $(1987)^{34}$ relata prevalência de $4 \%$ a $12 \%$ de ferro deficientes entre meninos de onze a quatorze anos, nos Estados Unidos da América.

BAILEY (1982) $)^{3}$ mostra que dentre jovens americanos negros ou de procedência hispânica, de baixo nível social, com idade entre doze e dezenove anos, $3 \%$ dos homens e $11 \%$ das mulheres apresentavam níveis de hemoglobina abaixo da normalidade. 
LAMPARELLI (1988) ${ }^{45}$, estudando escolares sul-africanos de dez e onze anos, encontrou uma porcentagem bastante significativa de anêmicos, que variou de $36 \%$, entre jovens negros, a $11 \%$ entre os brancos, da área urbana da Cidade do Cabo.

CESAR (1990)" examinando escolares paulistanos, encontrou alta porcentagem de anêmicos entre os jovens maiores de doze anos: $46 \%$ entre as meninas e $86 \%$ entre os meninos.

SALZANO E DRICOT (1983) ${ }^{39}$ encontraram $19,2 \%$ de anêmicos entre escolares na Zona da Mata do estado da Paraíba.

JOÃO $(1983)^{39}$ relata a prevalência de $53,3 \%$ de anemia entre meninos e $47 \%$ entre meninas de seis a quatorze anos em Belém, no estado do Pará. Ainda nesta Capital $20 \%$ de 2.000 escolares de sete a quatorze anos apresentavam anemia, com maior prevalência entre os meninos de sete a nove anos, e meninas de treze a quinze anos.

FUJIMORI $(1989)^{23}$ relata a prevalência de $18 \%$ de mulheres adolescentes anêmicas em uma região da Grande São Paulo.

Os adolescentes formam um grupo bastante específico da população, fisiológica e psicologicamente diferentes de adultos e crianças.

Um grupo de estudos da Organização Mundial da Saúde (OMS), reunido em Genebra em 1984 para trabalhar sobre a saúde dos jovens para o ano 2000, discutiu amplamente o tema da adolescência e concluiu que esta se constitui numa fase de desenvolvimento muito específica, com instabilidades marcantes e com características que dependem da interação de fatores psicossociobiológicos ${ }^{44}$. Alguns itens do desenvolvimento global do adolescente foram apontados: adaptação às mudanças anatômicas e fisiológicas; 
resolução de sua relação com seus pais e familiares; desenvolvimento das relaçōes com seus pares; estabelecimento de sua individualidade; utilização de maior competência intelectual em virtude da aquisição do sentido de "comunidade" e "visão do mundo" e desenvolvimento de potencial para a realização de atividades ocupacionais e recreativas.

A adolescência se caracteriza por uma série de modificações bioquímicas, anatômicas e mentais. Nos adolescentes jovens, entre dez e quatorze anos, há um aumento rápido das secreções de diversos hormônios e o crescimento é acelerado, seguindo-se o aparecimento dos caracteres sexuais secundários. Entre os quatorze e os dezenove anos o ritmo de amadurecimento fica mais lento, até chegar à idade adulta ${ }^{55}$.

A seqüência em que essas transformações se dão é sempre a mesma, mas não ocorrem na mesma idade, havendo variaçōes consideráveis no seu ritmo e amplitude, mesmo entre adolescentes do mesmo sexo. Dependem também de fatores hereditários, ambientais, nutricionais e sociais aos quais os jovens estão submetidos. Em geral, as jovens iniciam e terminam o processo de maturação sexual um ou dois anos antes dos homens, porém neles o crescimento físico é, em média, superior ${ }^{55}$.

Os adolescentes apresentam necessidades nutricionais absolutas e relativas maiores do que aquelas das crianças ou dos adultos, tendo em vista sua alta taxa de crescimento e a intensidade de suas atividades físicas, tanto no trabalho como no lazer ${ }^{59}$.

Uma evolução satisfatória da adolescência constitui base excelente para uma existência adulta sã e eficaz. O bom estado nutricional é fator fundamental para atingir esta evolução e para a prevençāo de inúmeros agravos físicos, tais como atraso no crescimento ou falta de aptidão física para o desempenho de tarefas, que podem interferir negativamente no amadurecimento psicológico do adolescente. A força muscular, a destreza, a resistência à fadiga permitem ao adolescente participar com 
êxito nas atividades de seu grupo, sentindo-se reforçado em seus sentimentos de competência e amor próprio.

Assim sendo, é importante prover uma alimentação suficiente e equilibrada ao jovem, que lhe proporcione nutrientes em quantidade e qualidade adequadas para o desenvolvimento de todo o seu potencial genético.

Nesse sentido o ferro tem papel preponderante, uma vez que influencia diretamente na capacidade de trabalho, resistência à fadiga e no rendimento do aprendizado.

A Organização Panamericana da Saúde (OPAS) e a Organização Mundial da Saúde (OMS) vêm discutindo a inclusão dos adolescentes nos programas de saúde, principalmente no continente sul-americano, onde o elevado índice de natalidade, aliado à diminuição gradual da taxa de mortalidade infantil tem contribuído para aumentar consideravelmente essa população ${ }^{60}$.

O presente estudo pretende contribuir para o conhecimento da situação alimentar do adolescente paulista, verificando o papel desempenhado pela alimentação como um dos determinantes da anemia ferropriva nessa população. 


\section{II - OBJETIVOS}

OBJETIVO GERAL:

- Identificar a ocorrência da anemia entre escolares adolescentes e o papel da alimentação na sua determinação.

\section{OBJETIVOS ESPECÍFICOS:}

- Verificar a prevalência de anemia na população de estudo.

- Verificar a prevalência da desnutrição e traçar o perfil de crescimento da população de adolescentes.

- Identificar a prática alimentar da população em estudo.

- Identificar a distribuição das atividades físicas no dia do adolescente.

- Avaliar a adequação do consumo alimentar de ferro, ferro biodisponível e de energia pelos adolescentes. 


\section{III - METODOLOGIA}

\section{LOCAL DO ESTUDO}

O estudo foi desenvolvido no município de Osasco, que pertence à Região Metropolitana da Grande São Paulo.

O município está situado à 18 quilômetros a oeste da capital do estado de São Paulo, ocupando uma área de 68 quilômetros quadrados. A população levantada pelo censo de 1991 é de 566.949 habitantes $^{75}$. Em 1985, 35,1\% da população geral eram menores de $15 \operatorname{anos}^{63}$.

É um município relativamente novo, desmembrado do município de São Paulo em 1958, reproduzindo o típico processo de desenvolvimento paulista. É um dos mais ricos da regiāo mais próspera do Estado, sendo o quinto em consumo energético e em produção industrial e o quarto em arrecadação de impostos ${ }^{63.75}$. A taxa de mortalidade infantil (TMI) de Osasco acompanhou a queda apresentada pela TMI do município de São Paulo na última década: em 1981 São Paulo apresentava TMI de 49,43\%., que evoluiu para 37,03\%. em 1985 e 25,21\%. em 1991; Osasco, por sua vez apresentava taxas de 76,28\%. em 1981 e 44,8\%. e 34,83\%. em 1985 e 1991, respectivamente ${ }^{75}$. 
Apresenta uma regiāo central com intenso uso comercial e de serviços diversificados, constituindo polo de atração regional para toda a sub-região oeste da Região Metropolitana de São Paulo ${ }^{63}$.

Contíguo a este centro de serviços e comércio, encontram-se áreas de uso industrial, ocupadas por indústrias pioneiras do município, ligadas aos setores metalúrgicos, de materiais elétricos e de comunicação, de transporte e de minerais metálicos, responsável pela absorção de parte importante da mão de obra do município.

No anel intermediário do município predominam os bairros residenciais, relativamente homogêneos, com bons níveis de infra-estrutura urbana, com habitações unifamiliares de médio e alto padrão de construção, com tendências à verticalização.

A periferia do município de Osasco, externa ao anel intermediário, é uma área de ocupação desordenada, com diferentes graus de consolidação urbana, integrando-se como bairros em função de suas divisas físicas, onde a infra-estrutura urbana é insuficiente e precária. $\mathrm{O}$ uso predominante é residencial, de baixo padrão de construção, sendo frequente a autoconstrução.

O município de Osasco tem, portanto, dupla função; é uma cidade dormitório para uma parcela considerável da população que oferece sua mão de obra para a cidade de São Paulo, ao mesmo tempo em que se apresenta como polo de atração regional para a área oeste da Região Metropolitana de São Paulo63.

Grande parcela da população do município pode ser caracterizada como pobre, já que $62 \%$ de sua População Economicamente Ativa (PEA) apresentava, em 1980, rendimento de até 3 salários mínimos ${ }^{63}$. 
O grau de escolaridade dessa população é bastante baixo. Em 1980, 13\% da população acima de quatorze anos era analfabeta. A maior parte da população acima de 10 anos $(69 ; 9 \%)$ não havia ultrapassado a quarta série do primeiro grau.

Ainda em $1980,3,1 \%$ da população frequentava a pré-escola, $77,5 \%$ frequentava o primeiro grau, enquanto apenas $12,4 \%$ se encontrava no segundo grau. Os dados mostram que daqueles que se matriculam na escola, apenas $16 \%$ chegam a ingressar no segundo grau, observando-se grande afunilamento entre o primeiro e o segundo graus. Constata-se, portanto, um alto índice de evasão escolar. Além desta alta evasão, o índice de reprovação escolar no primeiro grau chega a alcançar 30\% dos escolares a cada ano ${ }^{63}$.

Apesar dos dados acima, a cobertura do equipamento escolar deste município se mostra bastante eficiente. Em 1984 a população de 7 a 14 anos era estimada em 98.347 jovens, sendo que a oferta de vagas para o primeiro grau ( $1^{\mathrm{a}}$ a $8^{\mathrm{a}}$ série) era de 99.551 (considerando-se a rede pública e a privada), suficiente portanto, para atender à totalidade da população alvo $0^{63}$.

\section{POPULAÇÃO DE ESTUDO}

Alunos das quintas e oitavas séries das escolas da Rede Oficial de Ensino do Município de Osasco.

\section{SELEÇÃO DAS ESCOLAS}

Em 1990, Osasco contava com 81 escolas públicas distribuídas por duas delegacias de ensino, com quatro Administrações Regionais de Ensino (ARs) cada uma ${ }^{53}$. 
No ano de 1989, o Departamento de Nutrição da Faculdade de Saúde Pública e o Instituto de Saúde da Secretaria da Saúde de São Paulo desenvolveram um estudo sobre o déficit estatural de alunos ingressantes nas primeiras séries do primeiro grau das escolas de Osasco ${ }^{53}$. Através deste estudo foram identificadas três regiōes distintas com relação a este indicador do estado nutricional, segundo a localização das escolas nas oito ARs em que se divide o município (figura 1).

Figura 1 - Prevalência de Déficit de Estatura (\%) em Alunos Ingressantes nas Escolas do Primeiro Grau das Administrações Regionais. Município de Osasco, 1989(26)

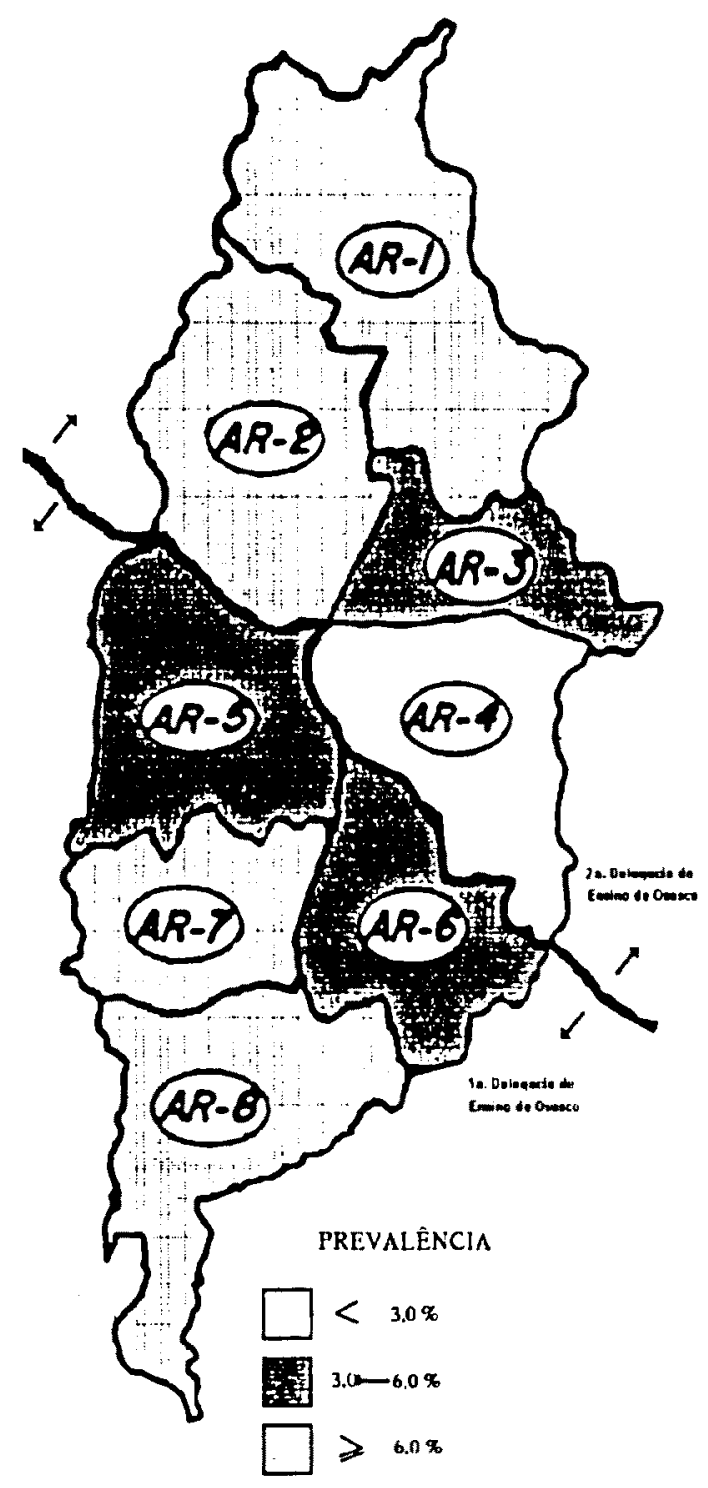


Com base nesta pesquisa optou-se por restringir a amostra à $2^{\mathrm{a}}$ Delegacia de Ensino de Osasco, da qual participam as três regiões definidas quanto ao déficit de estatura (figura 1) e na qual estão presentes trinta e seis escolas públicas.

Duas escolas de cada uma das quatro ARs da segunda delegacia foram selecionadas; a de maior e a de menor prevalência de déficit estatural da respectiva Administração, perfazendo um total de oito estabelecimentos, conforme a tabela abaixo:

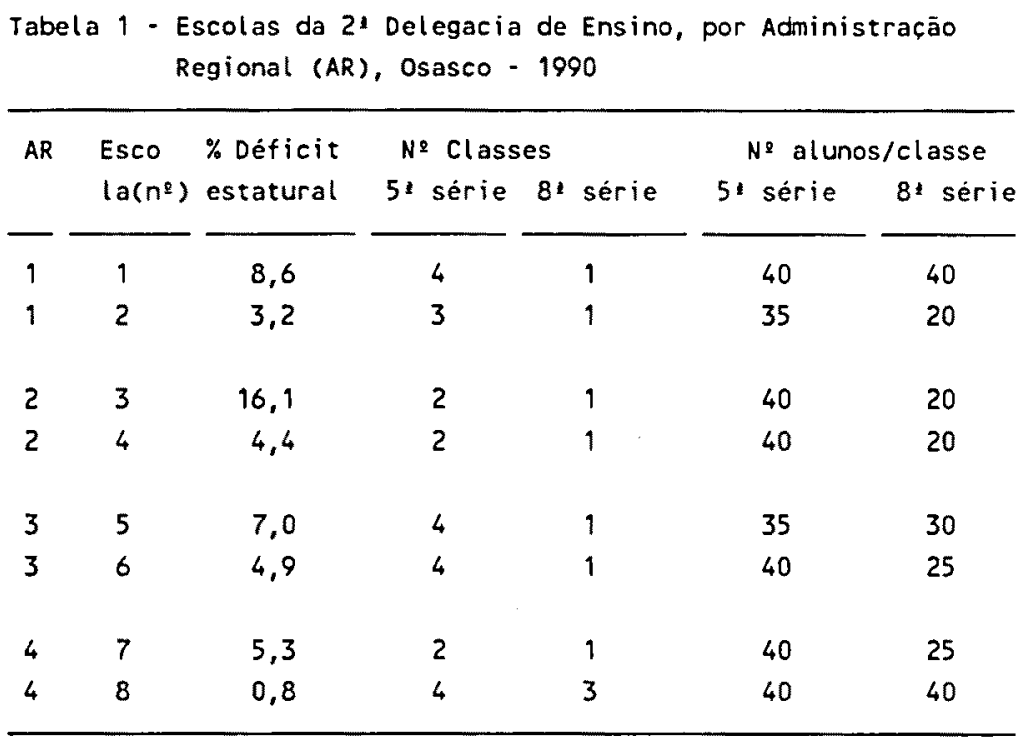

A numeração das escolas foi feita de modo que os números ímpares identificam aquelas onde os alunos apresentaram maior déficit estatural, enquanto que os pares correspondem àquelas escolas onde as crianças apresentaram menor déficit nutricional, em cada Administração Regional de Ensino.

Foi sorteada uma classe de quinta série de cada uma das oito escolas, obtendo-se um grupo de aproximadamente 300 adolescentes. Com relação às oitavas séries, com exceção de uma, todas as escolas ofereciam apenas uma classe, tendo-se optado por 
trabalhar com a totalidade delas, considerando ainda que o grupo assim obtido apresentaria tamanho semelhante ao da quinta série.

\section{DIAGNÓSTICO DA ANEMIA:}

A anemia foi diagnosticada pela dosagem da concentração sanguínea da hemoglobina $(\mathrm{Hb})$, através do método da cianometahemoglobina ${ }^{15,19}$.

A colheita de sangue foi feita por técnicos habilitados, da Faculdade de Saúde Pública da USP, através de puntura digital, com o uso de estiletes descartáveis, observando-se as recomendações para a técnica proposta por DALLMAN e SIIMES ${ }^{15}$. Estes pesquisadores referem a possibilidade de substituir o sangue venoso por capilar no diagnóstico da anemia, sem prejuízo da qualidade do exame laboratorial, desde que observados determinados cuidados técnicos na colheita da amostra.

O padrão usado foi o "CELLMÓGLOBINA" da CELM, tendo sido a leitura realizada em espectrofotômetro "Coleman", com comprimento de-onda de 540 mu.

Optou-se por colher a amostra de sangue através de punção digital por ser este procedimento o mais adequado, considerando o tamanho amostral, e por propiciar maior aceitação em relação à colheita. Acresce-se que este método de colheita de sangue é significantemente mais econômico do que aquele feito através de punção venosa.

Foi solicitada a autorização dos pais ou responsáveis para a dosagem bioquímica (anexo 1). 
O critério para diagnóstico de anêmicos foi aquele definido pela $\mathrm{OMS}^{19}$ :

- jovens de 6 a 14 anos $\quad-<12,0 \mathrm{~g}$ de $\mathrm{Hb} / \mathrm{dl}$

- homens $>=15$ anos $\quad-<13,0 \mathrm{~g}$ de $\mathrm{Hb} / \mathrm{dl}$

- mulheres $>=15$ anos $\quad-<12,0 \mathrm{~g} \mathrm{de} \mathrm{Hb} / \mathrm{dl}$

O resultado da dosagem de hemoglobina foi enviado individualmente para cada aluno; aqueles diagnosticados como anêmicos foram orientados a procurar a Unidade de Saúde para uma diagnóstico mais apurado e tratamento, se fosse o caso (anexos 2 e 3 ).

\section{CONSUMO E PRÁTICA ALIMENTAR}

O consumo alimentar foi obtido através do registro dos alimentos ingeridos, por três dias alternados, incluindo eqüitativamente os sete dias da semana.

Os alimentos foram registrados pelo estudante, em medidas caseiras, separados por refeição e local de consumo, em formulário próprio (anexo 4).

Os dias da semana escolhidos para registro foram selecionados da seguinte maneira: os formulários foram divididos em sete grupos, cada um destinado ao registro da alimentação relativa a três dias diferentes da semana, como segue.

\begin{tabular}{|c|c|c|c|}
\hline GRUPO & DIAS & $D A S$ & SEMANA \\
\hline 1 & 2 & $4:$ & 6: \\
\hline 2 & $3:$ & $5:$ & sab. \\
\hline 3 & $4:$ & $6:$ & dom. \\
\hline 4 & 22 & $5:$ & sab. \\
\hline 5 & 31 & 61 & dom. \\
\hline 6 & 2 & $4:$ & sab. \\
\hline 7 & $3:$ & $5:$ & dom. \\
\hline
\end{tabular}


A dieta de cada dia da semana foi, portanto, registrada por três grupos diferentes de jovens, em igual proporção - aumentando assim, a possibilidade de detectar as variaçōes do consumo alimentar decorrentes dos diferentes dias da semana, além daquelas inerentes à população ${ }^{77}$.

Antes da entrega dos formulários houve uma breve explanação sobre o preenchimento do mesmo, onde foram abordados os seguintes pontos:

. objetivo do estudo;

. dias marcados para o registro dos alimentos consumidos;

. registro da escolaridade dos pais;

preenchimento correto do cabeçalho (data e dia da semana);

. horário, definindo se o consumo foi feito pela manhã ou pela tarde;

. local da refeição (casa, escola, lanchonete, outro) e registro dos alimentos

- quantidades - registrar em medidas caseiras (colher, copo, etc.);

- lembrar que balas, chicletes, doces e outros alimentos "beliscados" durante o dia também devem ser registrados e

- quando industrializados registrar da forma como são conhecidos (danone, coca-cola, maisena, etc).

Optou-se por não registrar o nome da refeição para que os jovens não se sentissem constrangidos se deixassem de consumir uma das refeições e ficasse o espaço em branco.

Ao definir o registro de três dias alternados, procurou-se detectar maior variabilidade de alimentos consumidos pela população, evitando-se o registro de "sobras" do dia anterior. Houve o cuidado de se incluir, nesses dias alternados, os sábados e os 
domingos que tiveram assim, a mesma oportunidade de serem registrados que os outros dias da semana.

Vários autores definem que três dias de levantamento são suficientes para cobrir a quantidade e a variabilidade de alimentos consumidos por um grupo de indivíduos $4,8,21,27,62$.

Os alimentos foram registrados em medidas caseiras, e transformados em gramas através da utilização dos pesos de medidas caseiras apresentados no programa de computação "Sistema de Apoio à Decisão em Nutrição", desenvolvido pelo Centro de Informática em Saúde da Escola Paulista de Medicina (EPM). Os pesos não encontrados naquela tabela, foram retirados da "Tabela de Equivalência de Pesos em Grama dos Alimentos em Medidas Caseiras" do Departamento de Nutrição da Faculdade de Saúde Pública da Universidade de São Paulo. Finalmente, o peso dos alimentos não encontrados em nenhuma das duas tabelas foram estimados pela Autora, através da pesagem direta de diversas amostras dos mesmos.

Metade dos escolares da amostra foram submetidos a entrevista para o levantamento de suas atividades físicas diárias e suas práticas alimentares. O formulário, especialmente desenvolvido (anexo 5), foi aplicado nas escolas por entrevistadores treinados e supervisionados pela Autora.

\section{ADEQUAÇÃO DE CONSUMO}

Os cálculos para avaliar o teor de energia e de nutrientes foram feitos usando-se a tabela de composição de alimentos do ENDEF$^{24}$ e do Instituto de Nutrición de Centro America y Panamá (INCAP) ${ }^{86}$. 
O ferro biodisponível foi quantificado através da equação desenvolvida por MONSEN e BALINTFY ${ }^{50}$. Foi especialmente desenvolvido um programa computacional para essa quantificação que levou em consideração a composição de cada refeição, onde são analisadas 5 variáveis: a) ferro total; b) ferro heme ( $40 \%$ do ferro das carnes de mamíferos, de peixes e de aves); c) ferro não heme (Fe total - Fe heme); d) quantidade de ácido ascórbico presente na refeição; e) quantidade de todos os tipos de carnes na refeição.

A porcentagem de ferro não heme, para um indivíduo com estoques corporais de 500 mg de ferro pode ser assim calculada:

\% de ferro não heme biodisponível $=$

$$
3+8,93 \log _{n} \frac{(E F+100)}{100}
$$

$E F=$ "enhancing factors" (fatores favorecedores) que se define como sendo a soma de miligramas de ácido ascórbico e gramas de carnes, até o máximo de 75 unidades favorecedoras.

Obs: se a quantidade de $E F$ for igual a 0 , a porcentagem de absorção é $3 \%$; se for igual ou maior que 75 , a porcentagem de absorção é $8 \%$.

Ao ferro não heme biodisponivel é somada a parcela do ferro heme biodisponivel para se chegar à totalidade de ferro biodisponível da refeição e do dia.

Na avaliação da adequação da ingestão de ferro foi usado padrão de recomendação da OMS (1989) $)^{19}$, como segue: 


\begin{tabular}{|c|c|c|c|c|}
\hline \multirow{2}{*}{$\begin{array}{l}\text { Idade } \\
\text { (anos) }\end{array}$} & \multicolumn{2}{|c|}{ biodisponibilidade } & \multicolumn{2}{|c|}{ de ferro da dieta } \\
\hline & $<5 \%$ & $5-10 \%$ & $11-18 \%$ & $>19 \%$ \\
\hline $6 \cdot 11$ & $29 \mathrm{mg} / \mathrm{dia}$ & $16 \mathrm{mg} / \mathrm{dia}$ & $8 \mathrm{mg} / \mathrm{dia}$ & $5 \mathrm{mg} / \mathrm{dia}$ \\
\hline \multicolumn{5}{|l|}{$12-16$} \\
\hline (meninas) & $50 \mathrm{mg} / \mathrm{dia}$ & $27 \mathrm{mg} / \mathrm{dia}$ & $13 \mathrm{mg} / \mathrm{dia}$ & $9 \mathrm{mg} / \mathrm{dia}$ \\
\hline \multicolumn{5}{|l|}{$12-16$} \\
\hline (meninos) & $45 \mathrm{mg} / \mathrm{dia}$ & $24 \mathrm{mg} / \mathrm{dia}$ & $12 \mathrm{mg} / \mathrm{dia}$ & $8 \mathrm{mg} / \mathrm{dia}$ \\
\hline \multicolumn{5}{|l|}{ adul tos } \\
\hline (homens) & $28 \mathrm{mg} / \mathrm{dia}$ & $15 \mathrm{mg} / \mathrm{dia}$ & $8 m g / d i a$ & $5 \mathrm{mg} / \mathrm{dia}$ \\
\hline \multicolumn{5}{|l|}{ adultos } \\
\hline (mulheres) & $59 m g / d i a$ & $32 \mathrm{mg} / \mathrm{dia}$ & $16 \mathrm{mg} / \mathrm{dia}$ & $11 \mathrm{mg} / \mathrm{dia}$ \\
\hline
\end{tabular}

O documento "Aplicações das Recomendaçōes Nutricionais Adaptadas à População Brasileira" foi usado como referencial para a avaliação da adequação de ingestão de energia e dos outros nutrientes ${ }^{89}$.

Médias e desvios padrão da quantidade de energia e dos nutrientes ingeridos durante os três dias de registro, por refeição e por dia, foram calculados para cada um dos indivíduos e para cada grupo de indivíduos, definidos por sexo e idade, e caracterização social ${ }^{9}$.

\section{ATIVIDADES FÍSICAS DO ADOLESCENTE}

A identificação das atividades físicas foi feita através da entrevista realizada na escola (anexo 5), procurando verificar seu tipo e duração, durante as horas de estudo, de trabalho (se fosse o caso), de lazer e de descanso. Sua intensidade foi analisada através do gasto energético por hora e por dia, separando os jovens segundo a intensidade de atividades físicas.

As atividades consideradas foram:

- atividades leves: sentado ou em pé, movimentação, atividades sociais, banho, brincadeiras na escola; 
- atividades moderadas: caminhar, atividades dosmésticas (faxina, encerar o chão, lavar roupa, lavar pratos), jogos de bola e

- atividades intensas: carregar lenha, carregar tijolos, trabalho pesado em construção, trabalho agrícola intenso, treinamento esportivo (halterofilismo, corrida, etc).

O gasto energético foi classificado segundo as atividades, em leve, moderado e intenso, conforme as recomendações da FAO/OMS/UNU - $1985^{59}$, que recomenda os seguintes fatores de multiplicação da taxa de metabolismo basal (TMB), segundo a intensidade do trabalho físico:

$\begin{array}{lll} & \text { homens } & \text { mulheres } \\ \text { Trabalho leve } & 1,6 & 1,5 \\ \text { Trabalho moderado } & 2,5 & 2,2 \\ \text { Trabalho intenso } & 6,0 & 6,0\end{array}$

A partir da atividade física, foi calculado o gasto energético individual, segundo as recomendaçōes da FAO/OMS/UNU em seu documento "Necesidades de Energia y de Proteínas"59.

Para esse cálculo, foi estimado o número de horas gastas nas diferentes atividades diárias, durante os sete dias da semana, classificadas segundo sua intensidade, em leves, moderadas ou intensas. Calculou-se, então, a Taxa de Metabolismo Basal (TMB), segundo a fórmula abaixo recomendada para indivíduos com idade entre 10 e 18 anos de idade 59 . 


homens: $\mathrm{TMB}=17,5 \mathrm{P}+65 \mathrm{I}=\mathrm{kcal} / \mathrm{dia}$
mulheres: $\mathrm{TMB}=12,2 \mathrm{P}+746=\mathrm{kcal} / \mathrm{dia}$
$\mathrm{P}=$ peso corporal

A essa TMB foi acrescido o número de quilocalorias necessárias para garantir o crescimento, e as diversas atividades diárias, levando-se em conta os fatores relativos à idade e intensidade da atividade.

\section{NÍVEL SÓCIO-ECONÔMICO}

O nível sócio-econômico da população foi definido através da escolaridade do chefe da família dos participantes da pesquisa (anexo 4), como o fizeram MONTEIRO e colaboradores $^{51}$ e ZURAYK e colaboradores ${ }^{100}$. Estes Autores mostraram a grande dependência que a escolaridade apresenta com relação à classe social, a forte associação existente entre o nível de escolaridade e o nível de renda, a facilidade de obtenção deste dado e, também, que o seu uso é apropriado em estudos relacionados com saúde em sociedades urbanas em desenvolvimento.

\section{ESTADO NUTRICIONAL E PERFIL DE CRESCIMENTO}

O estado nutricional e o perfil de crescimento dos escolares foram avaliados através dos indicadores de peso para idade $(\mathrm{P} / \mathrm{I})$, altura para idade $(\mathrm{A} / \mathrm{I})$ e peso para altura $(\mathrm{P} / \mathrm{A})$. O padrão do National Center for Health and Statistics (NCHS), recomendado para uso internacional pela Organização Mundial de Saúde ${ }^{58}$ foi usado como referência para os indicadores $\mathrm{P} / \mathrm{I}$ e $\mathrm{A} / \mathrm{I}$. $\mathrm{O}$ indicador $\mathrm{P} / \mathrm{A}$ teve como referência $\mathrm{o}$ documento "Anthropometric Standards for the Assessment of Growth and Nutritional Status" de FRISANCHO22, que usou dados antropométricos do NCHS para a confecção de tabelas antropométricas de referência. 
A tomada das medidas antropométricas foi feita pessoalmente pela Autora, com o auxílio de equipe devidamente treinada e supervisionada.

A medida do peso foi feita com balança eletrônica portátil, marca Soehnle, produzida na Alemanha, com capacidade para $150 \mathrm{~kg}$ e precisão de $100 \mathrm{~g}$.

A altura foi medida através de estadiômetro portátil (trena fabricada pela Stanley Mabo, França), graduado em décimos de centímetros. Um degrau de madeira para anular a diferença do rodapé foi usado durante a mensuração. 


\section{IV - RESULTADOS E DISCUSSÃO}

A amostra foi constituída pelos alunos do período diurno das classes de quinta série sorteadas e pela totalidade dos alunos das oitavas séries das oito escolas de ensino básico selecionadas da rede pública de ensino do município de Osasco.

O total de alunos das dezoito classes que constituíram a amostra foi de 554 , conforme as listas de matrícula fornecidas pelas escolas. No dia do trabalho de campo estavam presentes 509 alunos (92\%) para os quais foram distribuídos os formulários. As medidas antropométricas foram feitas em 507 (dois estavam engessados), e houve impedimento da coleta de sangue para 23 jovens, por desaprovação dos pais ou por recusa, sendo então coletado material de 486 adolescentes $(87,7 \%)$.

Dos 509 formulários distribuídos, 238 (46,7\%) foram devolvidos no dia aprazado da coleta. Numa segunda solicitação, recolheu-se mais 142 , correspondendo a 380 no total $(74,6 \%)$. Destes, 11 foram inutilizados por erros no preenchimento ou letra ilegível, sendo que as análises relativas à alimentação foram realizadas para 369 formulários ( $72,5 \%$ dos formulários distribuídos e $97 \%$ dos devolvidos).

Com relação as entrevistas programadas (277), foram efetivamente realizadas 273 $(98,6 \%)$. 
A população estudada é, portanto, composta de 509 jovens, sendo 203 homens e 306 mulheres, assim distribuídos:

Tabela 2. Distribuiçāo da população segundo escolas, séries e sexo. Osasco, 1990.

\begin{tabular}{|c|c|c|c|c|c|c|c|c|c|}
\hline \multirow{2}{*}{$\begin{array}{l}\text { Es } \\
\text { co }\end{array}$} & \multicolumn{3}{|c|}{$5:$} & \multicolumn{3}{|c|}{81} & \multicolumn{2}{|c|}{ Total } & \multirow[b]{2}{*}{$T$} \\
\hline & $M$ & $F$ & $T$ & M & $F$ & $T$ & M & $F$ & \\
\hline las & $\%$ & $\%$ & $\%$ & $\%$ & $\%$ & $\%$ & $\%$ & $\%$ & $\%$ \\
\hline \multirow[t]{2}{*}{1} & 13 & 14 & 27 & 8 & 26 & 34 & 21 & 40 & 61 \\
\hline & $(48,1)$ & $(51,9)$ & $(100)$ & $(23,5)$ & $(76,5)$ & $(100)$ & $(34,4)$ & $(65,6)$ & $(100)$ \\
\hline \multirow[t]{2}{*}{2} & 16 & 10 & 26 & 3 & 13 & 16 & 19 & 23 & 42 \\
\hline & $(61,5)$ & $(38,5)$ & $(100)$ & $(18,8)$ & $(81,2)$ & $(100)$ & $(45,2)$ & $(54,8)$ & $(100)$ \\
\hline \multirow[t]{2}{*}{3} & 9 & 20 & 29 & 9 & 10 & 19 & 18 & 30 & 48 \\
\hline & $(31,0)$ & $(69,0)$ & $(100)$ & $(47,4)$ & $(52,6)$ & $(100)$ & $(37,5)$ & $(62,5)$ & $(100)$ \\
\hline \multirow[t]{2}{*}{4} & 17 & 17 & 34 & 4 & 15 & 19 & 21 & 32 & 53 \\
\hline & $(50,0)$ & $(50,0)$ & $(100)$ & $(21,0)$ & $(79,0)$ & $(100)$ & $(39,6)$ & $(60,4)$ & $(100)$ \\
\hline \multirow[t]{2}{*}{5} & 12 & 17 & 29 & 2 & 23 & 25 & 14 & 40 & 54 \\
\hline & $(41,4)$ & $(58,6)$ & $(100)$ & $(8,0)$ & $(92,0)$ & $(100)$ & $(25,9)$ & $(74,1)$ & $(100)$ \\
\hline \multirow[t]{2}{*}{6} & 13 & 19 & 32 & 5 & 20 & 25 & 18 & 39 & 57 \\
\hline & $(40,6)$ & $(59,4)$ & $(100)$ & $(20,0)$ & $(80,0)$ & $(100)$ & $(31,6)$ & $(68,4)$ & $(100)$ \\
\hline \multirow[t]{2}{*}{7} & 19 & 14 & 33 & 5 & 12 & 17 & 24 & 26 & 50 \\
\hline & $(57,6)$ & $(42,4)$ & $(100)$ & $(29,4)$ & $(70,6)$ & $(100)$ & $(48,0)$ & $(52,0)$ & $100)$ \\
\hline \multirow[t]{2}{*}{8} & 18 & 21 & 39 & 50 & 55 & 105 & 68 & 76 & 144 \\
\hline & $(46,2)$ & $(53,8)$ & $(100)$ & $(47,6)$ & $(52,4)$ & $(100)$ & $(47,2)$ & $(52,8)$ & $(100)$ \\
\hline \multirow[t]{2}{*}{ Total } & 117 & 132 & 249 & 86 & 174 & 260 & 203 & 306 & 509 \\
\hline & $(47,0)$ & $(53,0)$ & $(100)$ & $(33,1)$ & $(66,9)$ & $(100)$ & $(39,9)$ & $(60,1)$ & $(100)$ \\
\hline
\end{tabular}

Há predominância de mulheres, principalmente nas oitavas séries. É importante recordar que a oitava série da escola $n^{\circ} 8$ é constituída de três classes apresentando, portanto, maior número de alunos. 
A tabela 3 apresenta a distribuição etária da população por série.

\begin{tabular}{|c|c|c|c|c|}
\hline \multirow{2}{*}{$\begin{array}{l}\text { Idade } \\
\text { (anos) }\end{array}$} & \multicolumn{2}{|c|}{52 série } & \multicolumn{2}{|c|}{81 série } \\
\hline & $n$ & $\%$ & $n$ & $\%$ \\
\hline$<12$ & 56 & 22,5 & $\cdots$ & $\cdots$ \\
\hline$|2| \cdot 13$ & 65 & 26,1 & $\cdots$ & $\cdots$ \\
\hline $13 \mid \cdot 14$ & 53 & 21,3 & $\cdots$ & $\cdots$ \\
\hline $14 \mid-15$ & 43 & 17,3 & 108 & 41,5 \\
\hline $15 \mid-16$ & 19 & 7,6 & 86 & 33,1 \\
\hline$|6|-17$ & 10 & 4,0 & 42 & 16,2 \\
\hline$>=17$ & 3 & 1,2 & 24 & 9,2 \\
\hline Total & 249 & 100,0 & 260 & 100,0 \\
\hline
\end{tabular}

A amplitude de idades nas quintas séries é maior, podendo-se constatar a existência de jovens maiores de quinze anos não só frequentando o primeiro grau, mas ainda nesta série.

A distribuição etária da amostra indica que parte dos adolescentes que se encontra na quinta série já deveria estar cursando a oitava série, uma vez que a idade adequada para esta é de 13 anos e 10 meses até 15 anos e 10 meses na data da medida, enquanto que para a quinta é de 11 anos e 5 meses até 13 anos e 10 meses naquela mesma data. Entretanto, a distribuição da idade por série não se apresenta desta maneira (tabela 4). 
Tabela 4. Porcentagem dos alunos de 5 t e 81 séries com idade adequada* à série cursada, segundo escolas. Osasco-1990.

\begin{tabular}{|c|c|c|c|c|c|c|}
\hline \multirow{2}{*}{$\begin{array}{r}\text { Esco } \\
\text { las }\end{array}$} & \multicolumn{3}{|c|}{51} & \multicolumn{3}{|c|}{$8:$} \\
\hline & $M$ & $F$ & Total & $M$ & $F$ & Total \\
\hline 1 & 30,7 & 42,8 & 37,0 & 75,0 & 57,7 & 61,8 \\
\hline 2 & 50,0 & 50,0 & 50,0 & 100,0 & 69,2 & 92,3 \\
\hline 3 & 0,0 & 55,0 & 37,9 & 66,7 & 60,0 & 63,1 \\
\hline 4 & 11,8 & 23,5 & 17,6 & 0,0 & 60,0 & 47,4 \\
\hline 5 & 33,3 & 58,8 & 48,3 & 50,0 & 86,9 & 84,0 \\
\hline 6 & 30,8 & 31,6 & 31.2 & 100,0 & 85,0 & 88,0 \\
\hline 7 & 63,1 & 78,6 & 69,7 & 100,0 & 66,7 & 76,5 \\
\hline 8 & 61,1 & 71,4 & 66,7 & 72,0 & 70,9 & 71,4 \\
\hline Total & 38,4 & 51,5 & 45,4 & 72,1 & 70,7 & 71,1 \\
\hline
\end{tabular}

\#para 51, idade entre 11 a e $5 \mathrm{~m}$ e $13 \mathrm{a}$ e $10 \mathrm{~m}$ e para 84 , idade entre $13 a$ e $10 \mathrm{~m}$ e $15 a$ e $10 \mathrm{~m}$, na data da medida.

Os jovens que estão cursando as oitavas séries têm, com maior frequência idade esperada, enquanto que nas quintas séries esta situação não está presente, sugerindo um maior número de retenções, principalmente entre os homens, em quase todas as escolas.

Isto pode ser uma evidência de que a atual população de escolares de Osasco segue o mesmo modelo populacional levantado há 10 anos pela Administração Municipal, onde já era notória a taxa elevada de evasão e reprovação escolares ${ }^{63}$.

Nas quintas séries $45,4 \%$ estão com idade adequada à série que frequentam, indicando que os outros $54,6 \%$ dos alunos já repetiram o ano escolar anteriormente e/ou entraram com idade acima da esperada na primeira série escolar. Nas oitavas séries, um percentual menor dos alunos apresentam essa situação. 
O afunilamento do nivel educacional nesta população pode ser verificado através do número de classes de cada série (anexo 6): enquanto a primeira série das oito escolas selecionadas, contava com 44 classes com 1501 alunos (34 alunos/classe), as quintas contavam com 1212 alunos em 31 classes (39 alunos/classe) e as oitavas com 521 alunos em 16 classes (32 alunos/classe), em todos os periodos. A última série, em todas as escolas conta, portanto, com um número de alunos que corresponde a pouco mais de um terço do que os ingressantes do primeiro grau, ou seja, dos alunos que entraram no primeiro ano escolar somente $34,7 \%$ chegaram à oitava série. Apenas uma escola apresentava mais de uma classe de oitava série, no período diurno: escola número 8, pertencente à AR-4, a mesma que mostrou o menor indice de deficiência estatural durante o censo de estatura de 1989 (tabela 1).

O nível de escolaridade dos pais pode ser observado nas figuras $2 a$ e $2 b$. O nível de escolaridade tanto dos pais como das mães é melhor entre os alunos das oitavas séries, onde a proporção dos que continuaram a freqüentar a escola depois do primeiro grau completo (antigo ginásio) foi maior. Entre os pais e mães dos alunos das quintas séries verificou-se maior proporção de analfabetos e dos que tinham instrução aquém da quarta série do primeiro grau. Comparando os pais com as māes, verifica-se menor escolaridade geral entre os primeiros.

É interessante notar que a estrutura da escolaridade dos pais dos alunos reflete a situação de evasão e repetência escolar de toda a população brasileira na última década, conforme documento do IBGE - "Crianças e Adolescentes - Indicadores Sociais, Volume 4, 1992"13. A grande evasão se dá logo após a quarta série (primário completo), e as mulheres estão, em maior proporção, entre os que terminaram a oitava série (figura 2). Da mesma forma, entre os alunos estudados, no último ano do primeiro grau as mulheres estão em maior proporção do que os homens (tabela 2). 
Figura 2a - Escolaridade Pai, segundo séries do $1^{\circ}$ grau - Osasco, 1990.

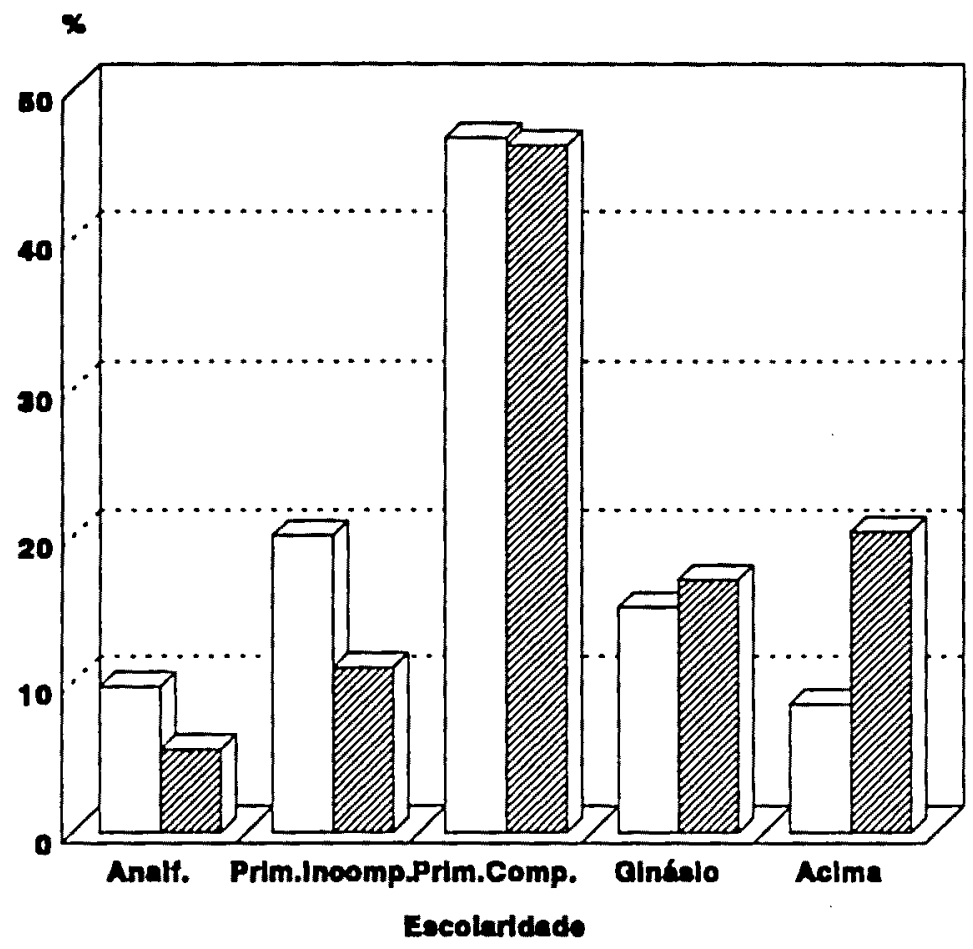

$\square$ Pals 5a.
Q Pals 8a.

Figura 2b - Escolaridade Mãe, segundo séries do $1^{\circ}$ grau - Osasco, 1990.

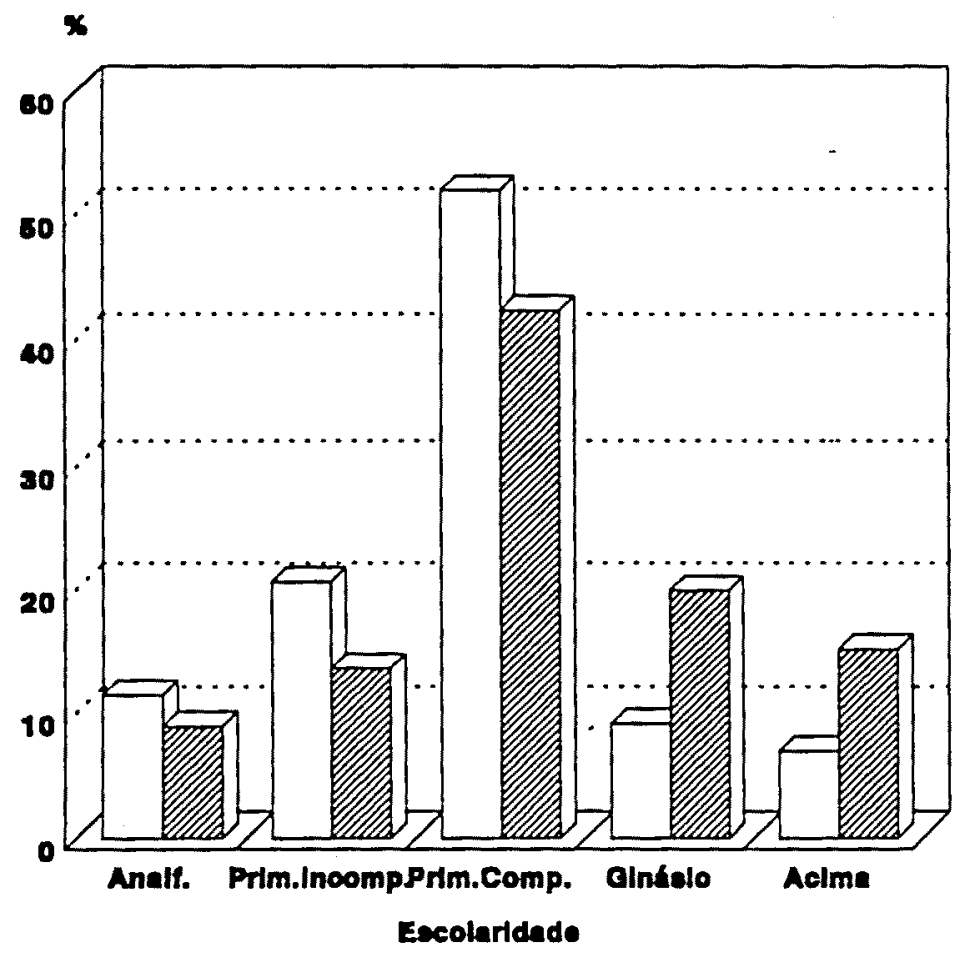

$\square$ Mães 5a. Yães 8a. 
Ao analisar os níveis máximo e mínimo da escolaridade paterna, segundo as escolas e ARs, pode-se observar que existe associação significante e inversa entre os alunos das escolas das regiões com maior déficit de crescimento (AR-1 e AR-2) e os das escolas das Regionais com menor déficit de crescimento (AR-3 e AR-4), como mostra a tabela 5 .

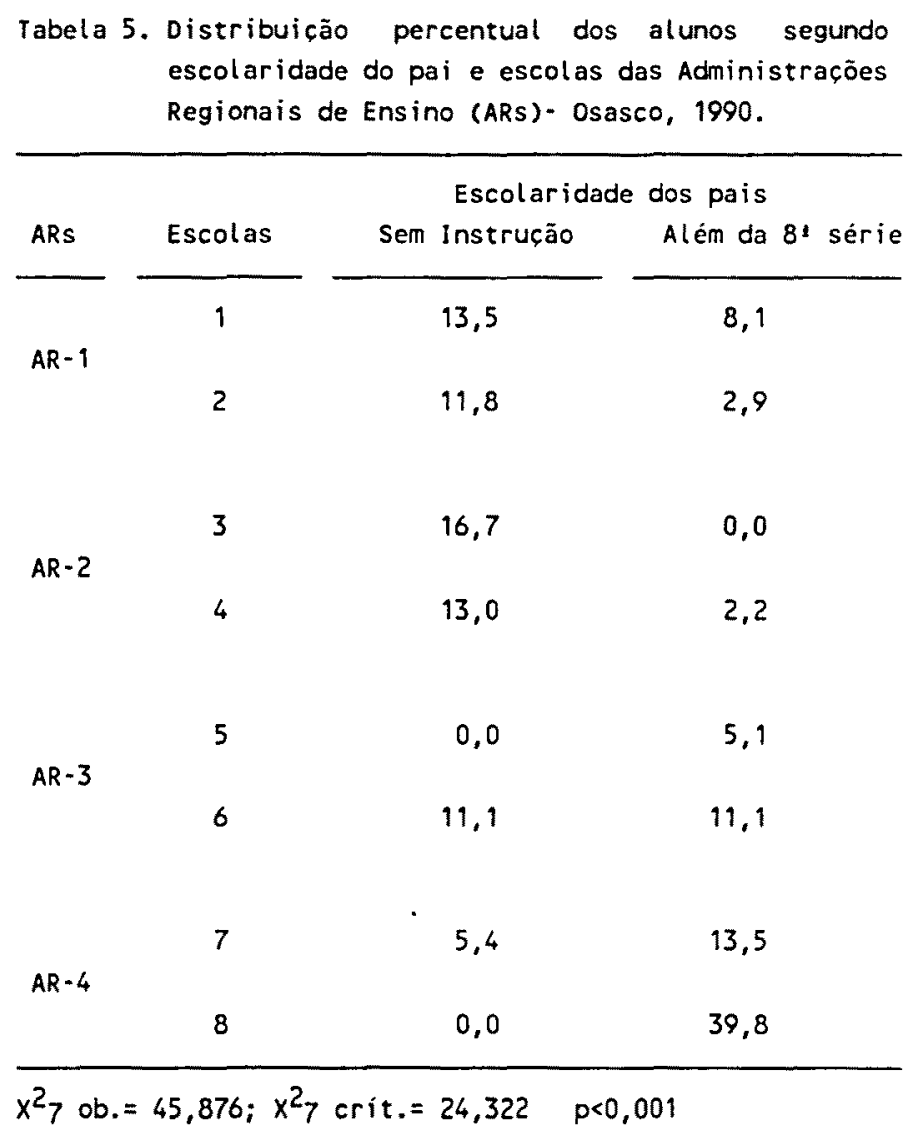

Como já descrito, a amostra abrangeu escolas das quatro Administraçōes Regionais de Ensino de Osasco que foram agrupadas segundo três regiōes consideradas homogêneas para classe social e para prevalência de déficit de crescimento de crianças ingressantes no primeiro grau, no ano de $1989^{53}$ (tabela 2). 
O estado nutricional dos adolescentes foi diagnosticado através de medidas de peso e altura.

O perfil de crescimento dos alunos, segundo os percentis de peso/idade (P/I), altura/idade $(\mathrm{A} / \mathrm{I})$ e peso/altura $(\mathrm{P} / \mathrm{A})$, pode ser observado nas figuras $3 \mathrm{a}$ e b, 4a e b e 5 a e b.

O perfil assim traçado representa a classificação de cada um dos jovens aqui estudados, conforme a sua localização na distribuição de percentis das medidas antropométricas da populaçāo de referência ${ }^{58}$.

Os indivíduos localizados abaixo do percentil $10\left(\mathrm{P}_{10}\right)$ podem ser classificados como moderadamente desnutridos, embora se espere que $10 \%$ de uma população normal esteja aí localizada. $\mathrm{O}$ mesmo mecanismo se dá para os abaixo do percentil $3\left(\mathrm{P}_{3}\right)$, que se classificam como severamente desnutridos, embora $3 \%$ de uma população normal seja o esperado.

É bastante controversa a escolha de um indicador para diagnóstico nutricional de adolescentes baseado em medidas antropométricas. 
Figura 3a - Perfil Antropométrico Peso/Idade por sexo, $5^{\text {a }}$ série (OMS)

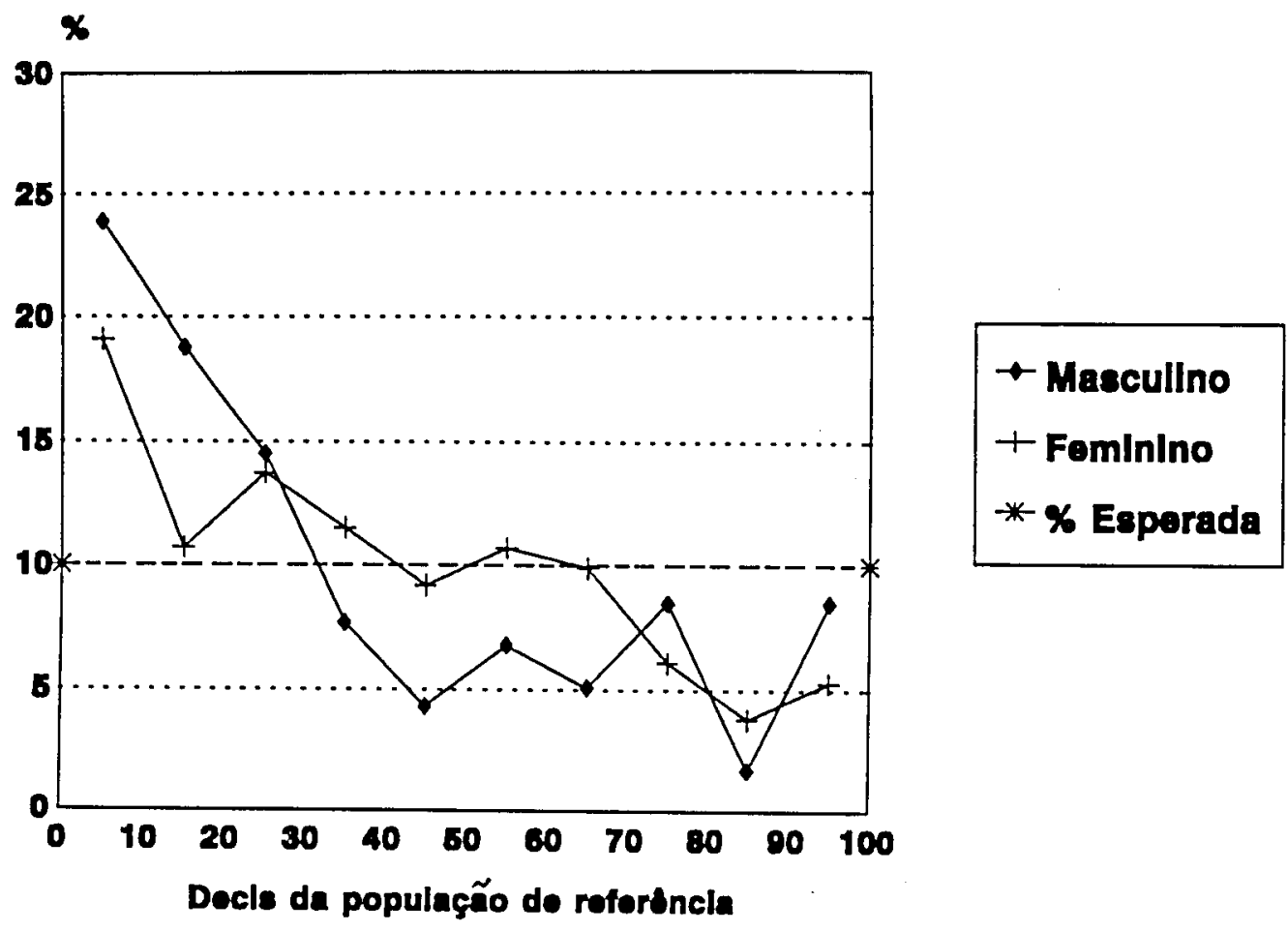

Figura $3 \mathrm{~b}$ - Perfil Antropométrico Peso/Idade por sexo, $8^{\mathrm{a}}$ série (OMS)

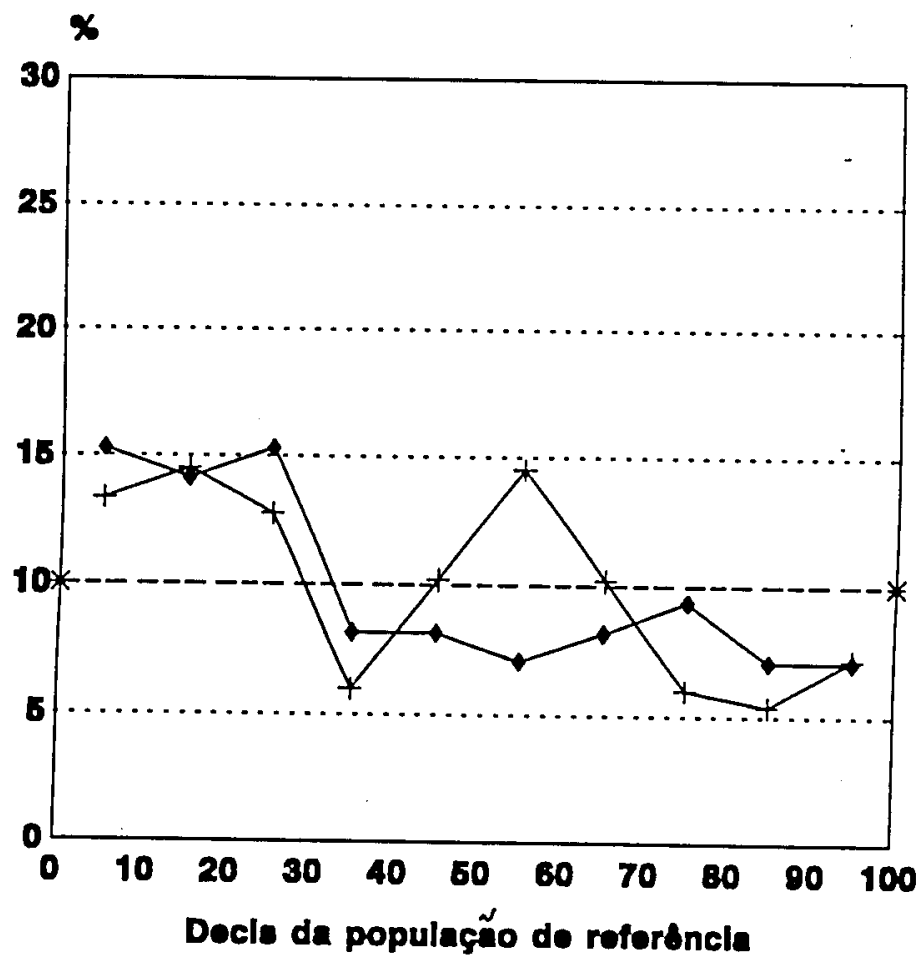

$\rightarrow$ Mascullno

+ Fominino

* X Esperada

Docle da populaçáo de roforencle 
Figura 4a - Perfil Antropométrico Altura/Idade por sexo, $5^{\mathrm{a}}$ série (OMS)

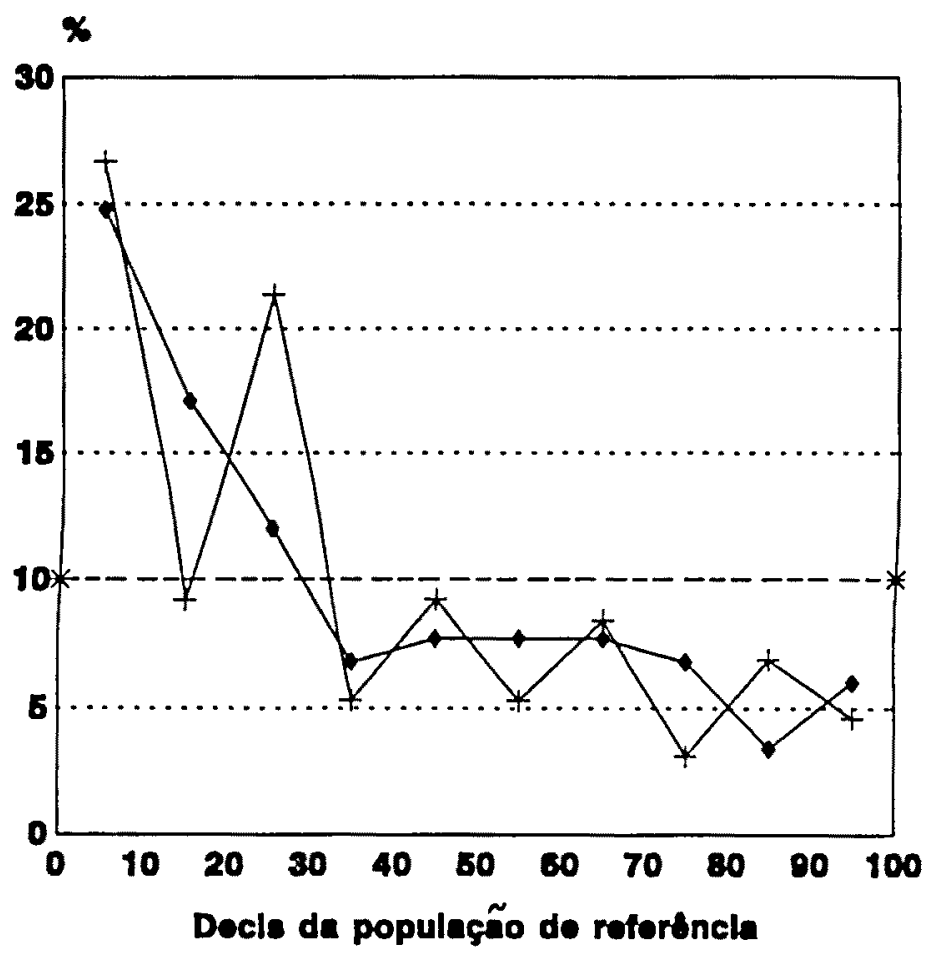

$$
\begin{aligned}
& + \text { Masculino } \\
& + \text { FomInIno } \\
& \text { * } \% \text { Esporada }
\end{aligned}
$$

Figura 4b - Perfil Antropométrico Altura/Idade por sexo, $8^{\mathrm{a}}$ série (OMS)

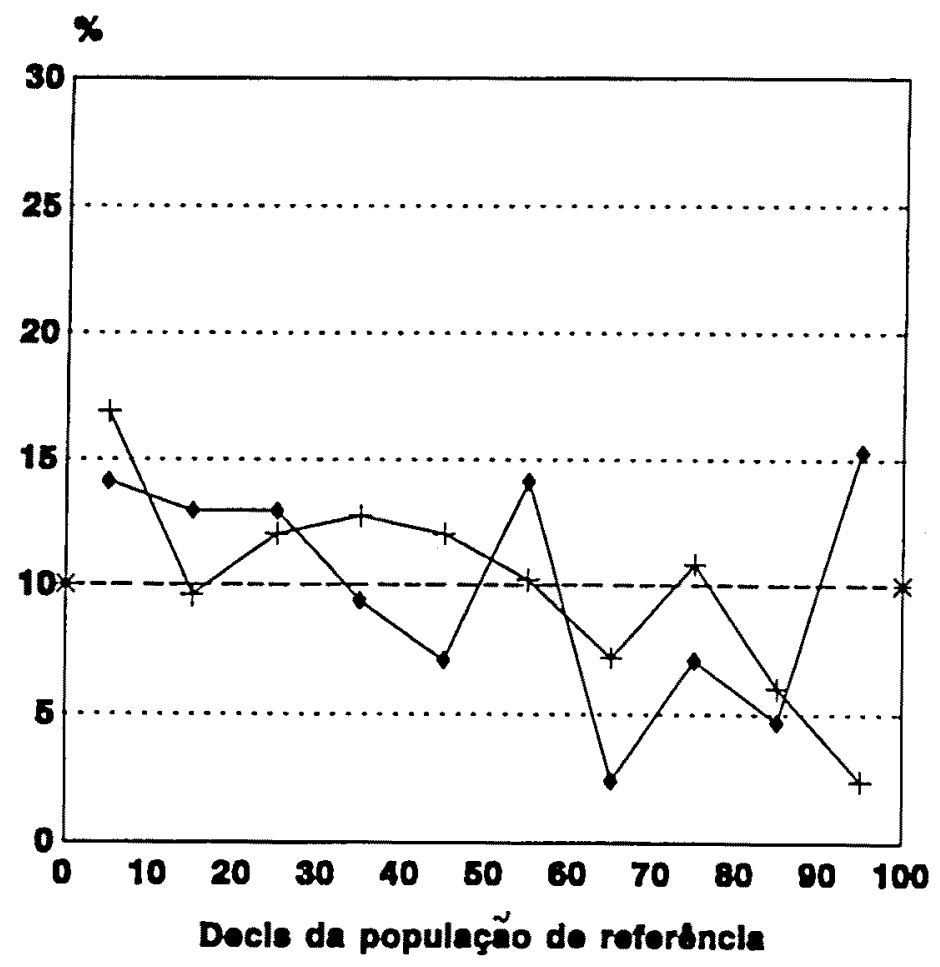

Masculino

+ Fominino

* X Esperada 
Figura 5a - Perfil Antropométrico Peso/Altura por sexo, $5^{\text {a }}$ série (FRISANCHO)

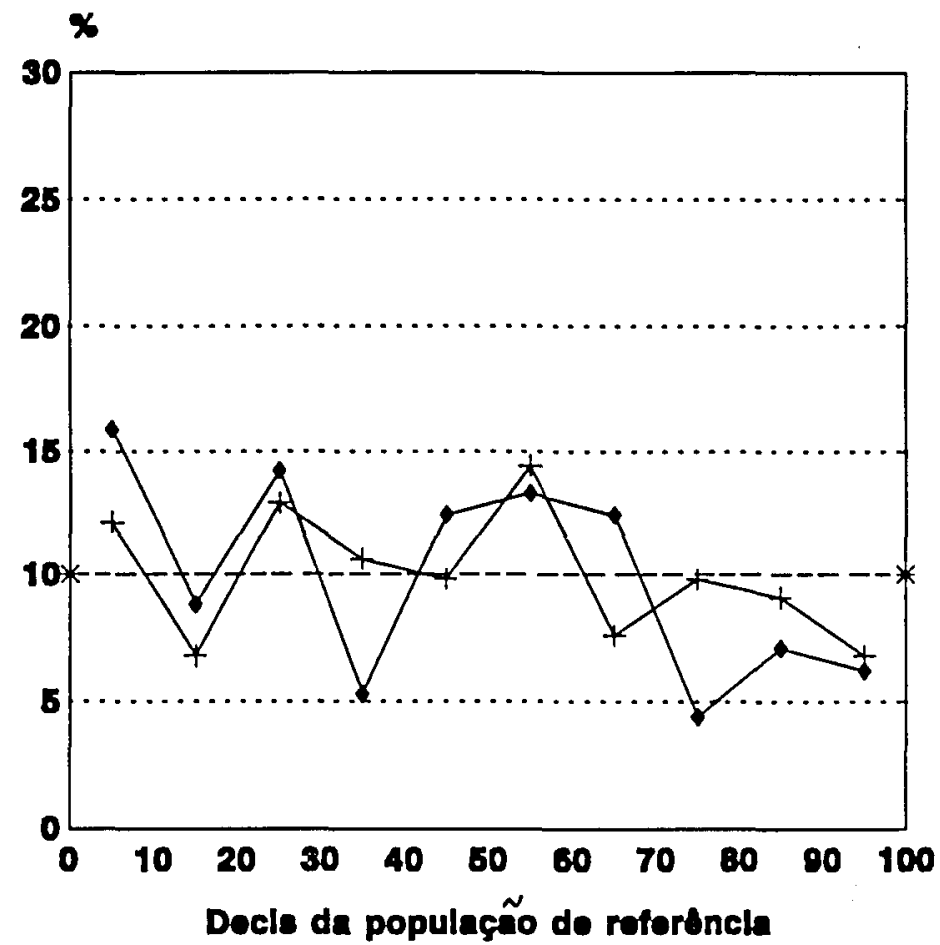

$\rightarrow$ Mascullno

+ Feminlno

* \% Esperada

Figura 5b - Perfil Antropométrico Peso/Altura por sexo, $8^{a}$ série (FRISANCHO)

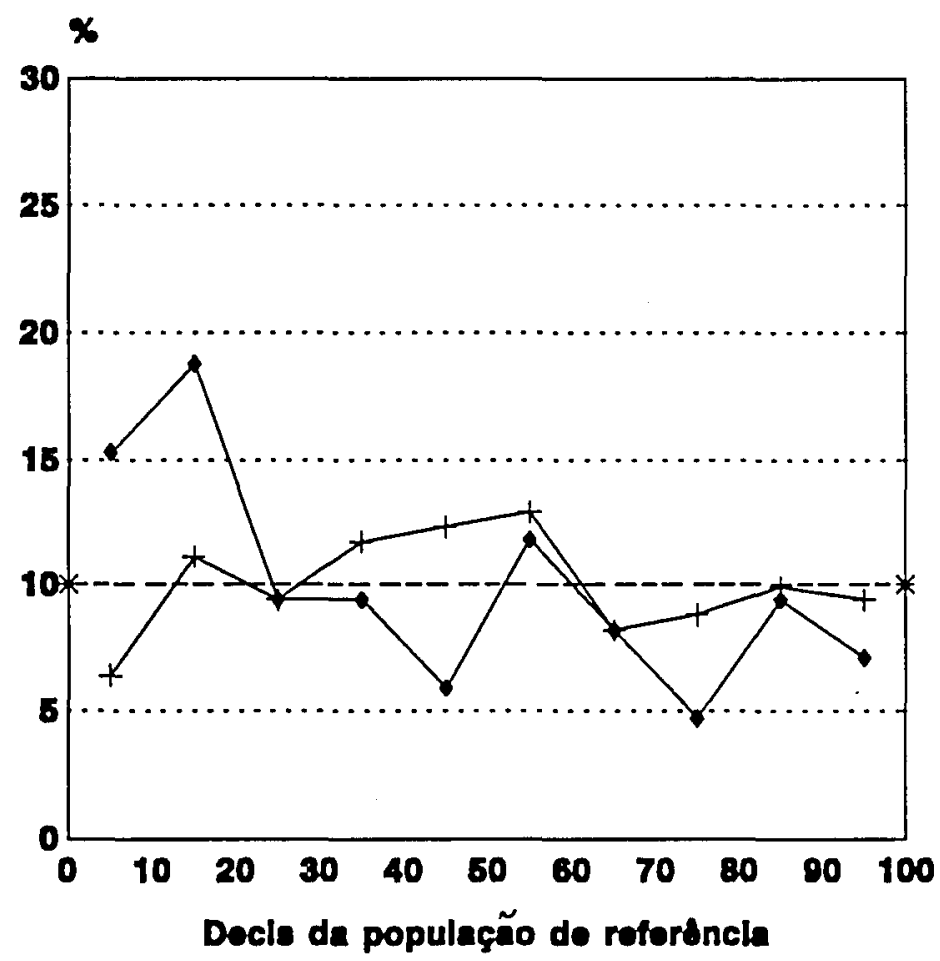

Mascullno

+ Fominino

* X Esperada 
Os três indicadores antropométricos (P/I, A/I e P/A) têm significados diferentes. O indicador $\mathrm{P} / \mathrm{I}$ mede a massa corporal total, detectando a perda de tecidos e o atraso de crescimento linear que levam à condição de baixo peso, e indica a magnitude do problema nutricional na população47. Esse indicador identifica, porém, os casos crônicos e agudos de desnutrição ao mesmo tempo.

WATERLOW 97.98 mostra a diferença entre os dois tipos de desnutrição ao comparar dois indivíduos com a mesma deficiência ponderal: enquanto um tem altura adequada para sua idade, o outro tem altura deficiente para sua idade, porém seu peso, embora baixo, é adequado a essa altura. O primeiro vinha crescendo bem, como mostra sua altura, quando sofreu um episódio agudo de desnutrição; o segundo não teve crescimento adequado devido a carências nutricionais de longa duração, resultando em um processo crônico de desnutrição.

Segundo o indicador que definiu seu estado nutricional, o indivíduo apresenta riscos de morbidade e mortalidade diferentes. Aqueles com P/A inadequado são mais suscetíveis às infecções severas e morte do que aqueles que apresentam baixa $A / I^{47}$. Portanto, enquanto $\mathrm{P} / \mathrm{I}$ refere-se a uma situação de desnutrição global, A/I reflete desnutrição pregressa de longa duração e P/A desnutrição aguda, de curta duração.

O estirão pubertário, sofrendo influências diversas, pode mascarar o verdadeiro estado nutricional; não é possível precisar, através da idade, em que fase do estirão o indivíduo se encontra.

A tabela 6 mostra a porcentagem de escolares localizados abaixo do $\mathrm{P}_{10}$ e do $\mathrm{P}_{3}$ para os três indicadores antropométricos, segundo sexo e série escolar. 
Tabela 6. Porcentagem de estudantes abaixo do P10 e P3 para os três indicadores antropométricos, segundo série e sexo. Osasco - 1990.

\begin{tabular}{|c|c|c|c|c|c|c|c|c|}
\hline \multirow[b]{2}{*}{ Série } & \multirow[b]{2}{*}{ Sexo } & \multirow[b]{2}{*}{$N^{*}$} & \multicolumn{3}{|c|}{$\left\langle P_{10}(\%)\right.$} & \multicolumn{3}{|c|}{$<P_{3}(\%)$} \\
\hline & & & $P / 1$ & $A / I$ & $P / A$ & $P / I$ & $A / I$ & $P / A$ \\
\hline & $M$ & 117 & 23,9 & 24,8 & 15,4 & 8,5 & 9,4 & 0,0 \\
\hline \multicolumn{9}{|l|}{$5^{2}$} \\
\hline & $F$ & 132 & 18,9 & 26,5 & 12,1 & 3,0 & 12,9 & 0,0 \\
\hline & $M$ & 86 & 15,1 & 19,9 & 15,1 & 5,8 & 5,8 & 0,0 \\
\hline \multicolumn{9}{|l|}{$8:$} \\
\hline & $F$ & 174 & 12,6 & 16,1 & 6,3 & 2,8 & 4,0 & 0,0 \\
\hline Total & & 509 & 17,3 & 20,4 & 11,4 & 4,7 & 7,8 & 0,0 \\
\hline
\end{tabular}

*Tamanho da amostra.

Ao analisar os perfis de crescimento da população, segundo os indicadores P/I e A/I, utilizando o padrão OMS como referência ${ }^{58}$ (figuras 3,4 e tabela 6), observa-se que a população apresenta déficit de altura maior do que de peso. Os homens têm maior proporção de deficiência de peso do que as mulheres; $8,5 \%$ e $5,8 \%$ deles nas quintas e oitavas séries, respectivamente são desnutridos severos. Para a altura, nas quintas séries a relação é inversa; os homens têm altura maior do que as mulheres. Há uma proporção de quase $13 \%$ de moças que apresentam desnutrição pregressa severa. Entre os homens também há desnutridos severos, embora em menor proporçāo. No geral os estudantes das oitavas séries se encontram com medidas antropométricas mais próximas do normal do que os das quintas séries.

A verificação da proporcionalidade do peso com relação à altura (P/A) é uma maneira de evitar os vieses de interpretação conseqüentes ao periodo de crescimento intenso que se dá durante o estirão pubertário, uma vez que nesta proporcionalidade, a idade não é levada em consideração. Quando a proporcionalidade está presente pode-se afirmar que o individuo não está passando por processo agudo de desnutrição, não podendo ser descartada, no entanto, a presença da desnutrição pregressa. 
É necessário enfatizar a importância de se acompanhar muito atentamente o desenvolvimento dos adolescentes. Aqueles que não apresentam P/I ou A/I adequados são merecedores de intervenções nutricionais, ou de outro teor que lhes permitam equilibrar estas medidas antes de terminado o estirão, a partir de quando a eficiência de tais intervenções são, certamente, menores.

O padrão usado como referência para o indicador peso/altura é o proposto por FRISANCHO 22, que estabeleceu as relações ideais dessas medidas para homens e mulheres de 0 a 74 anos. O padrão de referência recomendado pela $\mathrm{OMS}^{58}$ apresenta estas relações apenas para crianças até os dez anos de idade.

Utilizando o padrão de FRISANCHO 22 , verifica-se que o perfil de crescimento chega mais próximo do esperado entre as adolescentes, independentemente da idade (figura 5 e tabela 6). Os homens não apresentam uma relação tão equilibrada, havendo um pequeno déficit de peso para sua altura, principalmente entre aqueles das oitavas séries, que apresentam uma concentração maior do que a esperada de indivíduos nos dois primeiros decis. Nenhum dos elementos da amostra apresentou desnutrição aguda severa $\left(\mathrm{P} / \mathrm{A}<\mathrm{P}_{3}\right)$.

Pode-se dizer, portanto, que os jovens estudados se apresentam com altura menor do que a esperada para sua idade, mas que, em sua maioria, têm peso adequado para sua altura (tabela 6).

Este dado não é surpreendente. Os jovens desta amostra seguem de maneira bastante próxima, a mediana de altura dos adolescentes brasileiros da regiāo sudeste (figura 6). Estas medidas foram levantadas durante a "Pesquisa Nacional de Saúde e Nutrição" $(\mathrm{PNSN})^{40}$, realizada em 1989 pelo Instituto Nacional de Alimentação e Nutrição do 
Ministério da Saúde (INAN), em convênio com a Fundação Instituto Brasileiro de Geografia e Estatística (FIBGE) e o Instituto de Planejamento Econômico e Social do Ministério do Planejamento (IPEA). Esses dados mostram que os jovens brasileiros apresentam uma desvantagem de altura, quando comparados ao padrão de referência ${ }^{58}$ atingindo, essa desvantagem, seu valor máximo de 7 centímetros, para as mulheres aos 13 anos e de 9 centímetros, aos 14 anos, para os homens. Essa diferença se mantém nas mulheres na idade adulta. As mulheres brasileiras têm altura correspondente à das americanas de 12 a 13 anos. Para os homens a diferença final é de 7 centímetros quando adultos, correspondendo aos jovens americanos de 15 anos. $\mathrm{Na}$ área urbana da região sudeste essas diferenças são menores, ficando ao redor de 5 centímetros para as mulheres e 6 para os homens, nas mesmas idades.

Os dados antropométricos obtidos permitem pressupor que estes adolescentes, ao chegarem à idade adulta, terão altura muito parecida à dos atuais adultos brasileiros da mesma região.

O censo de altura realizado em 1989 pelo Departamento de Nutrição da Faculdade de Saúde Pública entre os escolares de Osasco ${ }^{53}$, usou o indicador A/1 expresso em escore $\mathrm{Z}$ para definir o déficit desse parâmetro. Foi definido o déficit quando a altura da criança situava-se abaixo de dois desvios padrão do valor mediano esperado para sua idade e sexo (-2 escore $Z)$.

O mesmo procedimento foi aqui adotado (tabela 7). Entre os jovens das quintas séries $8,5 \%$ estão abaixo do limite de -2 escore $Z$, enquanto que para os das oitavas séries $4 \%$ estão abaixo deste limite, mostrando uma melhor situação dos alunos de oitava série, como já era esperado. 
Figura 6 - Curvas de Crescimento de Adolescentes, Região Sudeste Urbana e Osasco (1990).

Altura em cm.

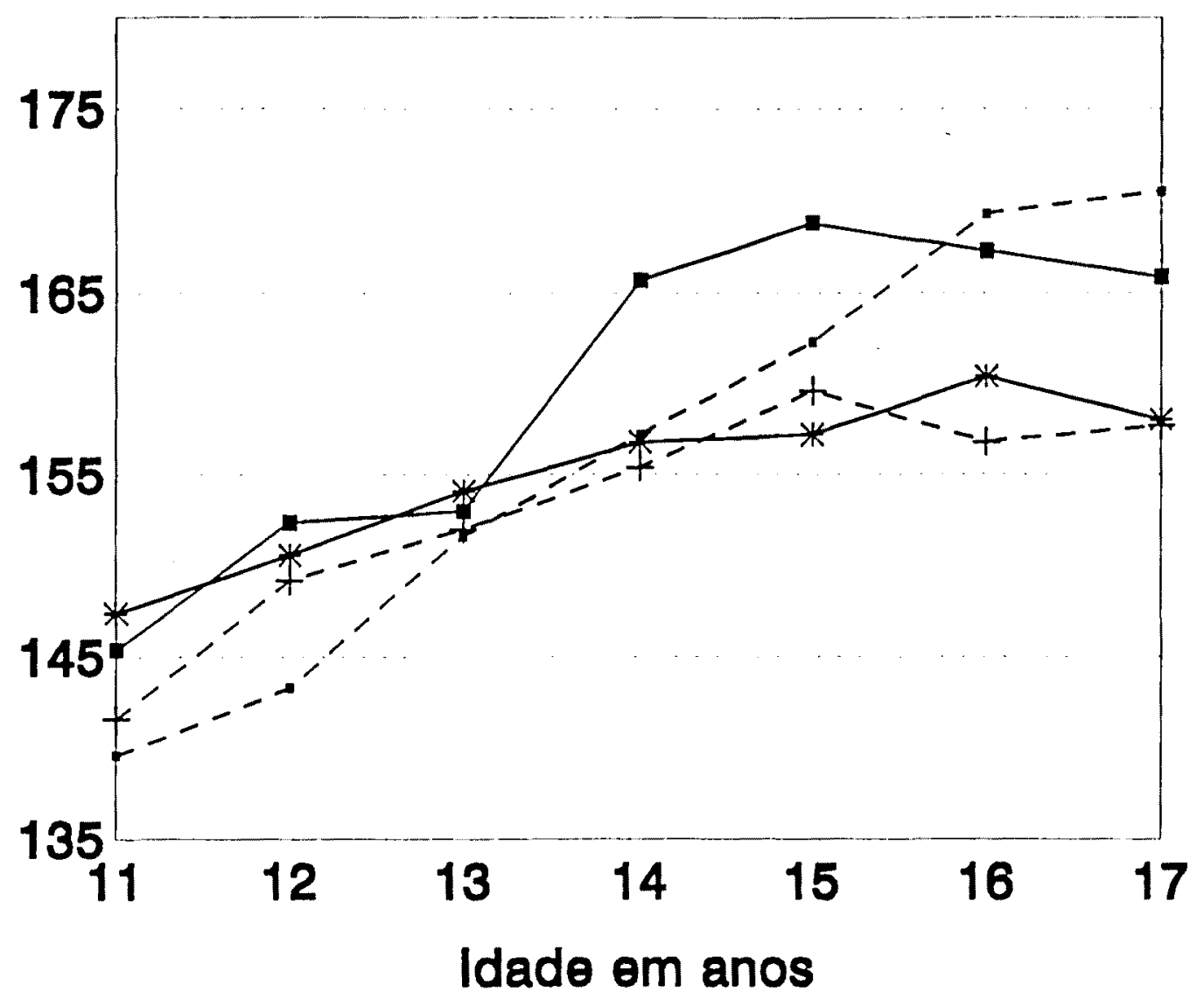

--PNSN Masc.

- Osasco Masc.

+ PNSN Fem.

* Osasco Fem. 
Tabela 7. Distribuicão dos jovens de $5^{\prime}$ e 8 ' séries, segundo escore $Z$ de altura/idade. Osasco- 1990.

\begin{tabular}{|c|c|c|c|c|c|c|}
\hline \multirow{2}{*}{$\begin{array}{c}\text { Escore } \\
2\end{array}$} & \multicolumn{2}{|c|}{51 sèrie } & \multicolumn{2}{|c|}{81 série } & \multicolumn{2}{|c|}{ Total } \\
\hline & $n^{\star}$ & $\%$ & $n * \star$ & $\%$ & $n$ & $\%$ \\
\hline$<-2$ & 21 & 8,5 & 10 & 4,0 & 31 & 6,2 \\
\hline$-2 \mid--1$ & 59 & 23,8 & 46 & 18,3 & 105 & 21,0 \\
\hline$-1 \mid-0$ & 94 & 37,9 & 101 & 40,3 & 195 & 39,1 \\
\hline$>=0$ & 74 & 29,8 & 94 & 37,5 & 168 & 33,7 \\
\hline Total & 248 & 100,0 & 251 & 100,0 & 499 & 100.0 \\
\hline
\end{tabular}

* un indivíduo sem informação.

** nove indivíduos sem informação.

Ao comparar a ocorrência do déficit estatural dos adolescentes deste estudo com o das crianças ingressantes na primeira série do primeiro grau em $1989^{53}$, segundo as escolas e as ARs (tabela 8), é possível verificar que tanto as regiōes como as escolas de maior déficit (as de número impar), mantém o mesmo posto na ordem da maior para a menor prevalência do déficit.

Tabela 8. Distribuição percentual do déficit estatural de crianças ingressantes no primeiro grau e dos adolescentes, segundo escolas e Administraçōes Regionais de Ensino (ARs). Osasco - 1990.

\begin{tabular}{|c|c|c|c|c|c|c|c|}
\hline \multirow{3}{*}{ ARs } & \multirow{3}{*}{$\begin{array}{l}\text { Déficit } \\
\text { criancas } \\
\text { 1989* }\end{array}$} & \multirow{2}{*}{\multicolumn{2}{|c|}{$\begin{array}{l}\text { AR } \\
\text { adolescentes }\end{array}$}} & \multirow{3}{*}{$\begin{array}{l}\text { Es } \\
\text { co } \\
\text { las }\end{array}$} & \multicolumn{3}{|c|}{ Déficit na escola } \\
\hline & & & & & \multirow{2}{*}{$\begin{array}{c}\text { crianças } \\
\text { 1989* }\end{array}$} & \multicolumn{2}{|c|}{ adolescentes } \\
\hline & & 51 & 81 & & & 51 & $8:$ \\
\hline & & & & 3 & 16,1 & 20,6 & 10,5 \\
\hline \multirow[t]{3}{*}{$A R-2$} & 6,8 & 12,7 & 7,9 & & & & \\
\hline & & & & 4 & 4,4 & 5,9 & 5,3 \\
\hline & & & & 1 & 8,6 & 7,4 & 8,8 \\
\hline \multirow[t]{3}{*}{$A R=1$} & 6,4 & 13,2 & 6,0 & & & & \\
\hline & & & & 2 & 3,2 & 19.2 & 0,0 \\
\hline & & & & 5 & 7,0 & 3,4 & 4,0 \\
\hline \multirow[t]{3}{*}{$A R-3$} & 4,5 & 9,8 & 4,0 & & & & \\
\hline & & & & 6 & 4,9 & 15,6 & 4,0 \\
\hline & & & & 7 & 5,3 & 0,0 & 0,0 \\
\hline \multirow[t]{2}{*}{ AR -4} & 2,3 & 0,0 & 1,6 & & & & \\
\hline & & & & 8 & 0,8 & 0,0 & 1,9 \\
\hline
\end{tabular}

*Fonte: MONTEIRO e colaboradores 55 
A situação nutricional dos alunos das escolas da rede estadual de ensino do município de Osasco vem se mantendo praticamente a mesma, pelo menos nos últimos anos, uma vez que os atuais alunos das quintas séries, e principalmente os das oitavas reproduzem uma situação bastante semelhante àquela dos alunos ingressantes. As quinta séries, que contam entre seus alunos com uma quantidade expressiva de repetentes ou alunos atrasados, acaba represando os de pior situação nutricional.

A concentração média de hemoglobina $(\mathrm{Hb})$ encontrada entre os adolescentes está apresentada na tabela 9. Há diferença significante entre as médias de concentração de Hb para homens e mulheres. Ao se distribuir as mulheres segundo a menarca, não há diferença significante entre as médias encontradas.

\begin{tabular}{|c|c|c|c|}
\hline Sexo & $n$ & $\mathrm{Hb}$ & $D P$ \\
\hline Mascul ino & 192 & 14,59 & 1,32 \\
\hline Feminino* & 294 & 14,01 & 1,29 \\
\hline \multicolumn{4}{|l|}{ Feminino } \\
\hline pré menarca & 61 & 14,04 & 1,14 \\
\hline \multicolumn{4}{|l|}{ Feminino } \\
\hline pós menarca & 203 & 14,07 & 1,33 \\
\hline \multicolumn{4}{|l|}{ Feminino } \\
\hline sem informação & 30 & 13,57 & 1,26 \\
\hline Total & 486 & 14,24 & 1,33 \\
\hline
\end{tabular}

As médias de concentração. de $\mathrm{Hb}$ encontradas são adequadas para uma população normal. 
BAILEY e colaboradores ${ }^{3}$ encontraram a concentração média de 15,1 e 14,0g/dl de $\mathrm{Hb}$ para homens e mulheres, respectivamente, entre uma população de adolescentes de baixo nível sócio econômico de Miami (USA). Para uma população de escolares de Guadalupe (Antilhas Francesas), GUILLOUD-BATAILLE e colaboradores ${ }^{26}$ relatam uma média de 12,5g/dl de Hb. Em Java, a média de concentração de Hb para as mulheres era de $12,7 \mathrm{~g} / \mathrm{dl}$, segundo HUSAINI e colaboradores ${ }^{38}$, enquanto VITERI e colaboradores $^{94}$ encontraram média de 13,9 e $13,6 \mathrm{~g} / \mathrm{dl}$ de $\mathrm{Hb}$ entre homens e mulheres de 13 a 16 anos de uma população sadia da América Central.

Alguns dos trabalhos que analisaram a concentração média de $\mathrm{Hb}$ entre a população brasileira mostraram valores similares: ROYSTON ${ }^{71}$, em levantamento de prevalência de anemia entre mulheres de países em desenvolvimento, através de dados de 1958 a 1979 da OMS relata uma média de 13,0 a $13,5 \mathrm{~g} \mathrm{Hb} / \mathrm{dl}$ para as mulheres brasileiras não gestantes; TRUGO e colaboradores ${ }^{87}$, estudando mulheres de 20 a 26 anos de favelas cariocas, encontraram média de $\mathrm{Hb}$ de $13,4 \mathrm{~g} / \mathrm{dl}$, sendo que entre essas mulheres havia uma porcentagem de $16,9 \%$ de anêmicas; e SANCHES e colaboradores ${ }^{74}$ encontraram a média de concentração de $\mathrm{Hb}$ de $12,28 \mathrm{~g} / \mathrm{dl}$ em uma população de 6 a 14 anos de Cáceres/MT.

A prevalência de anemia, diagnosticada através da concentração de $\mathrm{Hb}$, usando o padrão de referência da OMS foi de $5,3 \%$, sendo $6,2 \%$ nas $5^{\mathrm{a}}$ e $4,5 \%$ nas $8^{\mathrm{a}}$ séries.

É uma prevalência bastante baixa, próxima à estimativa de anemia nos países desenvolvidos: HALLBERG e colaboradores ${ }^{33}$, estudando a prevalência de anemia em mulheres de países Europeus, mostram que $8,6 \%$ a $6,6 \%$ das mulheres dos países Nórdicos e Reino Unido são anêmicas, enquanto na Europa Central 2,4\% a 1,3\% das mulheres apresentam carência do mineral; DeMAEYER e colaboradores ${ }^{19}$ relatam uma 
prevalência de anemia de $3 \%$ entre os homens e $11 \%$ entre as mulheres nos paises desenvolvidos.

Esta prevalência, no entanto, diferencia-se em muito da encontrada em outros estudos realizados no Brasil ${ }^{90}$ : entre escolares de 6 a 14 anos de Cáceres/Mato Grosso ${ }^{74}$ a prevalência foi de $36,12 \%$; em Sorocaba/São Paulo ${ }^{88} 23,7 \%$ dos escolares da mesma faixa etária eram anêmicos; no Vale do Jequitinhonha/Minas Gerais ${ }^{1} 20 \%$ dos escolares urbanos foram diagnosticados como anêmicos; em Viçosa/Minas Gerais ${ }^{72}$ foi encontrada a prevalência de $7,3 \%$ de anêmicos entre escolares de 7 a 14 anos e em São Carlos/São Paulo ${ }^{61}$ a prevalência entre escolares de até 12 anos foi de $9,6 \%$. Em estudo realizado entre escolares ingressantes, em 1991, no primeiro grau das escolas públicas do mesmo município de Osasco ${ }^{82}$, aqui estudado, foi encontrada a prevalência de $49,9 \%$ de anêmicos entre os alunos menores de 8 anos e $60,1 \%$ de anêmicos entre aqueles com 8 a 10 anos. A distribuição geográfica desses anêmicos revelou que a maior prevalência se encontrava nas ARs com déficit estatural igual ou maior de $6 \%$.

É interessante discutir o significado dos padrões-de referência usados para a identificação dos anêmicos em uma dada população.

O padrão proposto pela $\mathrm{OMS}^{19}$ apresenta a vantagem indiscutivel do reconhecimento internacional, permitindo a comparabilidade de estudos originários de diferentes nações. No entanto propõe valores fixos de concentração de hemoglobina para a definição do limite crítico, abaixo dos quais os indivíduos são considerados anêmicos, não sendo sensível às modificações que acompanham o seu desenvolvimento fisiológico. Para mulheres, o mesmo valor - $12,0 \mathrm{~g} \mathrm{Hb} / \mathrm{dl}$ - é usado a partir dos 6 anos de idade. Com relação aos homens, há uma variação brusca de 1 grama de hemoglobina aos 15 anos. A sensibilidade e especificidade obtidos com a utilização 
desses valores é muito variável havendo, portanto, uma menor capacidade de predição de risco de deficiência marcial para a população.

Uma alternativa viável para minimizar a grande variação da sensibilidade/especificidade encontrada quando se usa o padrão OMS é a utilização de curvas de referência como as elaboradas por DALLMAN e SIIMES em 197914 e utilizadas pelo International Nutritional Anemia Consultative Group (INACG) ${ }^{15}$. Baseados em um levantamento da concentração de hemoglobina de uma população sadia, estes Autores traçaram curvas de referência e propuseram o uso do $\mathrm{P}_{3}$ como o limite mínimo aceitável para esse parâmetro.

As figuras $7 \mathrm{a}$ e $\mathrm{b}$ apresentam a distribuição da concentração de $\mathrm{Hb}$ na população estudada, segundo os padrōes da OMS e DALLMAN e SIIMES (D \& S).

Os valores encontrados para concentração de $\mathrm{Hb}$ concentram-se, em sua maior parte, ao redor do $\mathrm{P}_{50}$, coincidindo com os níveis da população de referência.

Um número maior de jovens do sexo masculino são classificados como anêmicos ao se utilizar as curvas de $D \& S$, uma vez que a coincidência entre os dois padrões de classificação se dá aos 11 e 15 anos. Para a população do sexo feminino observa-se a coincidência dos resultados com qualquer dos dois padrōes (tabela 10). 


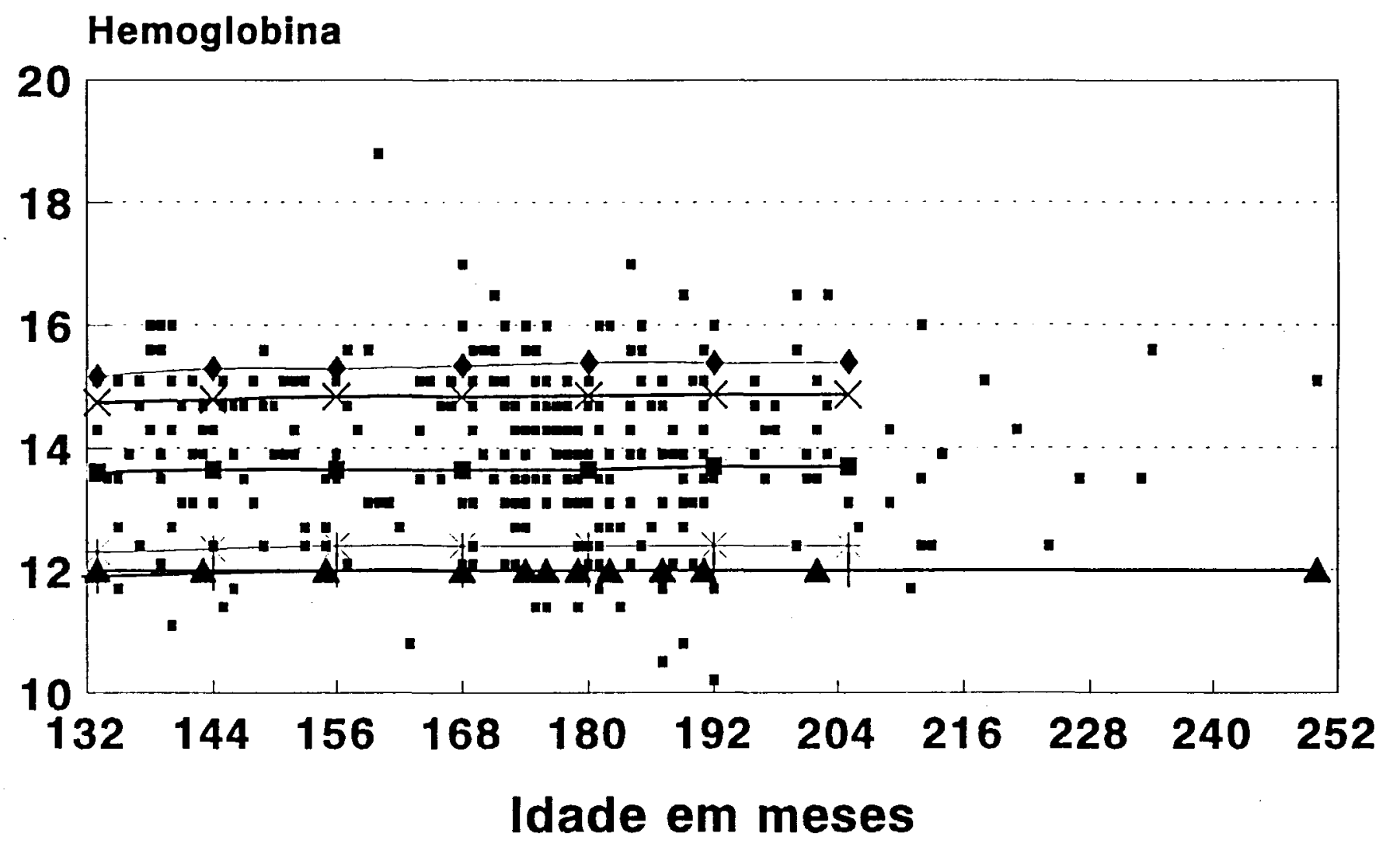

\footnotetext{
- Plots +Percentil 3 * Percentil $10 \rightarrow$ Percentil 50 * Percentil $90 \star$ Percentil $97 \star$ OMS
} 
7a - Comparação da Concentração de Hemoglobina dos Adolescentes do Sexo Mascullno com as Curvas de Percentis de D\&S e Critérlo da OMS

Osasco - 1990.

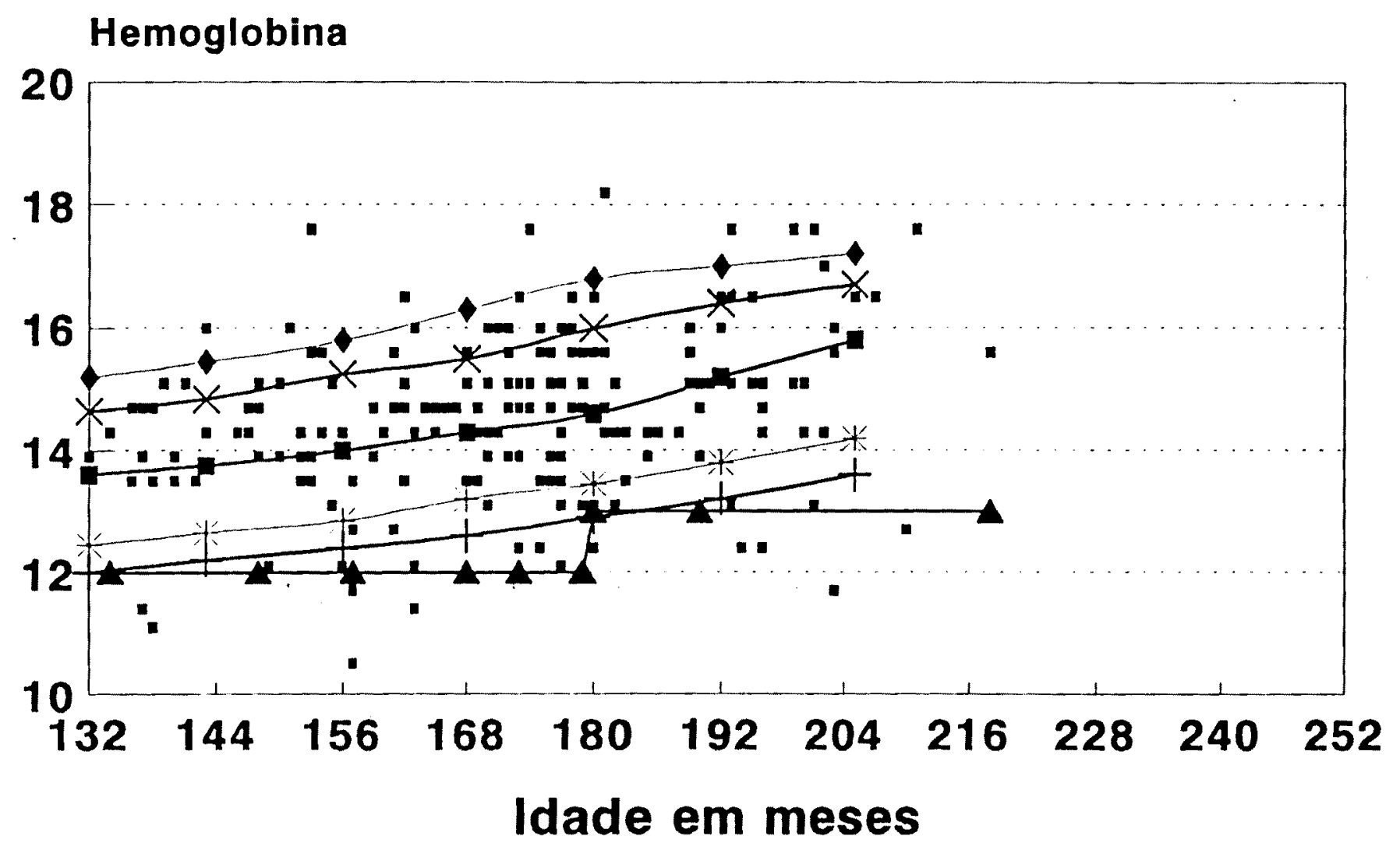

- Plots +Percentil 3 * Percentil $10 \rightarrow$ Percentil 50

* Percentil $90 \leftarrow$ Percentil $97 \star$ OMS 
Tabela 10. Prevalência de anemia segundo os padrões da OMS e de $D \& S$ entre os adolescentes. Osasco - 1990 .

\begin{tabular}{|c|c|c|c|}
\hline Sexo & $\begin{array}{c}\text { Tamanho } \\
\text { da } \\
\text { Amostra }\end{array}$ & $\begin{array}{l}\text { ons } \\
x\end{array}$ & $\begin{array}{c}D \& S \\
\%\end{array}$ \\
\hline mascul ino & 192 & 5,2 & 8,3 \\
\hline feminino & 294 & 5,4 & 5,4 \\
\hline Total & 486 & 5,3 & 6,6 \\
\hline
\end{tabular}

23 individuos não tiveram material colhido. $x^{2} 1$ obs $=0,772 ; x^{2} 1$ crit. $=3,84$ p<0,005.

Não foi encontrada diferença significativa de prevalência de anemia segundo os dois padrões.

Como já mencionado, a anemia é o estágio mais severo da deficiência de ferro, quando todas as reservas já estão esgotadas, tanto assim que DALLMAN e SIIMES ${ }^{14}$, ao analisar os níveis propostos como limites críticos para o diagnóstico da carência, afirmam que:" Em populações nas quais a deficiência de ferro é comum, os valores para hemoglobina e do volume corpuscular médio (VCM) abaixo do décimo percentil devem ser considerados como o limite para se levantar suspeitas sobre a ocorrência da deficiência de ferro". Nesse sentido $14,1 \%$ dos estudantes e $13 \%$ das meninas correm o risco de deficiência de ferro (figura 7).

VITERI e colaboradores $^{94}$ discutem amplamente 0 risco de deficiência de ferro. Observam estes Autores que o limite de um desvio padrão abaixo da média de concentração de $\mathrm{Hb}$ de um grupo de referência, altamente selecionado como normal para os fatores eritropoiéticos, indica um risco de $20 \%$ de estarem abaixo do adequado. O limite de um e meio desvios padrão abaixo da média indicaria risco de $75 \%$. 
Utilizando esses valores para a população aqui estudada, obteve-se os percentuais apresentados na tabela 11 .

\begin{tabular}{|c|c|c|c|c|}
\hline Idade & $x-10 p$ & (risco 20\%) & $x-1 \quad 1 / 2 D P$ & (risco $75 \%$ ) \\
\hline (anos) & $M$ & $\mathbf{F}$ & $M$ & $F$ \\
\hline $9-\mid 12$ & 6,8 & 7,0 & 4,5 & 5,6 \\
\hline $13-\mid 16$ & 9.8 & 18,0 & 4.9 & 13,6 \\
\hline $17-\mid 20$ & 20,0 & 38,9 & 20,0 & 27,8 \\
\hline
\end{tabular}

Segundo esses critérios, o risco de deficiência de ferro entre as adolescentes é muito maior do que entre os rapazes. A população da faixa etária acima dos 13 anos é a mais crítica para as mulheres, onde o risco de valores abaixo de um desvio padrão é quase o dobro do dos homens.

A prevalência de anemia e o risco de deficiência de ferro, assim obtidos, embora ainda baixos, estāo mais próximos aos valores referidos na literatura, onde a maior porcentagem de anêmicos é encontrada entre os indivíduos do sexo feminino.

A figura 7 permite ainda observar que a maior parte dos anêmicos tem idade inferior a 15 anos, idade esta onde o padrão da OMS apresenta alteração significativa de níveis críticos para os homens.

Mesmo ao se levar em conta as 264 informações sobre a ocorrência ou não da menarca ( $90 \%$ das mulheres), não se verificou qualquer influência desta nos percentuais de prevalência da anemia. 
Procurou-se relacionar o estado nutricional dos adolescentes com a ocorrência de anemia (tabela 12).

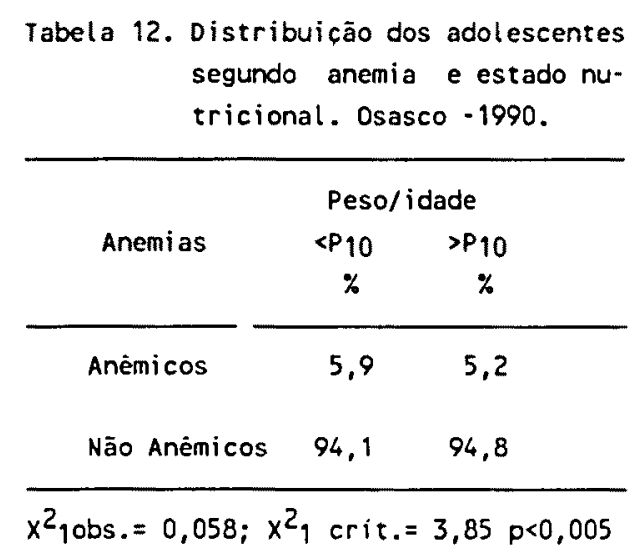

A proporção de anêmicos é semelhante entre os jovens, quer estejam acima ou abaixo do $\mathrm{P}_{10}$ para $\mathrm{P} / \mathrm{I}$, sugerindo não haver relação entre o estado nutricional e a ocorrência da anemia.

Verificando a escolaridade dos pais dos adolescentes anêmicos, encontrou-se que a totalidade deles não completou o primeiro grau, sendo que $42 \%$ dos pais e $50 \%$ das mães apresentam escolaridade, no máximo, até a quarta série. Isso mostra que, embora a anemia ocorra em crianças de qualquer classe social, à semelhança dos resultados encontrados por SANCHES $^{74}$ e SIGULEM ${ }^{79}$, fica reforçada fortemente a sua ligação com a situação social identificada pela escolaridade do pai.

A distribuição dos adolescentes das diferentes escolas, segundo a escolaridade dos pais também confirma a maior prevalência da anemia entre a população menos privilegiada do Município. Dentre os anêmicos, $45 \%$ frequentam a escola $n^{\circ} 1$, localizada em uma das regiōes mais pobres de Osasco (AR-1), que concentra $20 \%$ da amostra. 
A proporção de alunos que apresentam idade acima daquela adequada à série que cursa é de $41,5 \%$. A proporção de anêmicos que se encontram nesta condição é maior, chegando a 58,6\% . Entre os homens esta proporção é mais acentuada, situando-se ao redor de $77 \%$, enquanto entre as mulheres ela é de $43,7 \%$. Há, portanto, uma indicação de que a anemia pode ser um dos determinantes da condição de atraso na evolução escolar.

Mais uma vez há que se destacar a elevada evasão escolar. Os adolescentes que frequentam as quintas e especialmente, as oitavas séries do periodo diurno fazem parte da "elite" da população de Osasco. Os que estāo com idade adequada à série que frequentam ainda são bastante jovens para serem recrutados para o trabalho. Aqueles que continuam, embora mais velhos, não têm premência de sair em busca de trabalho, ou conseguem acomodar estudo e trabalho de modo razoavelmente eficiente. São, provavelmente, os adolescentes que têm melhores condições de vida e que usufruem do "privilégio" de poder estudar sem grandes preocupações, uma vez que suas famílias Ihes oferecem condiçōes para tal.

É bastante provável que a população evadida apresente condições semelhantes àquelas observadas entre as crianças ingressantes na primeira série do primeiro grau, seja em relação à desnutrição, seja em relação à anemia ${ }^{82}$. Taxas de evasão escolar que, segundo a FIBGE ${ }^{13}$, no Sudeste Brasileiro atingem os niveis mais elevados a partir da $5^{a}$ série, fazem com que a escola pública desta região não se constitua em lugar apropriado ao estudo de doenças carenciais na adolescência.

Através de entrevista (anexo 5), foi identificada a atividade física de 271 adolescentes, sendo $99(36,5 \%)$ homens e 172 mulheres $(63,5 \%)$. A partir dos resultados encontrados estas foram classificadas da seguinte maneira: 
- ESCOLARES - Assistir às aulas e realizar as atividades esportivas desenvolvidas no recreio e durante as aulas de educação física alem das atividades de lazer corriqueiras do final da semana.

. ESPORTIVAS - Treinos esportivos específicos: halterofilismo, corrida, musculação, capoeira.

. DOMÉSTICAS - para os meninos, foi considerado trabalho doméstico a arrumação do próprio quarto e ajuda na arrumação da casa; para as meninas o trabalho doméstico incluiu faxina da casa, lavar e passar roupa, lavar e enxugar pratos e arrumar a cozinha.

. TRABALHO NÃO REMUNERADO: construção (carregar areia, quebrar piso, etc.), agrícola (plantio e limpeza de terreno).

- TRABALHO PROFISSIONAL REMUNERADO: balconista de pequenos comércios (farmácia, padaria, bar, feira, granja), vendedor a domicílio, secretária, cabelereira e "office boy".

O número de jovens que desempenha essas tarefas pode ser observado na tabela 13 .

Tabela 13. Distribuiçāo das atividades fisicas desenvolvidas pelos adolescentes, segundo sexo. Osasco - 1990.

\begin{tabular}{|c|c|c|c|c|c|c|}
\hline \multirow[t]{2}{*}{ Tipo de atividade } & \multicolumn{2}{|c|}{ Mascul ino } & \multicolumn{2}{|c|}{ Feminino } & \multicolumn{2}{|c|}{ Total } \\
\hline & $n$ & $\%$ & $n$ & $\%$ & $n$ & $\%$ \\
\hline Só escolares & 55 & 55,5 & 32 & 18,6 & 87 & 32,1 \\
\hline Trabaltho remunerado & 20 & 20,2 & 8 & 4.6 & 28 & 10,3 \\
\hline Doméstica & 16 & 16,2 & 125 & 72,7 & 141 & 52,1 \\
\hline Esporte & 4 & 4,0 & -- & -. & 4 & 1,5 \\
\hline Construção & 2 & 2,0 & $\cdots$ & $-\cdot$ & 2 & 2,0 \\
\hline Agricola & 1 & 1,0 & - & $\cdots$ & 1 & 1,0 \\
\hline Trab. rem./Dom.* & 1 & 1,0 & 6 & 3,5 & 7 & 2,6 \\
\hline Esp./Dom.\# & -- & -- & 1 & 0,6 & 1 & 0,4 \\
\hline Total & 99 & 100,0 & 172 & 100,0 & 271 & 100,0 \\
\hline
\end{tabular}

*Trabalho remunerado + atividades domésticas

\#Esportes + atividades domésticas 
A maior parte dos homens $(55,5 \%)$, só desenvolvem a atividade escolar, enquanto as mulheres, em sua maioria, desempenham algum tipo de trabalho doméstico. $\dot{E}$ interessante notar que das 32 moças que não tem qualquer outra atividade além da escolar, 59\% (19), são alunas de escola pertencente à AR-4, a de melhor nível sócioeconômico.

Dos alunos que exercem algum tipo de atividade remunerada, $21,4 \%$ estudam na AR-1, $28,6 \%$ na $A R-2,17,8 \%$ na AR-3 e 32,0\% na AR-4. A distribuição desses alunos, segundo a série que cursam, é exatamente igual, ou seja $50 \%$ na quinta série e $50 \%$ na oitava.

Dentre os alunos que tiveram suas atividades conhecidas, 17 eram anêmicos, 6 homens e 11 mulheres. As atividades desempenhadas por eles foram as seguintes: 3 homens só têm atividade escolar exclusiva; um trabalha em construção, um é balconista de padaria e o último faz treino esportivo. Dentre as mulheres, duas só estudam e as outras nove executam trabalho doméstico.

Nenhuma das mulheres desenvolveu atividade física intensa. Os homens que tiveram atividade intensa foram em número de $10(10 \%)$, sendo caracterizada por trabalho em construção civil (ajuda o pai carregando areia ou blocos, ajuda a quebrar o chão), atividade agrícola (planta feijão com o tio) e treino esportivo diário de grande intensidade (capoeira, halterofilismo, corrida).

Dentre estes dez jovens, dois deles são anêmicos e ambos trabalham em construção.

O gasto médio diário de energia, assim como a média de horas diárias gastas nas diferentes atividades podem ser observados nas tabelas 14 e 15 . 
Tabela 14. Média do gasto energético diário (kcal/dia) nas diferentes atividades, segundo sexo e ARs. Osasco - 1990.

\begin{tabular}{|c|c|c|c|c|c|}
\hline Sexo & AR-1 & $A R=2$ & $A R-3$ & $A R=4$ & Total \\
\hline masc. & 2237,7 & 2383,1 & 2254,5 & 2464,2 & 2368,3 \\
\hline fem. & 1957,8 & 1877,5 & 1922,3 & 1929,5 & 1923,1 \\
\hline
\end{tabular}

Como esperado, o gasto energético dos homens é maior, qualquer que seja a AR onde a escola se situa. Não há diferenças marcantes no gasto energético entre a população das diferentes regionais.

\begin{tabular}{|c|c|c|c|c|c|}
\hline \multirow[t]{2}{*}{ Sexo } & At ividade & $A R-1$ & $A R-2$ & $A R-3$ & $A R-4$ \\
\hline & leve & 91,3 & 95,7 & 94,5 & 96,6 \\
\hline \multirow[t]{3}{*}{ masc. } & moderada & 18,3 & 15,2 & 16,6 & 12,4 \\
\hline & pesada & 3,9 & 8,1 & $\cdots$ & 3,0 \\
\hline & leve & 99,2 & 101,3 & 100,8 & 100,4 \\
\hline \multirow[t]{2}{*}{ fem. } & moderada & 11,3 & 8,2 & 8,6 & 7,7 \\
\hline & pesada & $\cdots$ & $\cdots$ & $\cdots$ & $\cdots$ \\
\hline
\end{tabular}

Com relação às horas gastas nas diferentes atividades, os alunos das escolas das AR-3 não executam tarefas de intensidade pesada. Observa-se também que, embora a maioria das mulheres executem trabalho doméstico, o número médio de horas em atividades leves é maior do que o dos homens. Os meninos gastam mais tempo em jogos (futebol, vôlei, etc..) em suas horas de lazer do que as mulheres, que durante o lazer, realizam atividades classificadas como leves.

O número de horas gastas, segundo as atividades, relacionado com o estado nutricional pode ser verificado na tabela 16 . 


\begin{tabular}{|c|c|c|c|c|}
\hline \multirow{3}{*}{$\begin{array}{c}\text { Tipo } \\
\text { de } \\
\text { Atividade }\end{array}$} & \multicolumn{3}{|c|}{ Peso/Idade } & \\
\hline & & & \multicolumn{2}{|c|}{$\lambda=P_{10}$} \\
\hline & $M$ & $\mathrm{~F}$ & M & $F$ \\
\hline Leve & 94,5 & 101.7 & 95,2 & 100,2 \\
\hline Moderada & 13,9 & 8,5 & 15,1 & 8,7 \\
\hline Pesada & 6,5 & $\cdots$ & 3,9 & $\cdots$ \\
\hline
\end{tabular}

Não houve diferenças significantes entre o número de horas semanais dedicadas às atividades leves e moderadas, independentemente do estado nutricional. Para as atividades pesadas, embora a diferença não tenha sido estatisticamente significante, os jovens que se encontram abaixo do $\mathrm{P}_{10}$ dedicam quase seis e meia horas semanais a este tipo de atividade, enquanto aqueles com situação nutricional mais favorável dedicam apenas 4 horas. Este resultado sugere que o consumo energético é insuficiente para atender à demanda de uma atividade mais intensa, levando à determinação da desnutrição.

O método adotado para o conhecimento das práticas e do consumo alimentares dos estudantes obteve boa resposta. O formulário para registro dos alimentos (anexo 4) foi distribuído por ocasiāo da coleta de sangue e da tomada das medidas antropométricas.

A colaboração da direção da escola, no sentido de estimular o preenchimento e a devolução dos questionários foi muito importante; foram devolvidos 380 questionários preenchidos $(74,5 \%)$.

Dos 369 questionários aproveitados $46,6 \%$ eram referentes a estudantes de quinta série e os outros $53,4 \%$ aos de oitava. 
Nem todos os estudantes registraram os três dias, e nem todos os dias registrados corresponderam àqueles indicados.

Dos 1107 dias possíveis, 1083 foram registrados, como segue:

. 1017 (94\%) corresponderam ao dia indicado;

$.41(4 \%)$ não corresponderam ao dia indicado e

$.25(2 \%)$ não informam o dia da semana.

A cobertura dos dias da semana correspondeu às expectativas, uma vez que a frequência entre os dias não apresentou grandes diferenças, variando entre $13 \%$ e $15 \%$ (tabela 17).

\begin{tabular}{lcc} 
Tabela 17. Frequència dos dias da semana registrados. Osasco - 1990. \\
\hline Dias da Semana & \multicolumn{2}{c}{ Frequéncia } \\
& $n$ & $\%$ \\
\hline segunda feira & 146 & 13,5 \\
terça feira & 151 & 13,9 \\
quarta feira & 145 & 13,4 \\
quinta feira & 157 & 14,5 \\
sexta feira & 162 & 15,0 \\
sábado & 142 & 13,1 \\
domingo & 155 & 14,3 \\
sem informação & 25 & 2,3 \\
\hline Total & 1083 & 100,0 \\
\hline
\end{tabular}

Verifica-se, com grande frequência em inquéritos alimentares, a ausência de anotação de condimentos que fazem parte da preparação normal dos alimentos. O óleo e o açúcar muito raramente merecem registro. Sendo alimentos muito importantes para o fornecimento de energia, optou-se por estimá-los mesmo quando não registrados.

Com base em avaliações feitas por especialistas em técnica dietética*, o óleo corresponde a $5 \%$ do peso dos alimentos consumidos refogados ou assados. Para

*Inquéritos alimentares realizados por profissionais da área de nutricão do Departamento de Nutrição da FSP/USP e do Departamento de Medicina Preventiva da Escola Paulista de Medicina. 
alimentos fritos, usou-se a notação da tabela da Escola Paulista de Medicina**. Para o açúcar adotou-se a proporção de $10 \%$ do peso dos alimentos fluidos, que é o valor médio usado por nossa população*.

Ao analisar os alimentos segundo as refeições, definidas pelo horário e preparações, observa-se que o hábito alimentar largamente obedecido pelos paulistas ainda está presente, havendo uma pequena tendência para o consumo de um jantar mais simplificado.

Assim, o dia alimentar da maior parte dos estudantes, levando em conta as três refeições principais, pode ser observado na tabela 18 .

\begin{tabular}{|c|c|c|}
\hline Refeição & Al imento & N\& de Citações \\
\hline & pão & 748 \\
\hline DESJEJUM & açúcar & 715 \\
\hline \multirow[t]{4}{*}{$(988)^{1}$} & leite & 583 \\
\hline & margarina & 424 \\
\hline & arroz & 777 \\
\hline & feijão & 637 \\
\hline ALMOÇO & carne bovina & 460 \\
\hline \multirow[t]{8}{*}{$(1017)^{1}$} & refrigerante ou & \\
\hline & suco em pó & 398 \\
\hline & alface & 173 \\
\hline & tomate & 161 \\
\hline & laranja & 87 \\
\hline & arroz & 666 \\
\hline & feijão & 570 \\
\hline & carne bovina & 449 \\
\hline JANTAR & refrigerante ou & \\
\hline \multirow[t]{4}{*}{$(998)^{1}$} & suco em pó & 376 \\
\hline & alface & 172 \\
\hline & tomate & 126 \\
\hline & laranja & 70 \\
\hline
\end{tabular}

$1_{\text {número de refeiçöes registradas. }}$

**Tabela mimeografada e sistema de Apoio à Decisão em Nutrição do Centro de Informática em Saúde Da Escola Paulista de Medicina. 
O hábito alimentar do paulista aqui identificado vem se mantendo desde o final da década de sessenta, conforme relatam ISHII e colaboradores ${ }^{42}$ ao fazerem uma análise crítica da dieta habitual da população do Estado de São Paulo.

Chama a atenção o elevado número de vezes que esta população ingeriu refrigerantes ou sucos em pó, integrando essas bebidas à prática alimentar diária dos adolescentes.

A tabela 19 apresenta os alimentos mais frequentes no dia alimentar, distribuídos segundo grupos, computando-se o número de vezes que ele é citado nas 4816 refeições, dos 1083 dias respondidos.

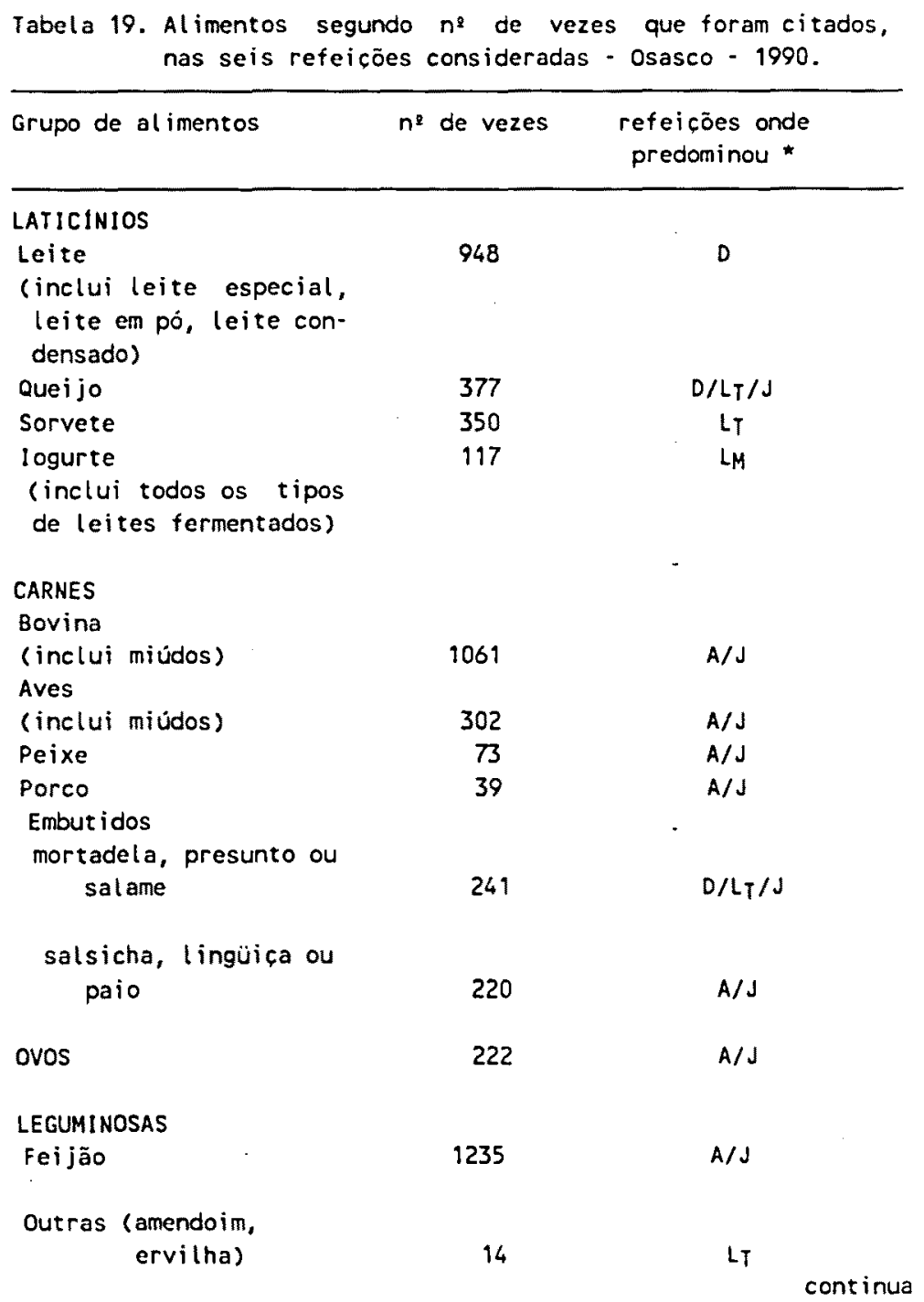




Grupo de alimentos $n^{2}$ de vezes $\begin{array}{r}\text { refeições onde } \\ \text { predominou }\end{array}$

\section{CEREAIS, FECULENTOS \\ E DERIVADOS}

Arroz

Pão

Bolo e Biscoitos doces

Macarrão

Batata

Matinais

Bolachas salgadas

Pipoca

Mandioca

Fubá

DOCES

Açucar

Balas

Doces em pasta

Chocolate

Gelatinas

GOROURAS

Oleo

Margarina

Maionese

VERDURAS FOLHA

Cruas

$$
\begin{aligned}
& \text { Alface } \\
& \text { Agrião }
\end{aligned}
$$

Cozidas

Repolho
Escarola
Couve
Brócoli
Espinafre

LEGUMES

Crus

Tomate
Pepino
Cenoura
Pimentão

Cozidos

Beterraba
Abobrinha
Abóbora
Chuchu

$D / L T / L N$

$L T$

LT

LT

J

$A / J$

D

A/J

$A / J$ 


\begin{tabular}{|c|c|c|}
\hline Grupo de alimentos & $n^{2}$ de vezes & $\begin{array}{l}\text { refeicōes onde } \\
\text { predominou * }\end{array}$ \\
\hline Ervilha & 10 & $A / J$ \\
\hline Berinjela & 5 & $A / J$ \\
\hline Vagem & 5 & $A / J$ \\
\hline Couve-flor & 5 & $A / J$ \\
\hline \multicolumn{3}{|l|}{ FRUTAS } \\
\hline \multicolumn{3}{|l|}{ Ricas Em Vit. C } \\
\hline Laranja & 343 & $A / J$ \\
\hline Mamão & 63 & $\mathrm{O} / \mathrm{A} / \mathrm{LT}$ \\
\hline Goiaba & 9 & $A / J$ \\
\hline Mixirica & 4 & A \\
\hline Maracujá & 3 & $A / J$ \\
\hline Morango & 3 & $A / J$ \\
\hline \multicolumn{3}{|l|}{ Outras } \\
\hline Maçā & 130 & $\mathrm{LM} / \mathrm{A}$ \\
\hline Banana & 124 & A \\
\hline Manga & 34 & $A / L T$ \\
\hline Melancia & 18 & $\mathrm{~J}$ \\
\hline Abacaxi & 12 & $L_{M}$ \\
\hline Abacate & 10 & A \\
\hline Ameixa & 7 & A \\
\hline \multicolumn{3}{|l|}{ DIVERSOS } \\
\hline Refrigerante & 771 & $A / L T / J$ \\
\hline Suco pacote & 474 & $A / J$ \\
\hline Cerveja & 27 & J \\
\hline Aguardente & 6 & J \\
\hline Vinho & 3 & $\downarrow$ \\
\hline Licor & 2 & $J$ \\
\hline
\end{tabular}

* $D=$ desjejum (988)

$L_{M}=$ lanche/manhã $(500)$

$A=\operatorname{almoço~(1017)~}$

$L_{T}=$ lanche tarde (886)

$\mathrm{J}=$ jantar (998)

$L_{N}=$ lanche noite (427)

Os alimentos fonte de ferro-heme (carnes e derivados) estiveram presentes em 96\% (1936 vezes) dos almoços e jantares registrados. A porção média ingerida foi de $81 \mathrm{~g}$ de carne bovina, ou $90 \mathrm{~g}$ de aves ou porco ou $115 \mathrm{~g}$ de peixe, sendo que em $56,5 \%$ dos dias foi registrado o consumo de carnes nas duas refeiçōes principais. 
Analisando a alimentação da região de São Paulo levantada pelo Estudo Nacional da Despesa Familiar - ENDEF36 em 1974/75, observa-se que a quantidade média diária ingerida de carne bovina foi de $44 \mathrm{~g}, 26 \mathrm{~g}$ de aves e $9 \mathrm{~g}$ de peixe, quantidade essa inferior à ingerida diariamente pela população estudada.

Sendo esses alimentos, ao mesmo tempo, fonte e favorecedores da absorção do ferro alimentar, sua presença em quase todas as principais refeições é uma indicação da boa qualidade da dieta dos adolescentes de Osasco, o que, de alguma forma, justifica a baixa prevalência de anemia encontrada.

Contrastando com o consumo das carnes, a prática alimentar referente às frutas ricas em ácido ascórbico revelou uma baixa ingestão. Esses alimentos aparecem em 425 das refeições anotadas, correspondendo a $21 \%$ dos almoços e jantares. Embora a laranja tenha sido a fruta citada, face sua abundância no mercado a preços acessíveis, surpreendeu o pequeno número de adolescentes que a consumiu.

Verduras e legumes também são pouco consumidos. Alface e tomate foram as hortaliças mais citadas, porém, a maior variedade é encontrada entre aquelas consumidas habitualmente cozidas (repolho, cenoura, beterraba) que além de serem pobres em vitamina $\mathrm{C}$ sofrem grande perda do nutriente durante a cocção.

Também no ENDEF 36 o legume mais citado foi o tomate e fruta referida maior número de vezes foi a laranja (78\% e $74 \%$ das famílias, respectivamente, os consumiram).

A ingestão de verduras e frutas é pouco frequente entre os adolescentes, correspondendo a $22 \%$ das principais refeições, o que indica uma baixa ingestão de ácido ascórbico, elemento importantíssimo no aproveitamento do ferro alimentar. 
DeMAEYER e colaboradores ${ }^{19}$ destacam que o simples aumento da ingestão de ácido ascórbico às refeições é uma medida eficiente para a diminuição da anemia ferropriva em uma população.

STECKEL ${ }^{81}$ obteve absorção 2,1 vezes maior do ferro ao adicionar $100 \mathrm{mg}$ de ácido ascórbico a uma fórmula láctea fortificada com $15 \mathrm{mg}$ de ferro sob a forma de sulfato ferroso.

O consumo médio de leite foi de $200 \mathrm{ml}$ por refeição. A frequência de consumo pode ser considerada elevada (948 vezes - $60 \%$ dos desjejuns e lanches da tarde), caracterizando-se como o principal alimento do desjejum, nesta população. Estudo realizado entre docentes, funcionários e alunos da Faculdade de Saúde Pública da USP revelou que $18,3 \%$ dos entrevistados não consomem leite, sendo que destes, $46,1 \%$ são alunos de graduação ${ }^{25}$.

Ao se verificar o consumo de embutidos, de queijo e de pão, observa-se que há uma maior quantidade desses alimentos no jantar, indicando que alguns dos jovens estão substituindo a composição tradicional dessa refeição por um lanche, tendência esta verificada empiricamente nos questionários.

A tabela 20 apresenta a composição média "per capita" diária da dieta consumida pelos alunos de Osasco. Esses valores foram cotejados com aqueles mensurados por COLLI e colaboradores $^{12}$ na dieta consumida na região de São Paulo, segundo o ENDEF $74 / 75^{36}$. 


\begin{tabular}{|c|c|c|}
\hline Nutrientes & Dieta Osasco & Dieta ENDEF \\
\hline Energia (kcal) & 2084 & 1830 \\
\hline Proteína (g) & 71 & 54 \\
\hline Fe Hene (mg) & 1,5 & 1,0 \\
\hline Fe Não Heme (mg) & 11,6 & 14,0 \\
\hline Fe Biodisponível(mg) & 1,1 & 0,8 \\
\hline
\end{tabular}

Embora os valores para São Paulo sejam aqueles consumidos por uma família representativa da região, o valor energético da alimentação dos adolescentes é maior, ao contrário do teor de ferro. Para os paulistas são $15 \mathrm{mg}$ de ferro total, contra $13 \mathrm{mg}$ dos adolescentes. Essa diferença, porém, acaba sendo compensada pela maior quantidade de ferro heme e, conseqüentemente pela maior biodisponibilidade desse mineral para os adolescentes.

A composição química da dieta média diária, com relação a energia, ao ferro e ao ácido ascórbico, dos alunos das quintas e oitavas séries, segundo as ARs está na tabela 21.

Tabela 21. Composição química da dieta "per capita" diária segundo série e AR. Osasco - 1990.

\begin{tabular}{|c|c|c|c|c|c|c|c|c|}
\hline \multirow{3}{*}{ Nutrientes } & \multicolumn{6}{|c|}{ Administrações Regionais de Ensino } & \multirow{2}{*}{\multicolumn{2}{|c|}{ AR -4}} \\
\hline & \multicolumn{2}{|c|}{$A R-1$} & \multicolumn{2}{|c|}{$A R-2$} & \multicolumn{2}{|c|}{$A R-3$} & & \\
\hline & $5 !$ & $8:$ & 51 & $8:$ & 5: & 81 & $5 !$ & $8:$ \\
\hline Energia (kcal) & 1813 & 2123 & 2069 & 2129 & 2093 & 2096 & 2055 & 2160 \\
\hline Fe Heme (mg) & 1,1 & 1.5 & 1,6 & 1.8 & 1,4 & 1.6 & 1,5 & 1,6 \\
\hline Fe Não Heme (mg) & 10,5 & 12,0 & 12,2 & 12,5 & 12,1 & 11,6 & 10,8 & 11,5 \\
\hline Fe Biodisponivel(mg) & 0,8 & 1,1 & 1,1 & 1,2 & 1,1 & 1,1 & 1,0 & 1,1 \\
\hline Acido Ascórbico (mg) & 45,5 & 56,3 & 38,5 & 61,9 & 61,7 & 59.7 & 58,7 & 54,1 \\
\hline
\end{tabular}

A alimentação dos alunos das diferentes ARs é muito semelhante, com exceção da $5^{\mathrm{a}}$ série da AR-1, onde quase todos os nutrientes estão em quantidades inferiores. Entre as 
quintas e oitavas séries, na mesma Regional de Ensino, a quantidade "per capita" dos nutrientes não sofre grande mudança.

A qualidade da dieta consumida pelos adolescentes pode ser avaliada através da análise da origem dos nutrientes, ou seja, qual foi a contribuição de cada grupo de alimentos na quantidade dos nutrientes presentes, como mostra a figura 8 .

O grupo dos cereais e feculentos é o que contribui com maior proporção no fornecimento de energia ( $37 \%)$, como ocorre comumente nas dietas da maioria dos países $^{42}$. Surpreende que o segundo grupo contribuinte para a energia seja o das carnes e ovos, alimentos esses que embora caros, são de alto valor biológico e estão presentes em proporçōes apreciáveis, o que denota uma qualidade bastante boa das dietas.

A contribuição dos diferentes grupos de alimentos para a proteína presente na dieta evidencia sua boa qualidade, uma vez que o grupo das carnes e ovos contribuem com $36,6 \%$ do nutriente, os cereais com $29 \%$ e as leguminosas com $12,1 \%$. Na alimentação de populações de regiões menos favorecidas as proteínas são fornecidas principalmente pelos cereais $(34 \%)$, sendo que carnes ovos contribuem com $19 \%$ e leguminosas com $30 \% 36.42$.

Mais da metade das proteínas ingeridas pela população estudada é de origem animal (carnes, ovos e laticínios), sendo que esse nutriente contribui com $13,7 \%$ do valor energético total da dieta. Esse valor é muito semelhante aos $13,9 \%$ referidos por HORNER $^{36}$ ao avaliar a qualidade da dieta da populaçāo pertencente ao estrato de classe de renda mais alto da região de São Paulo Urbano, levantada pelo ENDEF. 
Figura 8 - ORIGEM DE ENERGIA, PROTEÍNAS, FERRO E ÁCIDO ASCÓRBICO, POR GRUPO DE ALIMENTOS - OSASCO, 1990.

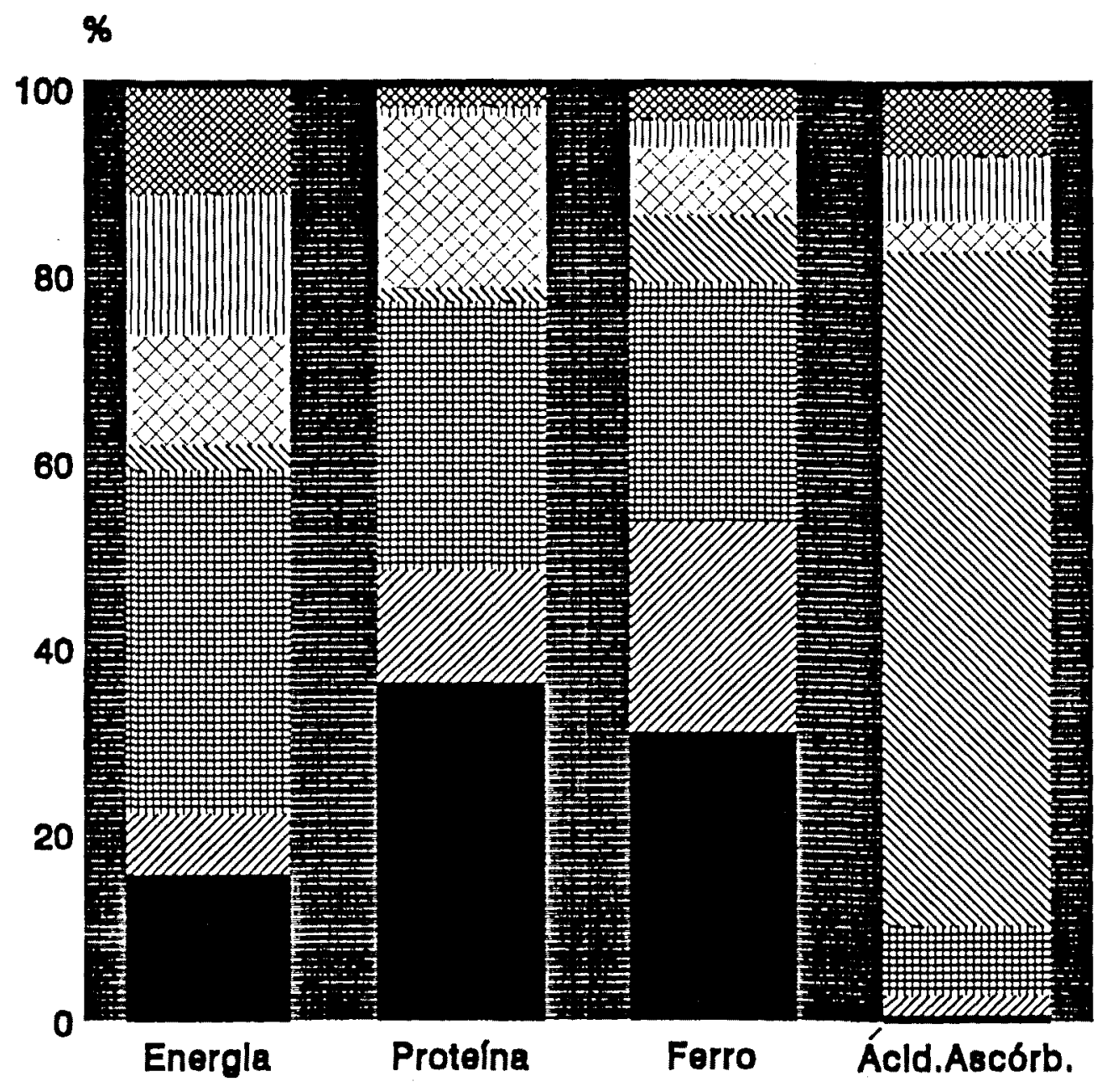

\begin{tabular}{|l|}
\hline Dlversos \\
III Aḉ́cares • Gorduras \\
Latlcinlos \\
Frutas o Hortallgas \\
Wereals a Feculentos \\
W/IL Legumlnosas \\
Carnes • Ovos
\end{tabular}


VEIGA $^{91}$, estudando a alimentação de adolescentes do sexo feminino, eutróficas e obesas, encontrou $13,6 \%$ a $15,0 \%$ das quilocalorias totais ingeridas provenientes de proteínas, sendo que aproximadamente $50 \%$ para o nível de renda baixo e e $70 \%$ para o de renda alto eram de alimentos de origem animal.

A qualidade relativa ao ferro da alimentação dos estudantes de Osasco é comparável às dietas de países desenvolvidos, uma vez que o maior percentual do mineral é proveniente do grupo das carnes (30,9\%), fazendo com que $11,4 \%$ do ferro presente nesta dieta seja ferro-heme, o que constitui uma justificativa para a pequena prevalência de anemia encontrada no grupo de estudo.

HECBERG e colaboradores ${ }^{35}$ e PREZIOSI e colaboradores ${ }^{68}$, estudando uma amostra da população parisiense, encontraram $20 \%$ a $23 \%$ do aporte diário de ferro dos adolescentes originários de carnes e peixes, com a proporção média de ferro hemínico de 11 a $12 \%$.

Outro indicador da qualidade da alimentação de um grupo é a medida da densidade dos nutrientes na dieta, isto é, a quantidade do nutriente por unidade de energia, permitindo verificar se a quantidade de nutrientes necessária para atingir as recomendaçooes nutricionais diárias está presente ao se atingir as necessidades energéticas do grupo estudado.

Usando este conceito (tabela 22), verificou-se a densidade do ferro e do ferro biodisponível ${ }^{29}$ da dieta dos escolares estudados. 
Tabela 22. Densidade de ferro e de ferro biodisponivel e quantidade de calorias necessárias para alcançar as recomendaçōes nutricionais diárias, por sexo. Osasco - 1990.

\begin{tabular}{|c|c|c|c|c|c|}
\hline Sexo & $\begin{array}{l}\text { Idade } \\
\text { (anos) }\end{array}$ & Nutriente & $\begin{array}{c}\text { Recom.diária } \\
\text { (mg/dia) }\end{array}$ & $\begin{array}{c}\text { Densidade } \\
\text { (mg/1000kcal) }\end{array}$ & $\begin{array}{l}\text { Quant. neces. } \\
\text { de kcal/dia }\end{array}$ \\
\hline \multirow{5}{*}{$M$} & & Ferro total & $26^{*}$ & 6,30 & 4.150 \\
\hline & 12 a 16 & Ferro biod. & $1,82^{* \star}$ & 0,52 & 3.500 \\
\hline & & & & & \\
\hline & & Ferro total & $16^{*}$ & 6,30 & 2.550 \\
\hline & & Ferro biod. & $1,14^{\star \star}$ & 0,52 & 2.200 \\
\hline & & Ferro total & $29^{\star}$ & 6,30 & 4.600 \\
\hline
\end{tabular}

12 a 16
$>=16$
* Referència 89.
** Referéncia 19.

Embora a maior parte do ferro tenha sua origem nas carnes, a densidade encontrada, tanto para o ferro total como para o biodisponível é baixa. A quantidade de calorias necessárias para satisfazer as recomendações do mineral é muito alta, incompatível com as necessidades energéticas do grupo estudado. Somente para os homens maiores de 16 anos a energia necessária para fornecer a quantidade de ferro ideal seria viável, porém, o valor energético médio encontrado foi de 2084 , aquém das $2.500 \mathrm{kcal}$ apontadas na tabela.

Existem, portanto, indícios de que a população estudada, embora apresente uma prevalência baixa de anemia, deve apresentar uma alta porcentagem de indivíduos ferro deficientes. 
A densidade de ferro biodisponível ideal é muito difícil de ser alcançada. LAYRISSE e colaboradores $^{46}$ encontraram $0,72 \mathrm{mg} / 1000 \mathrm{kcal}$ de ferro biodisponível em dietas venezuelanas de população de baixa renda, densidade esta considerada baixa, ao se comparar com as recomendações para mulheres maiores de 16 anos.

Mesmo em países desenvolvidos é muito difícil alcançar a densidade ideal. HALLBERG $^{28}$ relata a densidade de $0,9 \mathrm{mg} / 1000 \mathrm{kcal}$ para o ferro biodisponivel em dietas consumidas por mulheres suecas adultas. HECBERG ${ }^{35}$ relata a densidade de 4,6 a $6,0 \mathrm{mg} / 1000 \mathrm{kcal}$ de ferro alimentar para a população parisiense, concluindo que $90 \mathrm{a}$ 95\% das mulheres em idade de procriação não alcançam as recomendações nutricionais para esse mineral.

A biodisponibilidade do ferro da alimentação dos adolescentes poderia ser maior se a ingestão de alimentos fonte de vitamina $\mathrm{C}$ fosse aumentada. Como já foi visto, ela é restrita entre os alunos de Osasco. A prática alimentar observada destaca que não existe o hábito do consumo de frutas como sobremesa. Dentre os 988 desjejuns, 1017 almoços e 998 jantares, somente $83(8,4 \%), 190(18,7 \%)$ e $158(15,8 \%)$ refeições, respectivamente, registraram a presença de frutas, sendo que destas, $54,5 \%$ eram fontes de vitamina $\mathrm{C}$.

A adequação da ingestão de alimentos foi calculada para energia, ferro total e ferro biodisponível.

\section{ENERGIA}

A adequação foi calculada com relação às necessidades diárias individuais de cada adolescente. O gasto energético foi estimado, conforme já descrito, levando em consideração o sexo, o peso e a atividade física diária dos indivíduos (tabela 23). 
Tabela 23. Distribuição da amostra segundo adequação individual de ingestão energética. Osasco-1990.

\begin{tabular}{|c|c|c|c|c|c|}
\hline \multirow[t]{2}{*}{ Variáveis } & \multirow[b]{2}{*}{$n$} & \multicolumn{4}{|c|}{ Adequação da Ingestão Energética (\%) } \\
\hline & & $>=100$ & $75 \mid-100$ & $50 \mid-75$ & $<50$ \\
\hline Masculino & 82 & 48,8 & 26,8 & 19,5 & 4,9 \\
\hline Feminino & 161 & 52,8 & 28,0 & 16,1 & 3,1 \\
\hline Anèmicos & 12 & 33,3 & 33,3 & 33,3 & 0,0 \\
\hline $\mathrm{P} / \mathrm{I}<\mathrm{P} 10$ & 49 & 65,3 & 14,3 & 18,4 & 2,0 \\
\hline \multicolumn{6}{|l|}{ Escol. pai } \\
\hline$<=41$ série & 151 & 51,0 & 27,8 & 15,9 & 5,3 \\
\hline$>4:$ série & 76 & 52,6 & 29,0 & 17,1 & 1,3 \\
\hline$A R-1$ & 48 & 35,5 & 33,3 & 25,0 & 6,2 \\
\hline$A R-2$ & 52 & 46,1 & 28,9 & 19,2 & 5,8 \\
\hline$A R-3$ & 51 & 58,8 & 19,6 & 19,6 & 2,0 \\
\hline$A R-4$ & 92 & 58,7 & 28,3 & 10,9 & 2,1 \\
\hline Total & 243 & 51,4 & 27,6 & 17,3 & 3,7 \\
\hline
\end{tabular}

Não foram observadas diferenças significativas quando a amostra foi distribuída por sexo. No entanto, analisando a adequação de consumo segundo a escolaridade do pai, encontra-se que a maior proporção de consumo inadequado está presente entre aqueles cujo pai apresenta escolaridade até a quarta série do primeiro grau.

A adequação do consumo difere, ainda, segundo a localização da escola; as ARs mais pobres têm maior porcentagem de alunos com inadequação de consumo.

A relação entre adequação do estado nutricional e de consumo energético não foi encontrada. Entre os 49 estudantes com $\mathrm{P} / \mathrm{I}$ abaixo do $\mathrm{P}_{10}, 65,3 \%$ apresentam consumo adequado enquanto $2 \%$ ingeriram quantidades de calorias inferiores a $50 \%$ da necessidade específica. 
A anemia e o consumo energético também não estão associados. Nenhum dos 12 anêmicos consumiram energia em quantidade inferior à metade de suas necessidades.

Comparando esses dados com os das famílias da Região São Paulo Urbano investigadas pelo $\mathrm{ENDEF}^{36}$, o consumo energético aqui encontrado é muito semelhante; a população paulista urbana apresenta $51,6 \%$ de suas famílias com $100 \%$ de adequação do consumo energético. Porém, enquanto somente $0,7 \%$ das famílias não consomem nem a metade da energia necessária, um percentual maior dos adolescentes $(3,7 \%)$ assim se apresentam.

Procurou-se verificar qual a adequação do consumo energético daqueles alunos que se localizaram abaixo do $\mathrm{P}_{10}$ para $\mathrm{P} / \mathrm{I}$ e que desenvolvem atividades pesadas. $67 \%$ deles não atingem os $100 \%$ de adequação, podendo ser esta a justificativa para o baixo peso por eles apresentado.

\section{FERRO TOTAL}

Para a avaliação do consumo de ferro utilizaram-se as recomendações da OMS ${ }^{18}$, estimando-se a biodisponibilidade do mineral em $7 \%$, conforme indicação no documento "Aplicação das Recomendações Nutricionais Adaptadas à População Brasileira"89 (tabela 24). 
Tabela 24. Distribuição da amostra segundo adequação de ingestão de ferro total. Osasco-1990.

\begin{tabular}{|c|c|c|c|c|c|}
\hline \multirow[t]{2}{*}{ Variáveis } & \multirow[b]{2}{*}{$\mathrm{n}$} & \multicolumn{4}{|c|}{ Adequação da Ingestão de Ferro (\%) } \\
\hline & & $>=100$ & $75 \mid-100$ & $50 \mid-75$ & $<50$ \\
\hline Mascul ino & 126 & 6,3 & 18,2 & 42,9 & 32,6 \\
\hline Feminino & 243 & 2,0 & 5,8 & 25,5 & 66,7 \\
\hline Anèmicos & 18 & 0,0 & 11,1 & 27,8 & 61,1 \\
\hline$P / 1<P_{10}$ & 74 & 4,0 & 12,2 & 32,4 & 51,4 \\
\hline \multicolumn{6}{|l|}{ Escol. pai } \\
\hline$<=41$ série & 233 & 4,3 & 10,7 & 27,9 & 57,1 \\
\hline$>4$ série & 106 & 2,8 & 11,3 & 35,9 & 50,0 \\
\hline AR-1 & 77 & 0,0 & 9,1 & 26,0 & 64,9 \\
\hline$A R-2$ & 78 & 7,7 & 11,5 & 34,6 & 46,2 \\
\hline$A R-3$ & 82 & 3,7 & 7,3 & 30,5 & 58,5 \\
\hline$A R=4$ & 132 & 3,0 & 11,4 & 33,3 & 52,3 \\
\hline Total & 369 & 3,5 & 10,0 & 31,5 & 55,0 \\
\hline
\end{tabular}

A maior parte da população não atinge sequer a metade da quantidade de ferro recomendada. Maior proporção de mulheres do que de homens se encontram nessa condição. A maior parte dos anêmicos não atinge os $50 \%$ de adequaçào, sendo que nenhum deles consome a quantidade recomendada, sugerindo, mais uma vez que, com grande probabilidade, a anemia prevalente tem origem nutricional.

Com relação à distribuição geográfica, os alunos das escolas da AR-1, onde está a maior prevalência de anêmicos apresentam maior proporção de indivíduos com adequação abaixo dos $50 \%$. O mesmo se verifica para a variável escolaridade do pai; os alunos com pais que tem escolaridade abaixo da quarta série se concentram entre os que apresentam adequação marcial da dieta abaixo de $50 \%$. Embora a população como um todo esteja com adequação inferior ao desejável, existe um risco maior de anemia para a população pertencente aos estratos sociais mais baixos. 
Essa mesma associação foi encontrada por outros autores; SIGULEM e colaboradores ${ }^{79}$ em 1977, MONTEIRO e colaboradores ${ }^{52}$ em 1987 e STEFANINI e colaboradores ${ }^{82} \mathrm{em}$ 1992.

\section{FERRO BIODISPONÍVEL}

Foi estimada a necessidade diária individual do mineral levando-se em consideração sexo, peso, idade e estado fisiológico, conforme documento da OMS ${ }^{18}$. A tabela 25 foi elaborada cotejando-se a necessidade diária individual com a quantidade de ferro biodisponível na dieta, estimada pela equação de MONSEN e BALINTFY (M \& B $)^{50}$.

\begin{tabular}{|c|c|c|c|c|c|}
\hline \multirow[t]{2}{*}{ Variáveis } & \multicolumn{2}{|c|}{ Adequaçāo da } & \multirow{2}{*}{$\begin{array}{c}\text { Ingestäo de } \\
75 \mid-100\end{array}$} & \multicolumn{2}{|c|}{ Ferro Biodisp. $(\%)$} \\
\hline & $n$ & $s=100$ & & $501 \cdot 75$ & $<50$ \\
\hline Masculino & 126 & 15,9 & 30,2 & 30,9 & 23,0 \\
\hline Feminino & 241 & 5,0 & 16,6 & 28,6 & 49,8 \\
\hline Anémicos & 18 & 5,5 & 22,2 & 44,5 & 27,8 \\
\hline $\mathrm{P} / 1<\mathrm{P}_{10}$ & 74 & 21,6 & 29,7 & 25.7 & 23,0 \\
\hline \multicolumn{6}{|l|}{ Escol.pai } \\
\hline$<=41$ série & 231 & 10,0 & 20,3 & 29,0 & 40,7 \\
\hline$>41$ série & 106 & 7,5 & 20,8 & 33,0 & 38,7 \\
\hline$A R-1$ & 77 & 6,5 & 19,5 & 32,5 & 41,5 \\
\hline$A R-2$ & 78 & 15,4 & 20,5 & 30,8 & 33,3 \\
\hline$A R-3$ & 80 & 6,2 & 26,2 & 23,8 & 43,8 \\
\hline$A R-4$ & 132 & 7,6 & 19,7 & 30,3 & 42,4 \\
\hline Total & 367 & 8,7 & 21,2 & 29,5 & 40,6 \\
\hline
\end{tabular}

Ao analisar a tabela, fica evidente que as mulheres, mais do que os homens, têm dificuldade em obter, da alimentação, a quantidade de ferro necessária para atender à demanda diária; quase a metade delas não atinge sequer $50 \%$ dessa quantidade. 
A biodisponibilidade do ferro, calculada segundo $M$ \& $B$ leva em consideração a composição e, conseqüentemente, o teor de ácido ascórbico e a quantidade de carnes de cada uma das refeiçōes dos adolescentes. A influência da composiçāo da refeiçāo na biodisponibilidade do ferro fica evidente, ao se observar, na tabela 25 , que a associação da não adequação com os marcadores sociais aqui utilizados é menos intensa, do que para o ferro total (tabela 24).

A influência do ácido ascórbico para a biodisponibilidade do ferro parece ser fundamental, pois a porcentagem de indivíduos que atingem os $100 \%$ de adequaçào para o ferro biodisponível é maior do que o dobro daquela que atingem essa adequação para o ferro total. Esse fato se dá em uma população onde o consumo de alimentos fonte de vitamina $C$ às principais refeiçōes é pequeno ( $8 \%$ a 15\%). Fica a indagação de como seria a situação de anemia e ferro deficiência desses adolescentes se a ingestão de ácido ascórbico fosse aumentada.

É interessante lembrar que a estimativa da ingestão de alimentos obtida através de inquéritos alimentares é groosseira. Dificilmente tais informações, seja qual for o método usado, refletem a totalidade e a variabilidade dos alimentos ingeridos por uma população. Porém, esta estimativa apresenta dados preciosos que podem levar ao melhor conhecimento do provável estado nutricional de uma população.

Embora não se possa fazer uma relação causal entre alimentação e a presença ou ausência de anemia, ao se constatar, rotineiramente, os principais alimentos fonte de ferro (carne e feijāo) na alimentação diária da população estudada, pode-se esperar uma baixa prevalência de anemia, porém sem descartar a provável deficiência de ferro que a população deve apresentar, ao se verificar a baixa densidade, na dieta, do ferro potencialmente absorvivel. 
A população de adolescentes, alunos das escolas públicas do período diurno do município de Osasco pode ser considerada como socialmente privilegiada. Seu perfil antropométrico está pouco desviado do padrão de referência, e acompanha o da população urbana da Região Sudeste do país. A prevalência de anemia é pequena, comparável à de países desenvolvidos e, a qualidade da alimentação, de certa maneira, justifica esta baixa prevalência de carência marcial.

É uma alimentação de qualidade protéica satisfatória. A proporção de ferro hemínico presente na alimentação é semelhante a de países desenvolvidos. A concentração do mineral, por unidade de energia, porém, é pequena. A biodisponibilidade do ferro da dieta, dependente da presença, principalmente de carnes e de ácido ascórbico às refeições, tem uma melhor adequação de ingestão do que o ferro total. Esta melhoria de adequação é devida, em parte, à presença da vitamina $C$ às refeições de parte dos estudantes.

A prática alimentar encontrada, porém, revela que existe um contingente apreciável de indivíduos que não tem o hábito do consumo de frutas ricas em ácido ascórbico às refeições. Existe, portanto, um amplo espaço para o incentivo do consumo de alimentos ricos em vitamina $C$, principalmente das frutas tropicais, disponíveis em abundancia e a preços acessíveis à população.

O enriquecimento de refrescos com vitamina $C$ poderia ser outra medida desejável e encontraria ressonância na população estudada ao se observar o elevado consumo de refrigerantes e sucos artificiais em pó pela presente população. Embora sejam alimentos muito caros, frente aos elementos nutricionais que contém, fazem parte integrante da prática alimentar dos adolescentes. 
A prática alimentar mostrou também a tendência da substituição do jantar tradicional, onde o feijão - uma das mais frequentes e importantes fontes de ferro na dieta da população brasileira - está presente, por um lanche cuja composição nem sempre satisfaz aos preceitos da alimentação equilibrada.

Alguns dos questionários expressaram o consumo de sanduíches e pizzas comercializados por redes de "fast-foods", mostrando que este hábito, típico de adolescentes de outros países, já se faz presente entre a população de Osasco.

Houve consumo de bebidas alcoólicas pelos adolescentes mais velhos, sendo a cerveja a bebida mencionada o maior número de vezes, principalmente nos finais de semana.

Fica evidente que a população estudada não reflete a verdadeira situação nutricional dos adolescentes de Osasco. A enorme diferença de prevalência de anemia encontrada entre estes adolescentes e os escolares de sete anos, que ingressam na primeira série do primeiro grau só pode ser justificada pela alta evasão escolar e consequente seleção social da população que pemanece na escola.

Os dados sociais e de saúde globais da população de Osasco fazem acreditar que este município reflete a situação de saúde e nutrição encontrada na área urbana da região Sudeste, porém, fica evidente que a escola pública, após a quarta série, não se constitui no "locus" ideal de pesquisa para a identificação de problemas que apresentem algum grau de associação com a situação econômico-social da população.

A pesquisa entre adolescentes que não frequentam a escola revelará, certamente, problemas nutricionais importantes, principalmente aqueles ligados à carência de ferro, 
tendo em vista que mesmo entre esta população socialmente privilegiada, o ferro se encontra em densidade baixa na alimentação.

As políticas de nutrição relativas à prevenção da anemia carencial, nos municípios paulistas, devem levar em conta a prática alimentar encontrada entre os alunos das escolas de Osasco e optar pelo incentivo ao consumo de alimentos ricos em ácido ascórbico nas refeições principais, ao lado do enriquecimento de alimentos de consumo rotineiro com sais de ferro e vitamina $\mathrm{C}$. 


\section{V - CONCLUSÕES}

- A prevalência de anemia, entre os adolescentes das quintas e oitavas séries das escolas públicas de Osasco foi de $5,3 \%$, não havendo diferença entre os indivíduos segundo o sexo.

- A prevalência de desnutrição na população, identificada pelos indivíduos abaixo do $\mathrm{P}_{10}$ para $\mathrm{P} / \mathrm{I}$, foi de $17,3 \%$. Abaixo de $\mathrm{P}_{3}$, a proporção de indivíduos foi de $4,7 \%$. Entre os homens a proporção de desnutridos foi maior.

- A prática alimentar dos adolescentes mostrou-se semelhante à encontrada em São Paulo. Duas evidências importantes: a) o pequeno consumo de alimentos fontes de vitamina $\mathrm{C}$, apesar da abundância dos mesmos, a preços acessíveis, no mercado e b) a tendência da substituição da composição tradicional do jantar por um lanche, em detrimento do consumo de feijāo. 
- A maior parte dos adolescentes não desenvolve atividades consideradas intensas. Quase a totalidade das mulheres executam algum tipo de trabalho doméstico. No geral os homens gastam maior número de horas em atividades moderadas do que as mulheres. Pequeno percentual de adolescentes exerce atividade remunerada.

- O consumo energético foi adequado para a metade dos adolescentes estudados, não havendo diferenças significativas entre os sexos. Somente 3,7\% não atingiram $50 \%$ de adequação para a ingestão de energia.

- O consumo de ferro total foi inadequado para a maior parte da população. Mais de $55 \%$ não atingiu sequer a metade do ferro recomendado. Nenhum dos anêmicos teve consumo adequado de ferro.

- O ferro potencialmente absorvível também não esteve adequado. 40,6\% dos adolescentes não alcançam a metade de adequação para o ferro biodisponível. Nesta porcentagem está presente a metade das mulheres estudadas.

- A alimentação de boa qualidade pode ser considerada como um dos determinantes da pequena prevalência da anemia, embora a baixa densidade do ferro e do ferro biodisponível venha a ser um indicador da provável existência de indivíduos ferro deficientes em proporção apreciável na população. 


\section{VI - REFERÊNCIAS BIBLIOGRÁFICAS}

01.ARAÚJO, R.L. et al. Diagnóstico de hipovitaminose $\mathrm{A}$ e anemia nutricional: estudo realizado na populaçào do Vale do Jequitinhonha, Minas Gerais. Rev.Bras.Med., 43:225-28, 1986.

02.AUKETT, M.A. et al. Treatment with iron increases weight gain and psycomotor development. Archi. Dis. childh.,61:849-57,1986.

03.BAILEY, L.B. et al. Folacin and iron status and haematological findings in black and spanish american adolescents from urban low-income households. Am. J. Clin. Nutr.,35:1023-32,1982.

04.BASIOTIS, P.P. et al. Number of day of food intake records required to estimate individual and group nutrient intakes with defined confidence. J.Nutr., 117:1638-41,1987.

05.BASTA, S.S. et al. Iron deficiency anemia and the productivity of adult males in Indonesia. Am. J. Clin. Nutr.,32:916,1979.

06.BAYNES, R.D.; BOTHWELL, T.H. Iron deficiency. Ann. Rev. Nutr.,10:13348,1990 .

07.BEARD, J.; BOREK, M. Iron deficiency anemia and thermoregulation in adult women. In: HERCBERG, S.; GALAN, P.; DUPIN, H.,ed. Aspects actuels 
des carences en fer et en folates dans: le monde apud Colloque INSERM, 197:5.33-41,1990.

08.BINGHAM, S.A. The dietary assessment of individuals: method, accuracy, new techniques and recommendations. Nutr. Abstr. Rev.,57:705-42,1987.

09.BORRELLI, R. et al. Some statistical considerations on dietary assessment methods. Europ. J. Clin. Nutr.,43:453-63,1989.

10.BRUNE, M.; ROSSANDER, L.; HALLBERG, G.L. Iron absortion and phenolic compounds: importance of different phenolic structures. Europ. J. Clin. Nutr.,43:547-58,1989.

11. CESAR, A.T. O uso do ácido ascórbico no contròle da deficiência de ferro, utilizando a estrutura do Programa de Merenda Escolar. São Paulo, 1989 66 p. /Tese (mestre em saúde pública) - Faculdade de Saúde Pública da Universidade de São Paulo/

12. COLLI, C.; BARBÉRIO, J.C. In vitro estimation of iron bioavailability in S. Paulo regional diet. In: HERCBERG, S.; GALAN, P.; DUPIN, H, ed. Aspects actuels des carences en fer et en folates dans le monde apud Colloque INSERM,197:345-47,1990.

13.CRIANÇAS e adolescentes: indicadores sociais. Rio de Janeiro, IBGE,v.4, 1992. $159 \mathrm{p}$.

14.DALLMAN, P.R.; SIIMES, M.A. Percentile curves for haemoglobin and red cell volume in infancy and childhood. J. Pediatr.,94:26-31,1979.

15.DALLMAN, P.R.; SIIMES, M.A. Iron deficiency in infant and childhood: a report of the International Nutritional Anemia Consultative Group (INACG). Washington, D.C., The Nutrition Foundation, 1979. 49p.

16.DALLMAN, P.R. Iron deficiency and the immune response. Am. J. Clin. Nutr.,46:329-34, 1987 . 
17.DALLMAN, P.R. Iron deficiency: does it matter? J. Intern. Med.,226:36772,1989 .

18.DeMAEYER, E.M.; ADIELS-TEGMAN, M. The prevalence of anaemia in the world. Wld.Hlth. Statist. Quart., 38:302-16,1985.

19.DeMAEYER, E.M. Preventing and controlling iron deficiency anaemia through primary health care. Geneva, World Health Organization, 1989. $58 \mathrm{p}$.

20.DISLER, P.B. et al. The mechanism of the inhibition of iron absorption by tea. S. Afr. J. Med. Sci.,40:109-16,1975.2

21.FERRO-LUZZI, A. Meaning and constrain of energy intake studies in free-living populations. In: Harrison, G. A., ed. Energy and effort. London, Taylor \& Francis, 1982. p. 115-135.

22.FRISANCHO, A.R. Anthropometric standards for the assessment of growth and nutritional status. Ann Arbor, University of Michigan, 1990. 139 p.

23.FUJIMORI, E. Prevalência de anemia e deficiência de ferro em mulheres adolescentes do município de Taboão da Serra - SP (Brasil). São Paulo, 1988. 68 p./Tese (Mestre em saúde pública) - Faculdade de Saúde Pública da Universidade de São Paulo/.

24.FUNDAÇÃO INSTITUTO BRASILEIRO DE GEOGRAFIA E ESTATÍSTICA IBGE. Tabelas de composição dos alimentos. Rio de Janeiro, 1977. 201 p. (Estudo nacional da despesa familiar, v.3; publicações especiais,t.1)

25.GONZÁLEZ, L.J.; DUNKER, K.L.L.; SZARFARC, S.C. Consumo de leite e adequação da ingesta de cálcio. São Paulo, Faculdade Saúde Pública da USP, 1993. /mimeografado/

26.GUILLOUUD-BATAILLE, M. et al. Epidemiologie des anemies ferriprives dans une dependance de la Guadeloupe (Antilles Françaises). In: HERCBERG, S.; 
GALAN, P.; DUPIN, H.,ed. Aspects actuels des carences en fer et en folates dans le monde apud Colloque INSERM,197: 111-13, 1990.

27.GUNTHRIE, H.; CROCETTI, A. Variability of nutrient intake over a 3-day. period. J. Amer. Diet. Ass., 85:325-27,1985.

28.HALLBERG, L. Bioavailability of dietary iron in man. Ann. Rev. Nu.tr.,1:123-47,1981.

29.HALLBERG, L. Bioavailable nutrient density: a new concept applied in the interpretation of food iron absortion data. Am. .J. Clin. Nutr.,34:224247,1981 .

30.HALlBERG, L. Nutrição de ferro; trad. Sophia C. Szarfarc. RECEITA: Informativo sobre nutrição humana, edição especial,1. $20 \mathrm{p}$. /transcrição da palestra proferida em 17-12-1981 em São Paulo/

31.HALLBERG, L.; SCRIMSHAW, N.S. Iron deficiency and work performance. Washington, D. C., International Nutritional .Anaemia Consultative Group (INACG), $1981.53 \mathrm{p}$.

32.HALLBERG, L.; BRUNE, M.; ROSSANDER, L. Iron absortion in man: ascorbic acid and dose-dependent inhibition by phytate. Am. J. Clin. Nutr.,49:140-4,1989.

33.HALLBERG, L.; ROSSANDER-HULTHIN, L. Prevalence of iron deficiency in european countries and attempts to analyze possible causes of differences. Nutr. Prev. Dis.,44:94-105,1989.

34.HERBERT, V. Recommended dietary intakes (rdi) of iron in humans. Am. J. Clin. Nutr.,45:679-86,1987.

35. HERCBERG, S. et al. Evaluation du statut en fer et en folates d'un echantillon representatif de la population d'un departament de la region Parisienne. In: HERCBERG, S.; GALAN, P.; DUPIN, H. ed. Aspects actuels des carences en fer et en folates dans le monde apud Colloque INSERM,197:39-46,1990. 
36.HORNER, M.R. Avaliação da dieta. In: FUNDAÇÃO INSTITUTO BRASILEIRO DE GEOGRAFIA E ESTATÍSTICA - IBGE. Perfil estatístico de crianças e mães no Brasil: aspectos nutricionais, 1974 - 75 . Rio de Janeiro, IBGE/UNICEF, 1982. p.151-240.

37.HUNT, J.R. et al. Ascorbic acid: effect on ongoing iron absortion and status in iron depleted young women. Am. J. Clin. Nutr.,51:649-55,1990.

38.HUSAINI, M.A.; SUHARDJO; SCRIMSHAW, N.S. Field studies on work productivity in iron deficiency subjects, in west Java, Indonesia. In: HERCBERG, S.; GALAN, P.; DUPIN, H.,ed. Aspects actuels des carences en fer et en folates dans le monde apud Colloque INSERM, 197: 51521,1990 .

39.INSTITUTO NACIONAL DE ALIMENTAÇÃO E NUTRIÇÃO Considerações sobre anemia nutricional. Brasilia, D.F., 1986. 29 p.

40.INSTITUTO NACIONAL DE ALIMENTAÇ̃̃o E NUTRIÇÃO. Pesquisa nacional sobre saúde e nutrição. Perfil de crescimento da população brasileira de 0 a 25 anos. Brasília, D.F., 1990. 60 p.

41.INTERNATIONAL NUTRITIONAL ANEMIA CONSULTATIVE GROUP (INACG). Guidelines for the eradication of iron deficiency anemia. Washington, D.C., 1978. 29p.

42.ISHII, M. et al. Identificação e análise crítica da dieta habitual da população de baixa renda do Estado de São Paulo. RECEITA: informativo sobre nutrição humana, edição especial, 2. 1984. 16 p.

43.KIES, C.; BYLUND, D.M. Iron status of adolescent boys and girls as influenced by variations in dietary ascorbic acid and iron intakes. Nutr. Rep. Int., 40:43-51,1989.

44.KNOBEL, M. Caracteristicas y problemas de la psicologia de los adolescentes. In: CUSMINSKY, M.; MORENO, E.M.; SUAREZ OJEDA, E.N. ed. 
Crecimiento y desarrollo: hechos y tendencias. Washington, D.C., OPS, 1988. p. 453-61. (OPS Publicacion cientifica,510)

45.LAMPARELLI, R.D.V. et al. Nutritional anaemia in 11-year old schoolchildren in the western Cape. S. Afr. Med. J. Sci.,73:473-76,1988.

46.LAYRISSE, $M$. et al. Requerimientos de nutrientes que participan en la eritropoyesis. Arch. Lat. Amer. Nutr.,30:622-46,1988.

47.LEI, D.L.M. Estudo antropométrico da evolução do estado nutricional de crianças beneficiárias de um programa de suplementação alimentar. São Paulo, 1986. 107 p. /Tese (mestre em saúde pública) - Faculdade de Saúde Pública da Universidade de São Paulo/

48.LLEWELLYN-JONES, D. Severe anaemia in pregnancy. Aust. N. Z. J. Obstet. Gynaec.,5:191-197,1965.

49.MacGREGOR, M.W. Maternal anaemia as a factor in prematurity and perinatal mortality. Scot. Med. J.,8:134-40,1963.

50.MONSEN, E.R.; BALINTFY, J.F. Calculating dietary iron bioavailability: refinement and computerization. J. Amer. Diet. Ass.,80:307-11,1982.

51.MONTEIRO, C.A. et al. Estudo das condiçōes de saúde das crianças do Município de São Paulo,SP.(Brasil), 1984-1985. I-Aspectos metodológicos, características sócio - econômicas e ambiente físico. Rev.Saúde Públ.,20:43545,1986 .

52.MONTEIRO, C.A.; SZARFARC, S.C. Estudo das condiçōes de saúde das crianças no Município de São Paulo, SP (Brasil), 1984-1985. V-Anemia. Rev. Saúde Públ.,21:255-60,1987.

53.MONTEIRO, C.A., coord. Coleta e análise da altura de escolares em um sistema de vigilância nutricional: desenvolvimento de metodologia, implantação e avaliação. São Paulo, Faculdade de Saúde Pública, 1989. 56 p. /Relatório Técnico mimeografado/ 
54.NUSSENZVEIG, I. et al. Prevalência de anemia e de parasitoses intestinais em escolares do Município de São Paulo. Resultados do emprego da merenda escolar e de drogas antiparasitárias. Rev. Paul. Med.,100:32-9,1982.

55.ORGANIZACION MUNDIAL DE LA SALUD. Problemas de salud de la adolescencia. Ginebra, 1965. 29 p. (OMS. Serie de informes tecnicos, 308) 56.ORGANIZACIÓN MUNDIAL DE LA SALUD. Anemias Nutricionales. Ginebra, 197232 p. (OMS Serie de informes tecnicos, 503)

57. ORGANIZACIÓN MUNDIAL DE LA SALUD. Lucha contra la anemia nutricional, especialmente contra la carencia de hierro. Ginebra, 1975. 71 p. (Serie de informes tecnicos, 580)

58.ORGANIZACIÓN MUNDIAL DE LA SALUD. Medición del cambio del estado nutricional: directrices para evaluar el efecto nutricional de programas de alimentación suplementaria destinados a grupos vulnerables. Ginebra, 1983. $105 \mathrm{p}$.

59.ORGANIZACIÓN MUNDIAL DE LA SALUD. Necesidades de energia y de proteinas. Ginebra, 1985. 220 p. (OMS. Serie de informes tecnicos,724). 60.ORGANIZACIÓN PANAMERICANA DE LA SALUD. La salud del adolescente y el joven en las Americas. Washington, D.C., 1985. 37 p. (OPS. Publicvación cientifica, 489).

61.PEDRAZZANI, E.S. et al. Helmintoses intestinais II. Prevalência e correlação com renda, tamanho da familia, anemia e estado nutricional. Rev. Saúde Públ., 22:384-9,1988.

62.PERSSON, L.A.; CARLGREN, G. Measuring children's diets: evaluation of dietary assessment techniques in infancy and childhood. Int. J. Epidemiol., 13:506-17,1984.

63.PLANO estrutural do município de Osasco, 1986: documento preliminar. Osasco, escritório de Planejamento integral, 1986. 234 p. /mimeografado/ 
64.POLLITT, E. et al. Iron deficiency and cognitive test performance in preschool children. Nutr. Behav., 1:137-46,1983.

65.POLLITT, E. et al. Cognitive effects of iron deficiency anaemia. Lancet,1:158,1985.

66.POLLITT, E. et al. Iron deficiency and behavioral development in infants and preschool children. Amer. J. Clin. Nutr.,43:555-65,1986.

67.POLLITT, E. Functional effects of iron deficiency anemia and the role of context. In: HERCBERG, S.; GALAN, P.; DUPIN, H., ed. Aspects actuels des carences en fer et en folates dans le monde apud Colloque INSERM,197: 553-58, 1990.

68.PREZIOSI, P. et al. Facteurs alimentaires determinants du statut en fer: etude de population. In: HERCBERG, S.; GALAN, P.; DUPIN, H., ed. Aspects actuels des carences en fer et en folates dans le monde apud Colloque INSERM, 197:307-10,1990.

69.RAMDATH, D.D.; GOLDEN, M.H.N. Non-haematological aspets of iron nutrition. Nutr. Res. Rev.,2:29-49,1989.

70.RATTEN, G.J.; BEISCHER, N.A. The significance of anaemia in an obstetric population in Australia. J. Obstet. Gynaec. Brit Cwlth,79:228-37,1972.

71.ROYSTON, E. The prevalence of nutritional anaemia in women in developing countries: a critical review of available information. WId. HIth. Statist Quart.,35:59-91,1982.

72.RUIZ,T. et al. Prevalência de parasitismo intestinal e anemia em escolares da Micro-Região de Viçosa. In: CONGRESSO LATINOAMERICANO DE NUTRICIÓN, 7, Brasília, D.F. 1984.

73.SADDI, R.; SCHAPIRA, G. Iron requirements during grow. In: HALLBERG, L. et al. Iron deficiency, pathogenisis, clinical aspects and theraphy. London, Academic Press, 1970. 
74.SANCHEZ, E.M.C.; BARROS, M.D.; MELLO, P.R.B. Anemia em pessoas da cidade de Cáceres e suas relações com a renda per capita. Rev. Inst. Med. Trop. S. Paulo,30:165-68,1988.

75.SÃO PAULO (Estado) Secretaria de Estado de Planejamento e Gestão. Empresa Metropolitana de Planejamento da Grande São Paulo SA. Sumário de dados da Grande São Paulo, 1992. São Paulo, 1993. 240 p.

76.SCHOENE, R.B. et al. Iron repletion decreases maximal exercise lactate concentration in female athletes with minimal iron-deficiency anaemia. J. Lab. Clin. Med.,102:306-12,1983.

77.SCHUTZ, H.G. Prediction of nutritional status from food consumption and consumer attitude data. Am. J. Clin. Nutr.,35:1310-18,1982.

78.SICHIERI, R.; SZARFARC, S.C.; MONTEIRO,C.A. Relação entre dieta e ocorrência de anemia ferropriva em crianças. J. Pediat.,64:169-74,1988.

79.SIGULEM, D.M. et al. Anemia ferropriva em crianças do Município de São Paulo. Rev. Saúde Públ.,12:168-78,1978.

80.SOEMANTRI, A.G.; POLLITT, E.; KIM, I. Iron deficiency anaemia and educational achievement. Am. J. Clin. Nutr.,42:1221-28,1985.

81.STECKEL, A. The planning of an intervention program: a case study. In: DALLMAN, P.R.; SIIMES, M.A. Iron deficiency in infant and childhood: a report of the International Nutritional Anemia Consultative Group (INACG). Washington, D.C., The Nutrition Foundation, 1979. cap.8, p.44-7.

82.STEFANINI, M.L.R. et al. Anemia: estudo de prevalência em escolares da rede pública do município de Osasco, São Paulo - Brasil. /no prelo/.

83.SZARFARC, S.C. Prevalência de anemia nutricional entre gestantes matriculadas em Centros de Saúde do Estado de São Paulo, São Paulo, 1983. 110 p. $\quad$ /Tese - Faculdade de Saúde Pública da Universidade de São Paulo/ 
84.SZARFARC, S.C. A anemia nutricional entre gestantes atendidas em Centros de Saúde do Estado de SÃo Paulo (Brasil). Rev.Saúde Públ.,19:450-7,1985.

85.SZARFARC, S.C. Diagnóstico de deficiência de ferro na infância. Rev. Saúde Públ., 19:278-84,1985.

86.TABLA de composición de alimentos para uso en America Latina, INCAP ICNND. In: BURTON, B.T. Nutrición Humana: un tratado completo sobre nutrición en la salud y la enfermedad. Washington, D.C., OPS, 1966. p. 461-600. (OPS. Publicación cientifica, 146)

87.TRUGO, N.M.F. et .al. Evaluation of iron and folate status in urban brazilian mothers of low socioeconomic status and their infants. In: HERCBERG, S.; GALAN, P.; DUPIN, H., ed. Aspects actuels des carences en fer et en folates dans le monde apud Colloque INSERM,197:95-8,1990.

88.VALLADA, E.P. et al. Distribuiçào dos níveis de hemoglobina em crianças, adultos e idosos na população de Sorocaba apud SANCHEZ, E.M.C. et al. Anemia em pessoas da cidade de Cáceres e suas relaçōes com a renda per capita. Rev. Inst. Med. Trop. S Paulo,30:165-8,1988.

89.VANNUCCHI, H. et al. Aplicaçōes das recomendaçōes nutricionais adaptadas à população brasileira. Cadern. Nutr.,2:1-156,1990.

90.VANNUCCHI, H.; FREITAS, M.L.S.; SZARFARC, S.C. Prevalência de anemias nutricionais no Brasil. Cadern. Nutr.,4:7-26,1992.

91.VEIGA, G.V. Contribuição ao estudo da obesidade em adolescentes do sexo feminino: uma avaliação comparativa entre os dois níveis sócio-econômicos. São Paulo, 1992. 163 p. /Tese - Escola Paulista de Medicina/.

92.VIGLIETTI, G.C.; SKINNER, J.D. Estimation of iron bioavailability in adolescents' meals and snacks. J.A.D.A.,87:903-8,1987. 
93.VISWESWARA RAO, K.; RADHARAH, G.; RAJU, S.V.S. Association of growth status and the prevalence of anaemia in preschool ch.ildren. Indian J. Med. Res., 71:237-246,1980.

94.VITERI, F.E.; TUNA, V.; GUZMÁN, M.A. Normal haematological values in the Central American population. Brit. J. Haemat.,23:189-204,1972.

95.VITERI, F.E.; TORUN, B. Anaemia and physical work capacity. In: GARBY, L., ed. Clinics in haematology, London, W.B. Saunders, 1974. v.3.,p.609-26

96.WALTER, T. et al. Iron deficiency anaemia: adverse effects on infant psychomotor development. Pediatrics,8.4:7-17,1989.

97.WATERLOW, J.C. Note of the assessment and classification of protein-energy malnutrition in children. Lancet, 2:87-9,1973.

98.WATERLOW, J.C. Some aspects of chilhood malnutrition as a public health problem. Brit. Med. J.,4:88-90,1974.

99.YUSUFJI, D. et al. Iron, folate and vitamin $B_{12}$ nutrition in pregnancy:study of 1000 women from Southern India. Bull. Wld. Hith. Org.,48:15-22,1973.

100.ZURAYK, H.; HALABI, S.; DEEB, M. Measures of social class based on education for use in health studies in developing countries. J. Epidemiol. Comm. Hlth.,41:173-179,1987. 
Anexo 1 
São Paulo, 12 de Outubro de 1990.

Prezados Pais,

A anemia é um problema de saúde muito importante que vem atingindo quase metade da populaçăo de nossas cidades. Entre escolares esse problema é muito grave porque leva os jo vens a se tornarem distraidos, cansados, sem vontade de fazer muitas coisas, com pouca capacidade de aprender e com resistência baixa às infecçōes. Assim sendo estamos medindo o nivel de anemia entre os alunos da classe de seu filho. Para tanto solicitamos a sua autorização para realizar esse exame, que será feito com uma picada de agulha no dedo. O material usado será totalmente descartável. O resultado do exame será enviado à escola dentro de 15 dias depois do dia do exame.

\section{Atenciosamente,}

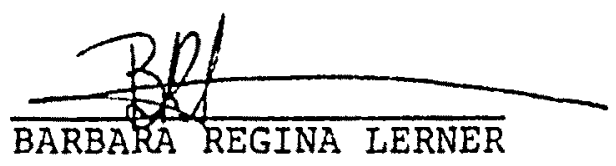

Data 11990

Autorizo o exame de anemia em meu filho

Nome do aluno

Classe

Nome do responsável

Assinatura 
Anexo 2 
2001

Sä Faula, dEzEmtio d5 1990

Caro(a) Ilaniel Afonso Fiartiosa

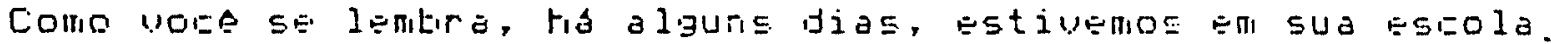
para coltis dados para un setujo sotire finEmift. Gostariamos Je agradever a sua ualiosa zolatorago, aprousitando fara informar os resultados dos axames realizados.

Sev peso $453,6 \mathrm{~kg}=$ sua altura $6172,9 \mathrm{~km}$.

o resultado do sev Exami ge sanguefoi "n

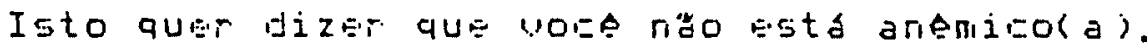

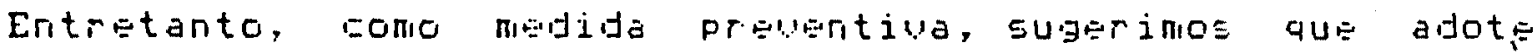
a lyuns riálitos na rora di suas refeisose.

Froigure gomer aljuma verjura de foltia esgura no almogo ou no jantar E una fruta como sobremesa. Ileixe os Jo:ses para conier nos intervalos das refeisoses, rôo esquendo de escovar os dentes para evitar as báries. Ss poseluel, proure ingerir algun tipo de Earnis, ou mortajela, ou lingeica, ou franzo, ou peixe, pelo menos uná vez pot dia.

Mostre estes rosultados para seus pais ou resfonsáuis, a proizuresesulir as orientabos doima.

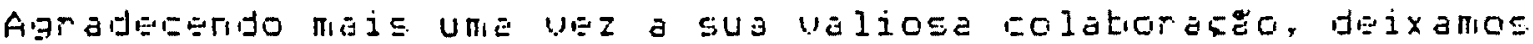
aqui o nosso abía singera a wose e e sua escola,

Contia Inonte,

Fiartiara Fiagina Leringr

Fiesquisador Cisintifico

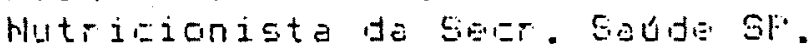


Anexo 3 
3111

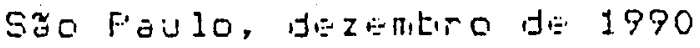

Carosa) Willians da S. Oliusira

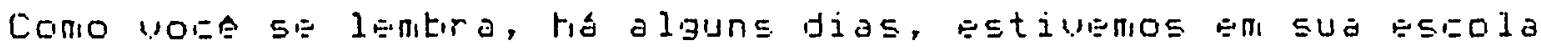
para coltier gados para un Estudo sotire AlEMIA. Gostariamos. Jo agrader a sua ualiosa rolatioraro, aprousitando fara infornar os resultados dos exanus realizados.

SEU PESO \& 44,8 K. E sua altura $\Leftrightarrow 150,7$ E.

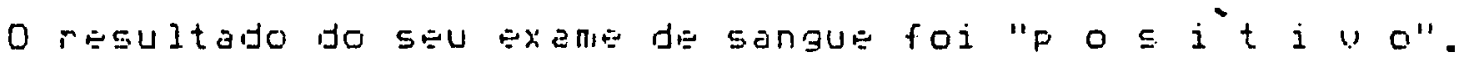

Isto quet dizer que vole esta bom uma leve anemia. .

Hăo nado graue. Entretanto sugerimos que passe a adotar alguns hábitos rá hora de suas refeisedes, que deuen resoluer $\because$ cts protilema.

Froeure comer a lauma verdura de foltia eseura no a lmogo ou no

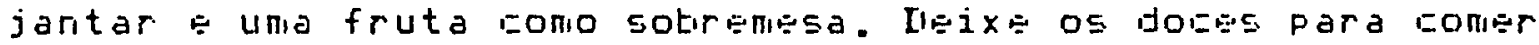
nos intervalos das refeicoss, nzo esquesendo de ssouar os dentes para euitar as baries. Se possluel, probure inaerir. algun tifo de sarne, ou mortalela, ou linglica, ou frango, ou pEixe, pElo menOE uma vez por bia.

Mostre estes resultajos fara seus pais ou responsáuis, E. prabure soguir as orientabos arima.

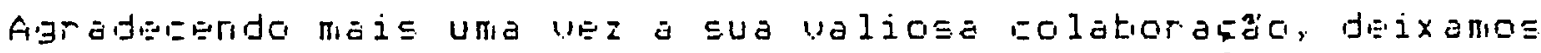

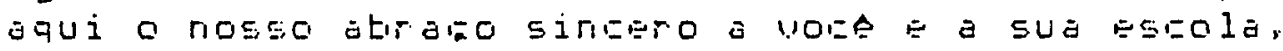

Conjia lment:

Bätuara Figgina Lernet

Fesquisador Cititifico

Hutrigionista da SEgr. Saude SF. 


\section{Anexo 4}


Prezado estudante

Estamos realizando, na sua série, um estudo sobre a alimentação dos escolares adolescentes.

A alimentação $\triangleq$ um fator :undarental para a saúde dos individuos. 3 partir do connecimento da alimentação é possivel icentificar a sua aciequação e, propor modificações capazes de prevenir pioblemas de saúde que poderiam aparecer quario a alimentação não esta correta.

Dois dos problemas mais coiluiss entre adolescentes estão diretzmente asscaiados à alimentação. São cles, o baixo peso e a peouená iltura para a irade $=2$ anemia, relacionados, respecivamente, con a quanticiade e o tipo de alimentos consumicios.

Este trabalho pretende conhecer a alimentação de vocês com a finalicade do propor orientaça alimentar adequada, se for necessário.

Assim sendo, pedimos a sua colaboração, no sentido de fornecer as informaçōes solicitadas.

Para conhecez a sua alimentação, é necessário que vocês anotem todos os alimentos que comerem, nos dias determinados no questionario que vocês vão leval peya casa.

i muito importante que vocess anotem todos os alimentos, mesmo aqueles que não parecer: importantes, como balas, pipoca, chicletes ou verduras. D quantidade também deverá ser arotacia, en medidas fáceis, como: uma colher de sopa, um pacote, um sopo, uma fatia grande, uma fruta pequena, etc.

Em seguida estí um exemplo de como devem ser anotados os aiimentos que vocês comeram. Se for possivel, é bom anotar logo derois da refeição. Se não for possivel, anotem no fim do dia, mas sen esquecer de nada - todos os alimentos são importartes, assim como a anotação da hora em que foi comido - o local - em casa, na casa de alguém, na escola, na iancinonete, no restaurante, etc.

$0=$ resuitados obtidos serão enviados, oportunamente, para a slia escola, acompanhados das orientaçōes que se fizerem necessárias. 
A AIIMENTAÇEO NA DETEREINAÇO DA ANEMIA CARRENCIAI EP IDOLFSCINTES

PEGISTRO DIA:TO DE AIIHEHTOS

EXEMPLO

110. 40

DINS A BETER REGIBTRADOS
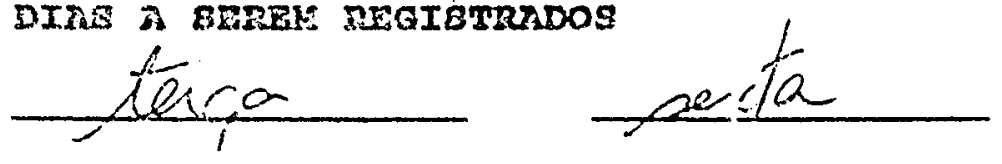

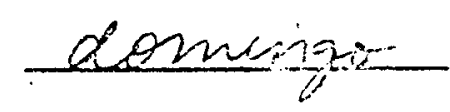

Tontificação

WOHE TOANINHA CATNEIRO

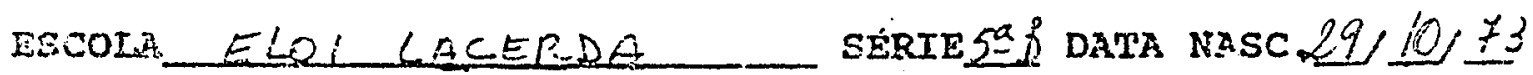

MOEE DO FAT TOEO DA SLVA CARNEIRO

Seu pai estuaiou ate gue ano? 40 GLNA'S 10

MORE DA KAE TOANA CARNETRO

Sua mãe estudou ate que ano? 2LCOLEG/AL

As folnas a seguix são para anctar totos os alimentos gua voce coner nos dias da semana marcaāos ne parte de cima doste ugestionirio. 

Data $2,3 / 10 / 90$
Die cia semana
30
$48 \quad 12$
Hora
LecaI
Alimento
Quantidade

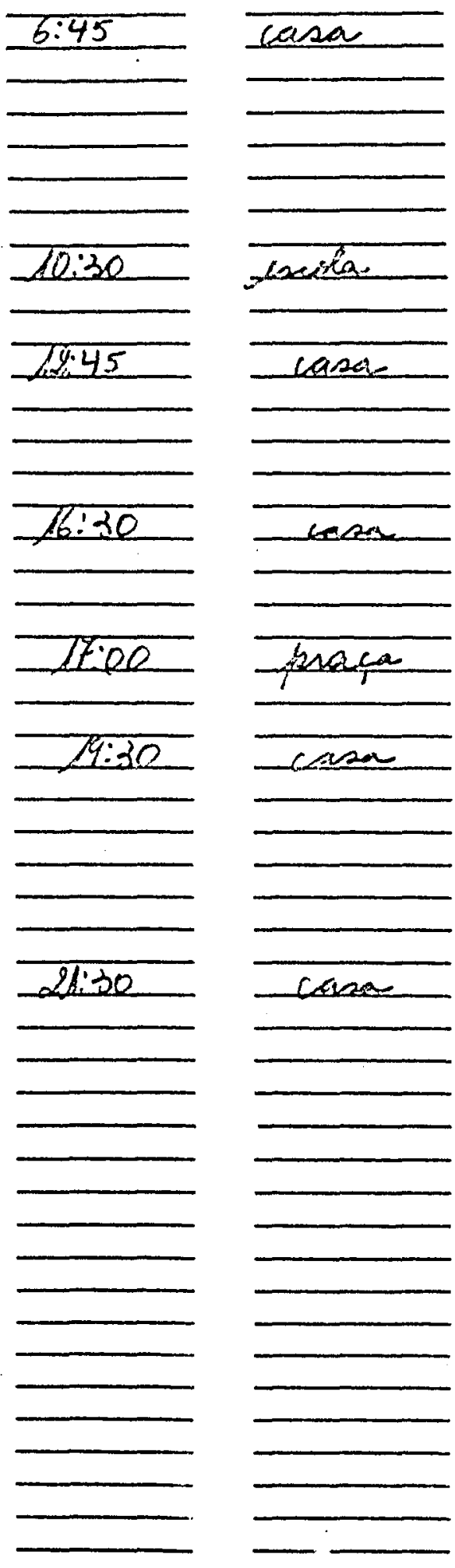

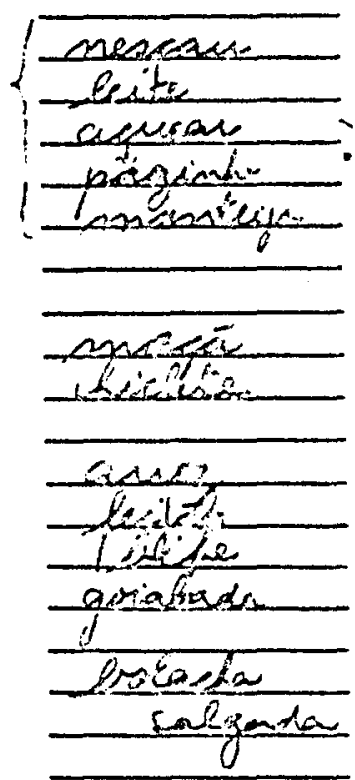

opupe

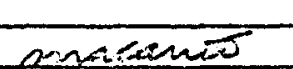

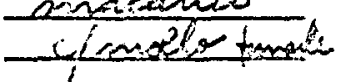

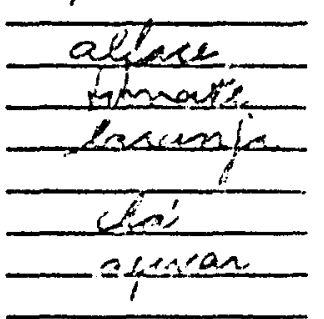

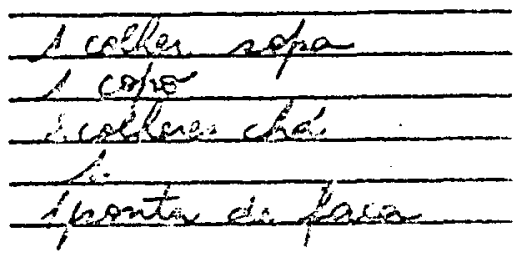
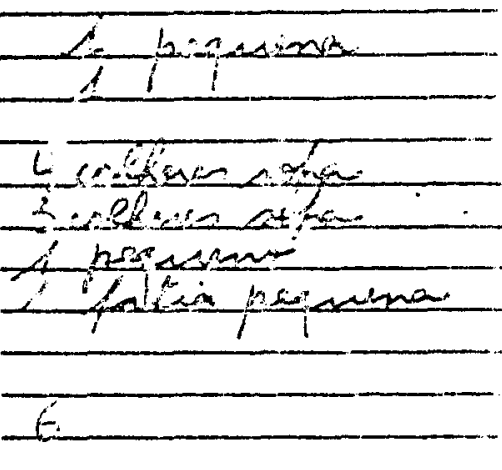

$\frac{1}{1}+x_{2} x^{2}$

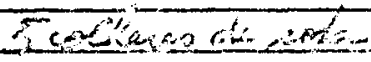

$320 f^{4}$

Stribla

4hesponaro

Coso

Senhoes sitena 
A AJIMENTAÇÃO NA DETERMINAÇÃO DA ANEMIA CARENCIAL EM ADOLESCENTES

REGISTRO DIÁRIO DE AIIMENTOS

No.

DIAS A SEREH REGISTRADOS

segunda
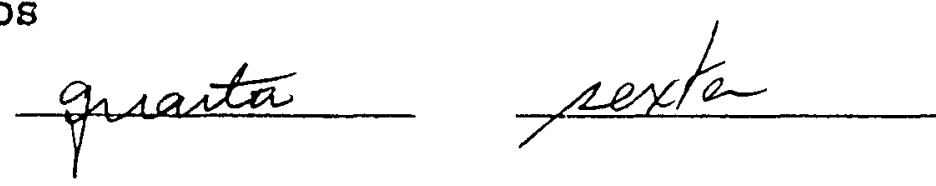

Iàentificação

NOME

Escoris

SÉRIE

DATA NASC.

NOME DO FAI

Seu pai estudou ate que ano?

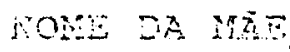

Eive mà estudou até que ano?

As folnas a seguir são para anotar todos os ajimentos que vocé comer nos dias da semana marcados na parte de cima deste questionario. 
Data

1

Hora

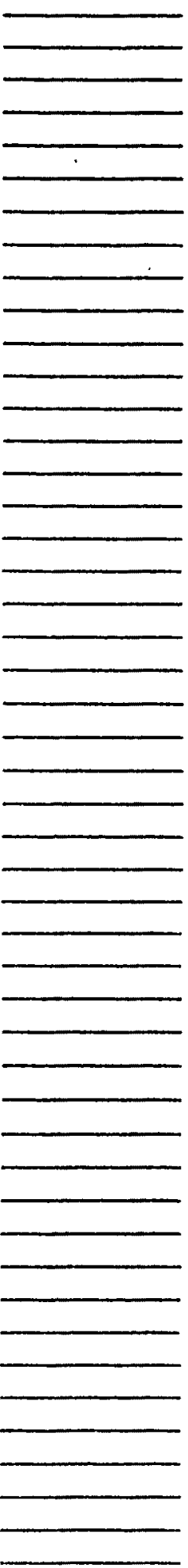

Dia da semana

1

Alimento

Quantidade 
Data

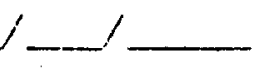

Hora

Local

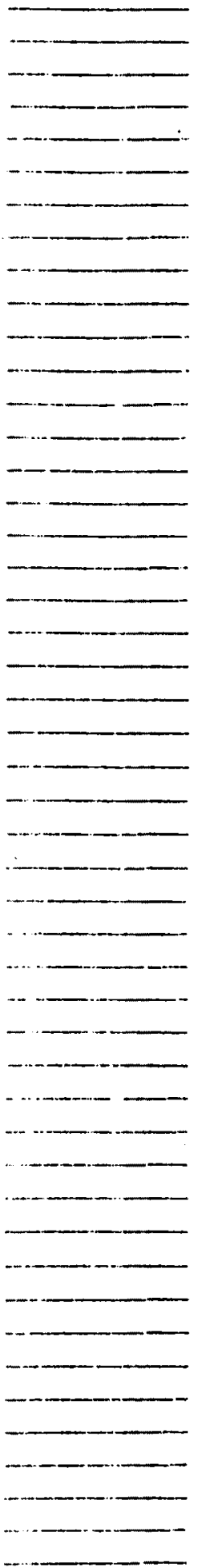

Dia da semana 12
Alimento Quantidade

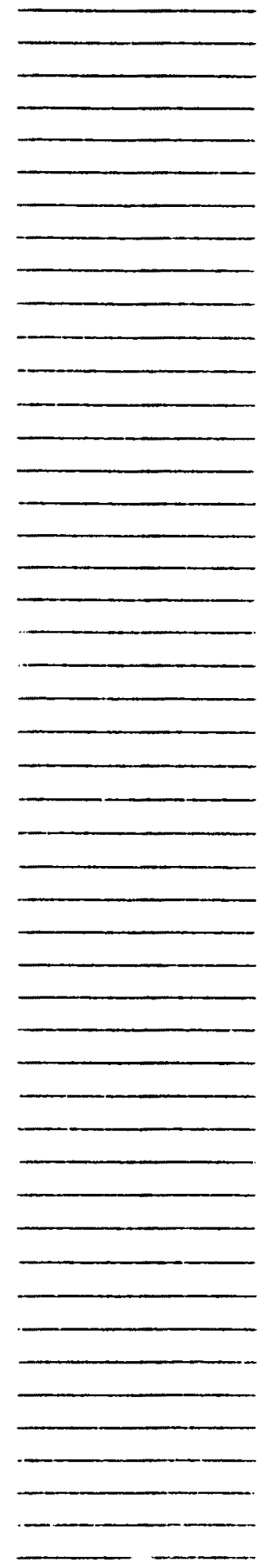

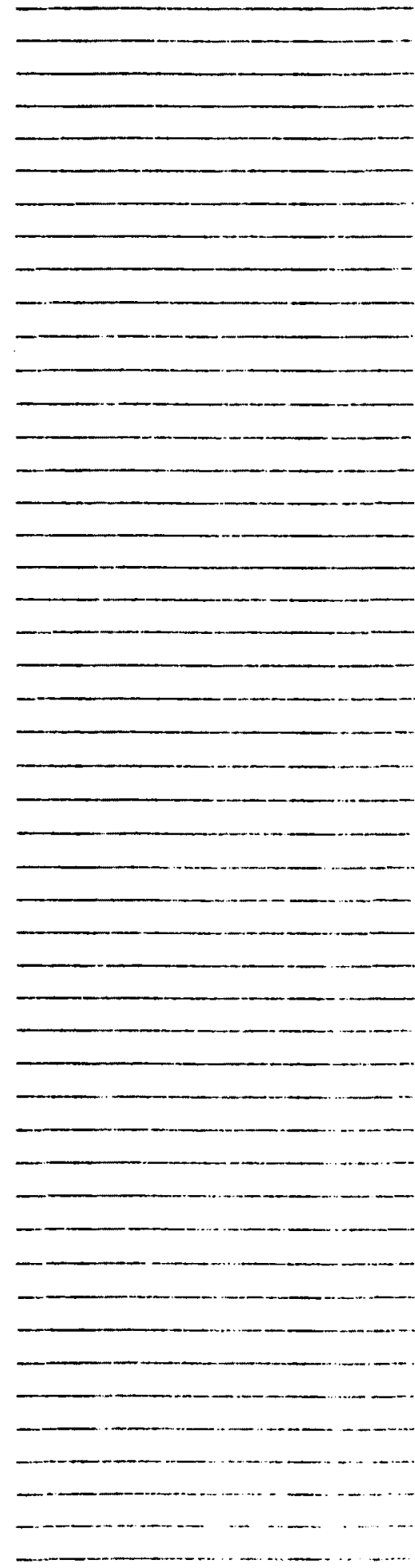




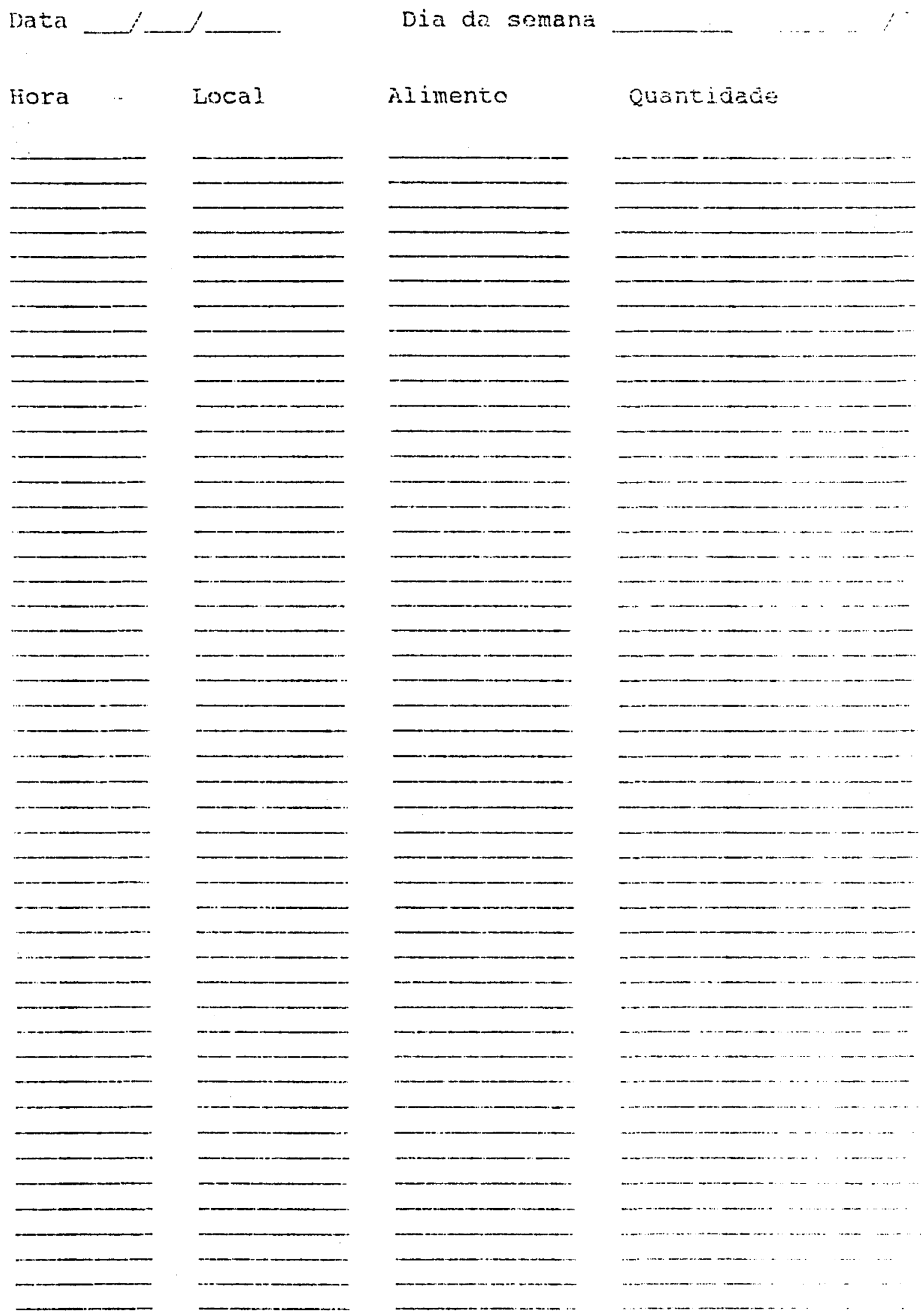


Anexo 5 
A ALIMENTAÇÃO NA DETERMINAÇÃO DA ANEMIA CARENCIAL EM ADOLESCENTES

HISTÓRICO ALIMENTAR E AVALIAÇÃO DO ESTADO NUTRICIONAL

No.

NOME

ESCOLA

SERIE

DATA NASC.

IDADE

SEXO

MENSTRUOU? $\mathrm{N}$

$S$

QUANDO? anos

ALIMENTAÇÃO:

o que você costuma comer e beber...

I- No café da manhä?

ALIMENTO

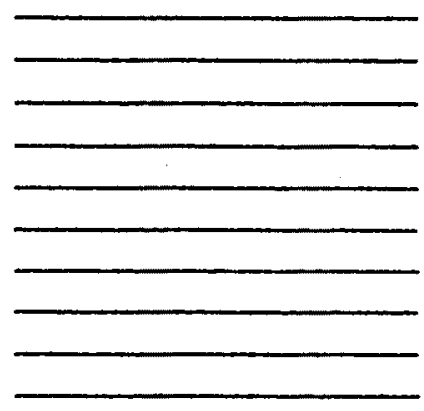

onde?
QUANTIDADE

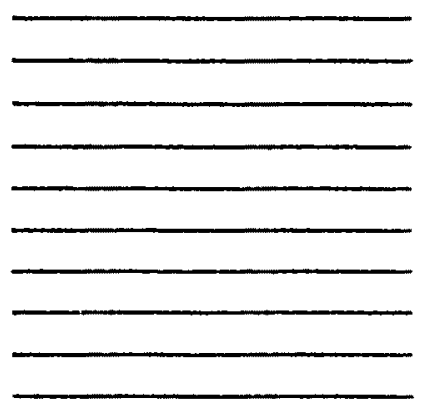

A que. horas?

FREQ./sen (dia, mes)

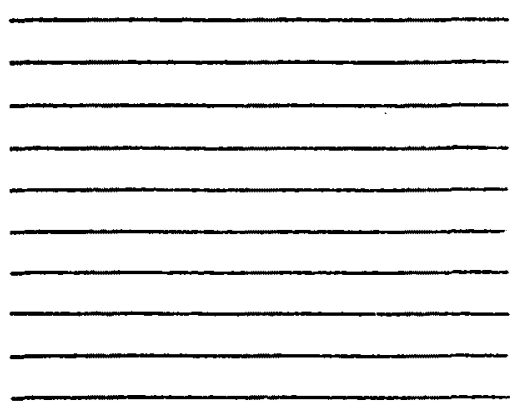
? 
2-. No almoco?

No.

Al, MENTO

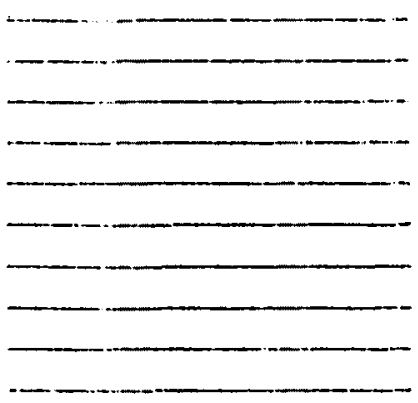

onde?

3- No jantar?

ALIMENTO

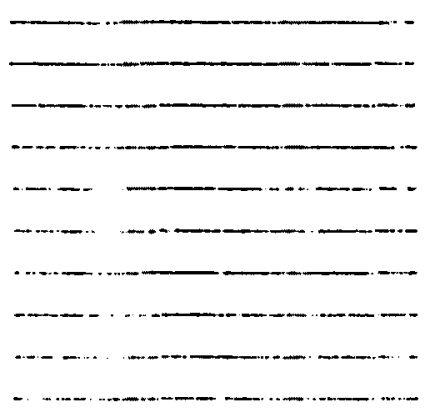

Cndo?
QUANTIDADE

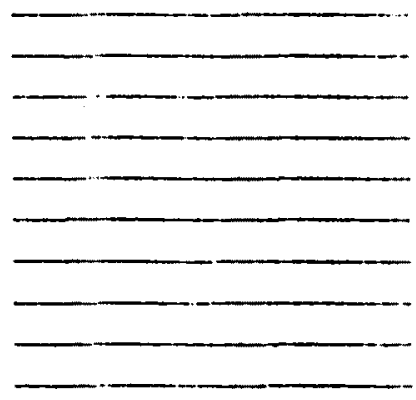

A que hora:?
FREQ $/$ /Sen $(\dot{x}$ s. $:$

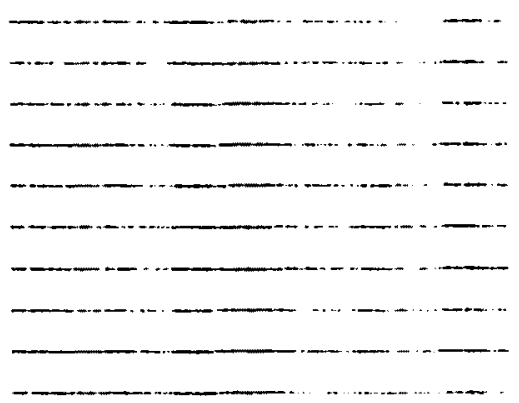

QUANTIDADE

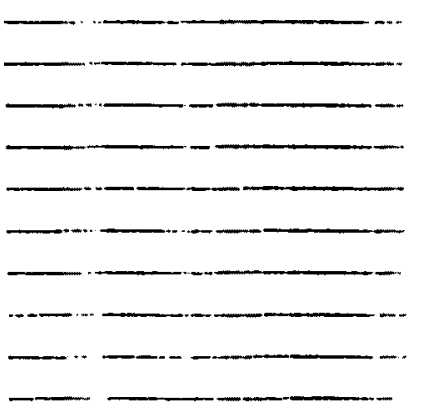

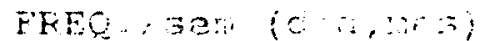

A que horas?

costuma comer ou beber alguma coisa entro...

4- O café da manhá e o almoço? I

AL [MENTO

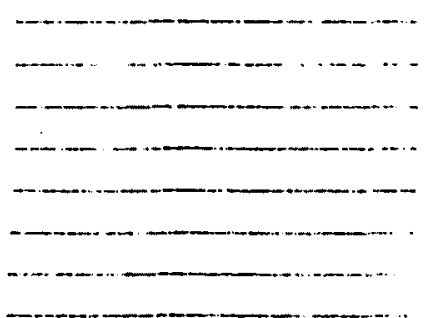

onde?
OUANTIDRET:

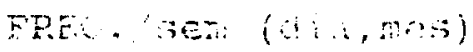

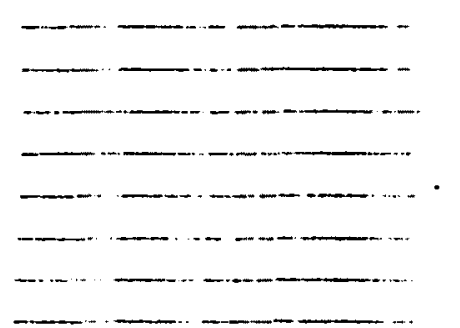

$\therefore$ Gue hora? 


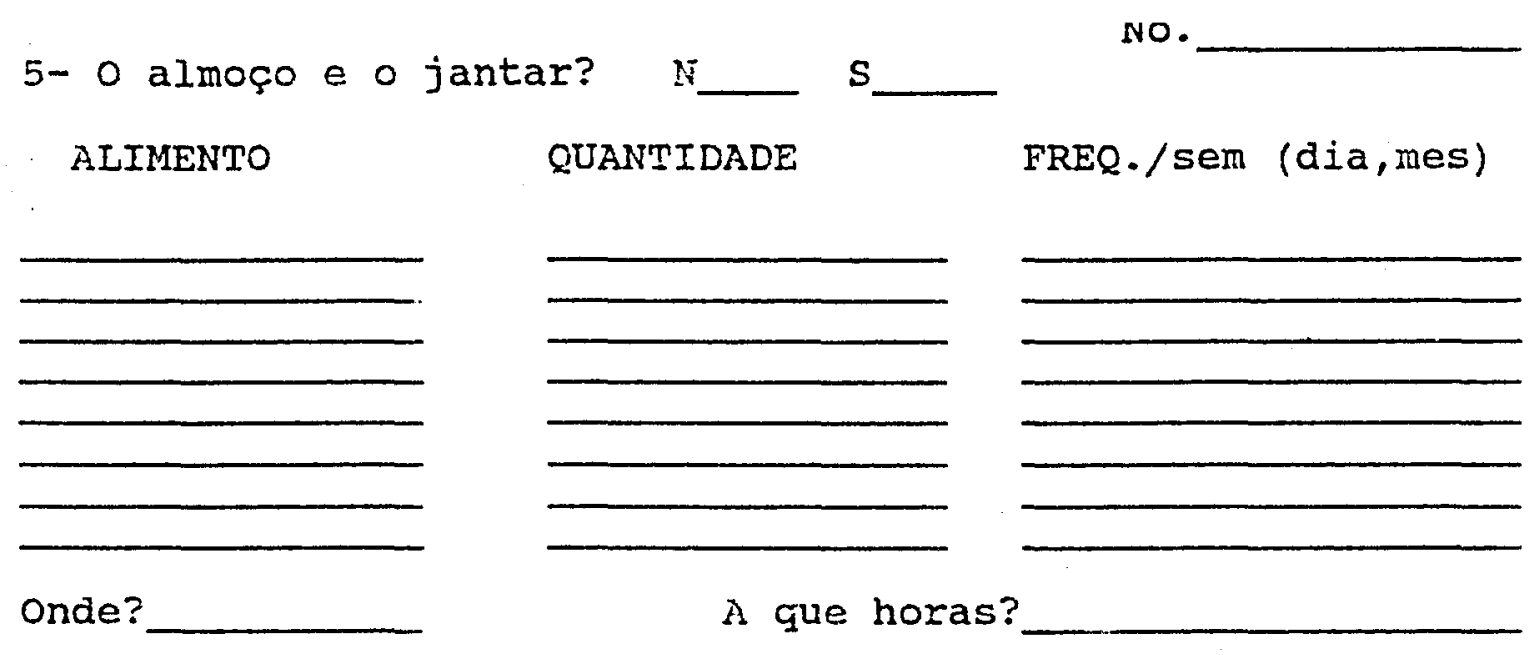
6- O jantar e horário de dormir? N__ S
ALIMENTO
QUANTIDADE
FREQ./sem (dia, mes)

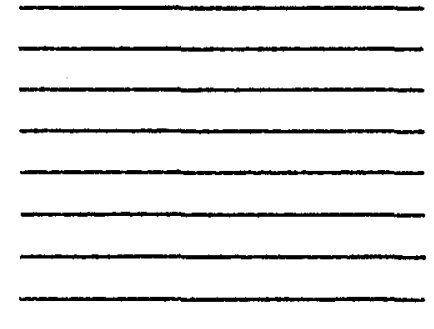

onde?

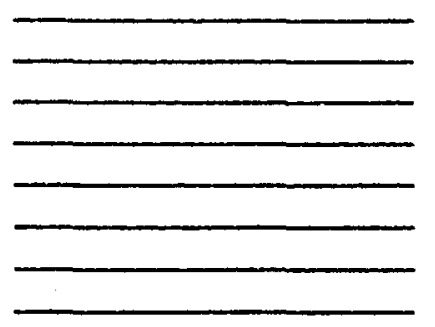

A que horas?

7- Você come ou bebe alguma coisa em outras horas do dia? $\mathrm{N}$

BLIMENTO

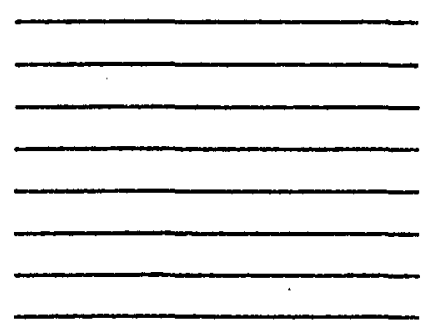

onde?

$$
\text { QUANTIDADE }
$$

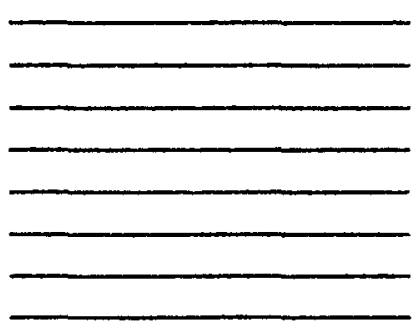

is que horas?

FREQ./sem (dia, mes)

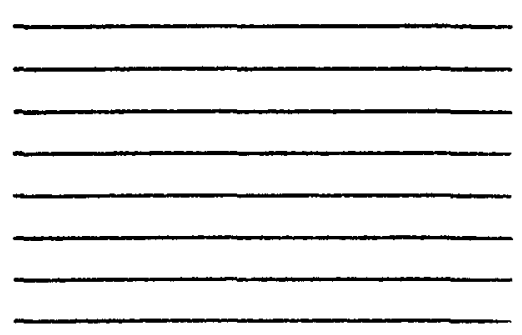

$$
\text { ? }
$$


Ho.

8- Você costuma comer algum alimento alem desses ji mencionados? $\mathrm{N}$ s

ALIMENTO

QUANTIDAD:

FREQ-/sen (cia,mes)

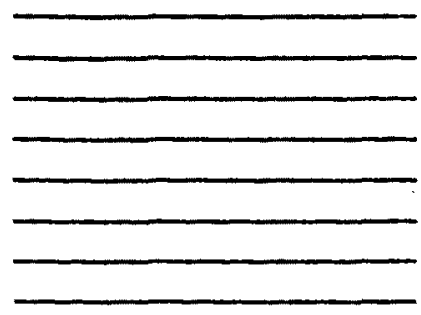

onde?

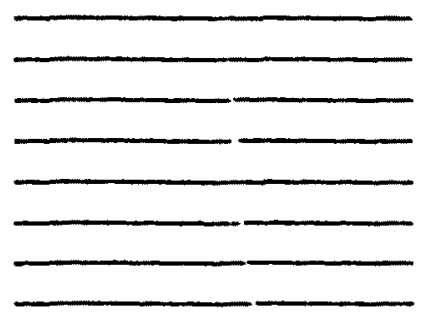

A cue horas?

9- Quais são as suas atividades em um dia de semana normal? (descrever as atividades de casa, escola, trabalio e lazer)

ATIVIDADE

IIANHĀ

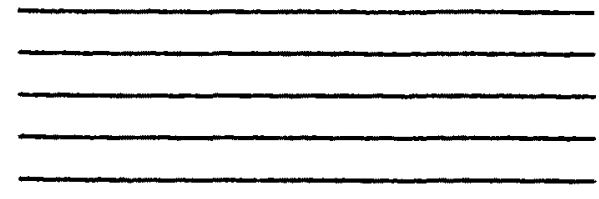

TARDE

NOITE
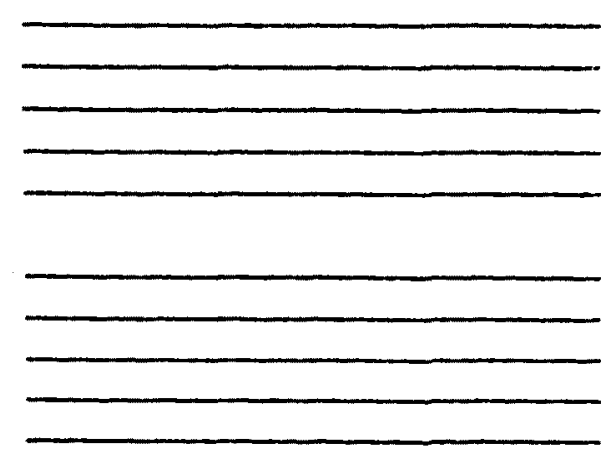

PERTODO EM HORAS E DIAS ISEMANA

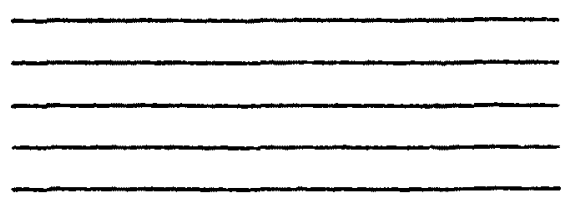


No.

10- o que você faz nos sábados?

ATIVIDADE

MANHÃ

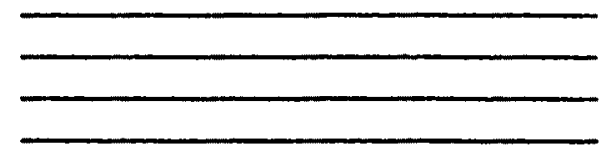

TARDE

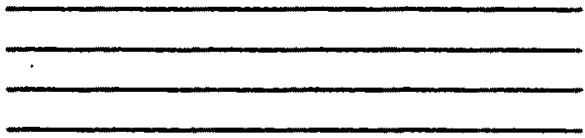

NOITE

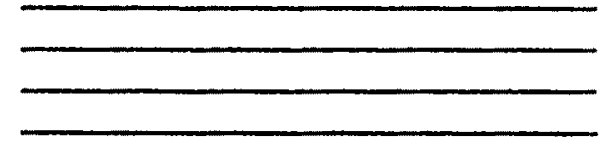

II- O que você faz nos domingos? ATIVIDADE

MANHÃ

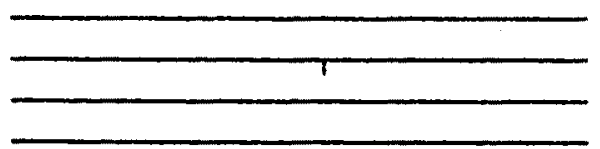

TARDE

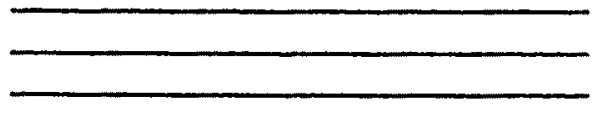

NOITE

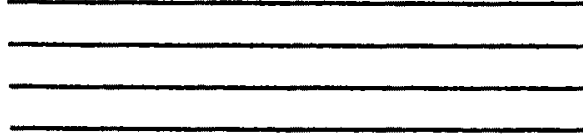

PERIODO EM HORAS
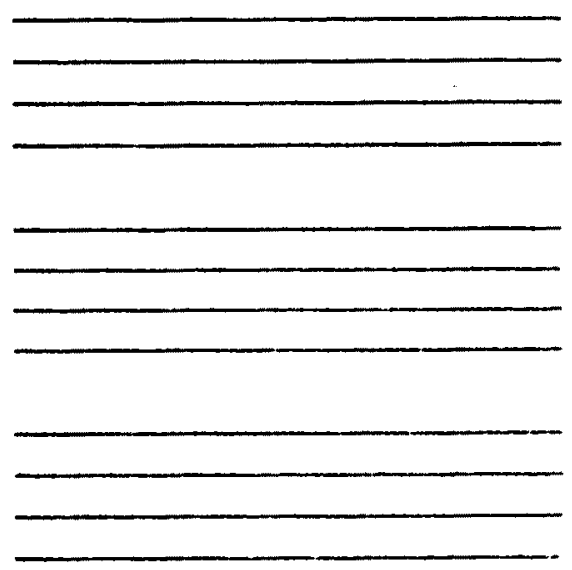

PERIODO EH WORAS
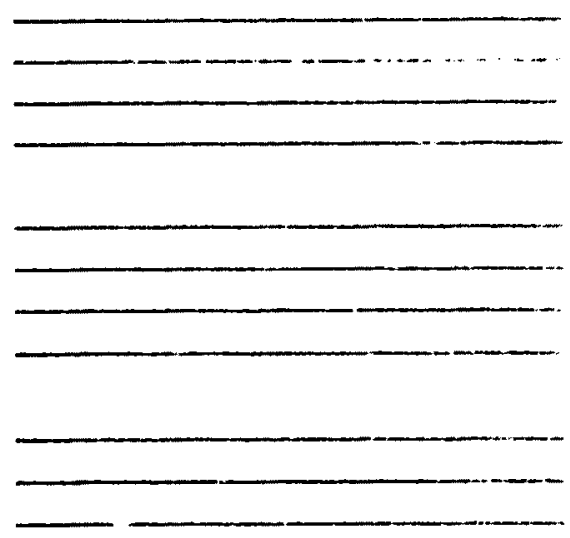

12- Você costuma fazer alguma outra atividade fisile que ainda não mencionou? Não Sim

Qual?

onde?

Quando?

Quanto tempo?

Data da entrevista ______ Entrevistaxor 
Anexo 6 
Número de alunos e classes segundo as séries de 12 grau das escolas selecionadas Osasco - 1990

\begin{tabular}{|c|c|c|c|c|c|c|c|c|}
\hline \multirow[b]{2}{*}{ ESCOLA } & \multirow[b]{2}{*}{12} & \multirow[b]{2}{*}{$2:$} & \multicolumn{2}{|c|}{$\begin{array}{c}s \text { é } r \text { i e s } \\
\text { (Alunos/classes) }\end{array}$} & \multirow[b]{2}{*}{52} & \multirow[b]{2}{*}{$6:$} & \multirow[b]{2}{*}{$7 !$} & \multirow[b]{2}{*}{$8:$} \\
\hline & & & 32 & $4:$ & & & & \\
\hline 1 & $145 / 04$ & $264 / 08$ & $144 / 05$ & $110 / 03$ & $149 / 04$ & $79 / 02$ & $66 / 02$ & $36 / 01$ \\
\hline 2 & $104 / 03$ & $126 / 04$ & $107 / 03$ & $106 / 03$ & $101 / 03$ & $72 / 02$ & $26 / 01$ & $19 / 01$ \\
\hline 3 & $148 / 04$ & $192 / 06$ & $154 / 04$ & $99 / 03$ & $79 / 02$ & $68 / 02$ & $56 / 02$ & $21 / 01$ \\
\hline 4 & $222 / 06$ & $308 / 08$ & $201 / 05$ & $127 / 03$ & $85 / 02$ & $65 / 02$ & $12 / 01$ & $21 / 01$ \\
\hline 5 & $245 / 08$ & $194 / 06$ & $208 / 06$ & $146 / 05$ & $179 / 05^{*}$ & $107 / 03^{*}$ & $135 / 04^{*}$ & $106 / 03^{*}$ \\
\hline .6 & $356 / 11$ & $498 / 14$ & $269 / 07$ & $178 / 05$ & $327 / 08^{*}$ & $196 / 05^{*}$ & $157 / 04^{\star}$ & $134 / 04^{\star}$ \\
\hline 7 & $101 / 03$ & $151 / 05$ & $108 / 03$ & $109 / 03$ & $124 / 03^{*}$ & $126 / 04^{\star}$ & $89 / 03^{*}$ & $60 / 02^{*}$ \\
\hline 8 & $180 / 05$ & $176 / 05$ & $161 / 04$ & $161 / 04$ & $168 / 04$ & $134 / 03$ & $146 / 03$ & $124 / 03$ \\
\hline TOTAL & $1051 / 44$ & $1909 / 56$ & $1352 / 37$ & $1036 / 29$ & $1212 / 31^{\star}$ & $847 / 23^{\star}$ & $687 / 21^{\star}$ & $521 / 16^{*}$ \\
\hline
\end{tabular}

* Algumas das classes no período noturno - no total 6 de $5:$ serie, 4 de 62 serie, 6 de 71 serie e 6 de 81 serie.

Fonte: 22 Delegacia de Ensino de Osasco. 